Portland State University

PDXScholar

TREC Final Reports

Transportation Research and Education Center

(TREC)

$1-2017$

\title{
Improving Walkability Through Control Strategies at Signalized Intersections
}

\author{
Sirisha Murthy Kothuri \\ Portland State University \\ Andrew Kading \\ Portland State University, andykading@hotmail.com \\ Edward J. Smaglik \\ Northern Arizona University \\ Christopher Sobie \\ Northern Arizona University
}

Follow this and additional works at: https://pdxscholar.library.pdx.edu/trec_reports

Part of the Transportation Commons, Transportation Engineering Commons, Urban Studies

Commons, and the Urban Studies and Planning Commons

Let us know how access to this document benefits you.

\section{Recommended Citation \\ Kothuri, Sirisha, Kading, Andrew, Smaglik, Edward, and Sobie, Christopher. Improving Walkability Through Control Strategies at Signalized Intersections. NITC-RR-782. Portland, OR: Transportation Research and Education Center (TREC), 2017. https://doi.org/10.15760/trec.156}

This Report is brought to you for free and open access. It has been accepted for inclusion in TREC Final Reports by an authorized administrator of PDXScholar. Please contact us if we can make this document more accessible: pdxscholar@pdx.edu. 


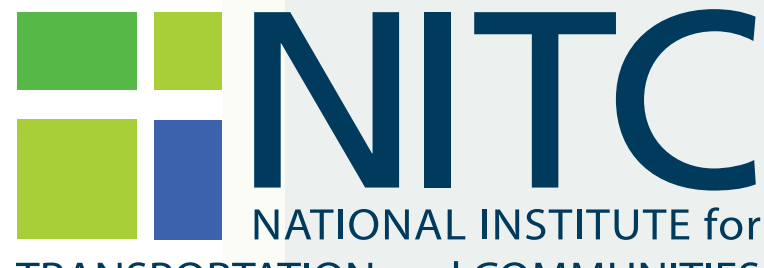

TRANSPORTATION and COMMUNITIES

FINAL REPORT

\section{Improving Walkability Through Control Strategies at Signalized Intersections}

NITC-RR-782 January 2017

NITC is the U.S. Department of Transportation's national university transportation center for livable communities.

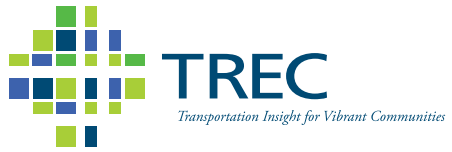





\title{
IMPROVING WALKABILITY THROUGH CONTROL STRATEGIES AT SIGNALIZED INTERSECTIONS
}

\author{
Final Report
}

NITC-RR-782

by

Sirisha Kothuri, Ph.D.

Andrew Kading

Portland State University

Edward Smaglik, Ph.D., P.E.

Christopher Sobie

Northern Arizona University

for

National Institute for Transportation and Communities (NITC)

P.O. Box 751

Portland, OR 97207
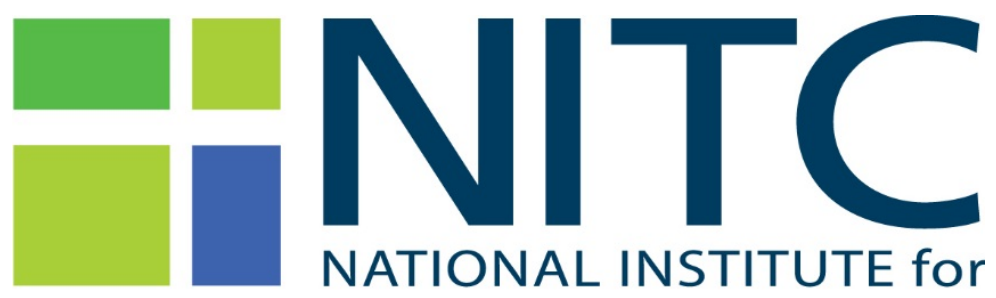

TRANSPORTATION and COMMUNITIES

January 2017 


\begin{tabular}{|c|c|c|c|c|}
\hline \multicolumn{5}{|c|}{ Technical Report Documentation Page } \\
\hline $\begin{array}{l}\text { 1. Report No. } \\
\text { NITC-RR-782 }\end{array}$ & \multicolumn{2}{|l|}{ 2. Government Accession No. } & \multicolumn{2}{|c|}{ 3. Recipient’s Catalog No. } \\
\hline \multirow{3}{*}{\multicolumn{4}{|c|}{$\begin{array}{l}\text { 4. Title and Subtitle } \\
\text { Improving Walkability Through Control Strategies at Signalized Intersections }\end{array}$}} & 5. Report Date \\
\hline & & & & \\
\hline & & & \multicolumn{2}{|c|}{ 6. Performing Organization Code } \\
\hline \multicolumn{3}{|c|}{$\begin{array}{l}\text { 7. Author(s) } \\
\text { Sirisha Kothuri, Andrew Kading, Edward Smaglik, and Christopher Sobie }\end{array}$} & \multicolumn{2}{|c|}{ 8. Performing Organization Report No. } \\
\hline \multirow{2}{*}{\multicolumn{4}{|c|}{ 9. Performing Organization Name and Address }} & 10. Work Unit No. (TRAIS) \\
\hline & & & \multicolumn{2}{|c|}{ 11. Contract or Grant No. } \\
\hline \multicolumn{3}{|l|}{ 12. Sponsoring Agency Name and Address } & \multicolumn{2}{|c|}{ 13. Type of Report and Period Covered } \\
\hline \multicolumn{2}{|c|}{$\begin{array}{l}\text { National Institute for Transportation and Communities (NITC) } \\
\text { P.O. Box } 751 \\
\text { Portland, Oregon } 97207\end{array}$} & & \multicolumn{2}{|c|}{ 14. Sponsoring Agency Code } \\
\hline \multicolumn{5}{|l|}{ 15. Supplementary Notes } \\
\hline \multicolumn{5}{|c|}{$\begin{array}{l}\text { 16. Abstract } \\
\text { As cities and communities nationwide seek to develop Complete Streets that foster livability and accommodate all modes, signal timing control } \\
\text { strategies that include pedestrians in the operational decision process are gaining importance. This research tested several efficiency-focused } \\
\text { pedestrian treatments - coordination, actuated-coordination, free operation, short cycle lengths - and safety-focused treatment including leading } \\
\text { pedestrian intervals and Barnes Dance. Using a software-in-the-loop simulation, the operational impacts of these treatments on all users (vehicles, } \\
\text { heavy vehicles, bicyclists and pedestrians) at an intersection were evaluated. Results showed that among the efficiency-based treatments, free } \\
\text { operation was most beneficial for reducing minor-street pedestrian delays. Both safety treatments increased major-street vehicle delays. A new } \\
\text { pedestrian priority algorithm is proposed and developed, which is designed to prioritize pedestrian service under certain traffic conditions. The } \\
\text { algorithm is designed to analyze field data and change the user-defined operational strategy to match the conditions in the field. The developed } \\
\text { algorithm was deployed at three separate locations, two of which used a Raspberry Pi device and one used the onboard logic processor of the } \\
\text { ASC/3 controller. Before-and-after data analysis showed that the algorithm was successful in reducing pedestrian delay. While this research } \\
\text { provides field-implementable solutions for reducing pedestrian delays, there is no one "right solution”. Ultimately, choice of a control strategy } \\
\text { may rest on operational objectives and geometric characteristics of an intersection. The findings from this research may benefit cities that are } \\
\text { looking to create safe, sustainable streets capable of accommodating multiple modes. }\end{array}$} \\
\hline \multicolumn{2}{|l|}{$\begin{array}{l}\text { 17. Key Words } \\
\text { Pedestrian Priority, Control Strategies }\end{array}$} & \multicolumn{3}{|c|}{$\begin{array}{l}\text { 18. Distribution Statement } \\
\text { No restrictions. Copies available from NITC: } \\
\text { www.nitc.us }\end{array}$} \\
\hline $\begin{array}{l}\text { 19. Security Classification (of this report) } \\
\text { Unclassified }\end{array}$ & $\begin{array}{l}\text { 20. Security Classification (of } \\
\text { Unclassified }\end{array}$ & & 21. No. of Pages & 22. Price \\
\hline
\end{tabular}





\section{ACKNOWLEDGEMENTS}

The authors gratefully acknowledge NITC and the Portland Bureau of Transportation for sponsoring this project. The authors are also thankful to Peter Koonce, Paul Zebell, Mark Haines, Willie Rotich and Ty Reynolds for their assistance with field deployment and data procurement. The authors would also like to thank Dan Brandesky from Econolite Corporation for his assistance with the simulation.

\section{DISCLAIMER}

The contents of this report reflect the views of the authors, who are solely responsible for the facts and the accuracy of the material and information presented herein. This document is disseminated under the sponsorship of the U.S. Department of Transportation University Transportation Centers Program [and other SPONSOR/PARTNER] in the interest of information exchange. The U.S. Government [and other SPONSOR/PARTNER] assumes no liability for the contents or use thereof. The contents do not necessarily reflect the official views of the U.S. Government [and other SPONSOR/PARTNER]. This report does not constitute a standard, specification, or regulation. 



\section{TABLE OF CONTENTS}

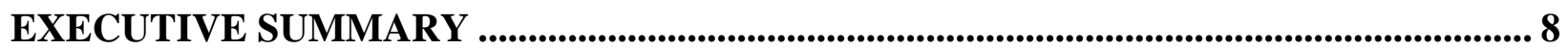

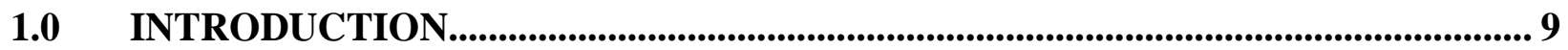

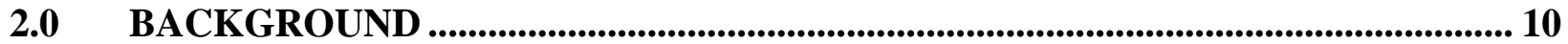

2.1 SIGNAL TIMING CONTROL STRATEGIES....................................................... 10

2.1.1 Leading Pedestrian Interval ............................................................................ 10

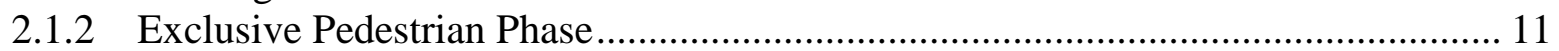

2.1.3 Cycle Length Manipulation .................................................................................. 12

2.1.4 Permissive Period Change ....................................................................................... 12

2.1.5 Actuated-Coordinated Operation ...................................................................... 13

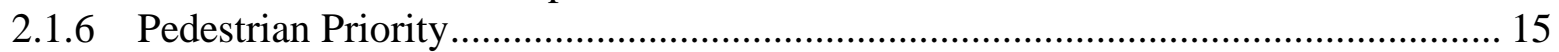

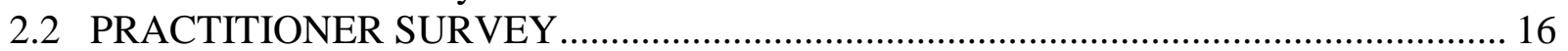

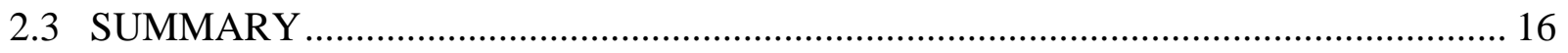

3.0 SIMULATION DEVELOPMENT ................................................................... 17

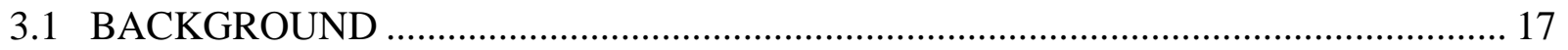

3.2 GENERAL SIMULATION MODEL DEVELOPMENT ……………………….......... 18

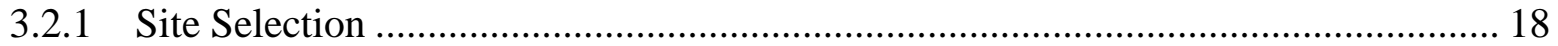

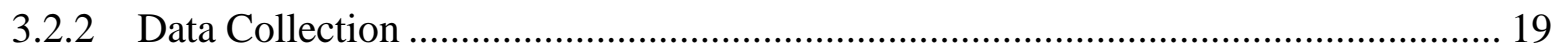

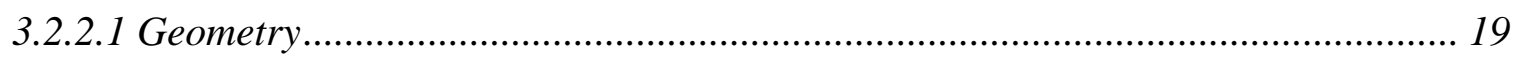

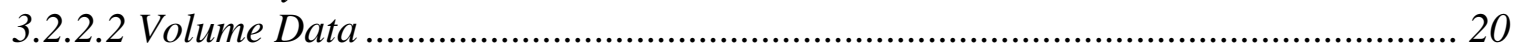

3.2.2.3 Vehicle Composition ..................................................................................... 21

3.2.2.4 Signal Timing ....................................................................................... 22

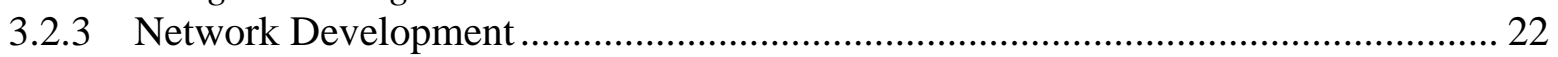

3.2.3.1 Lane Widths ................................................................................................ 23

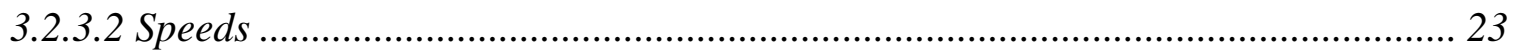

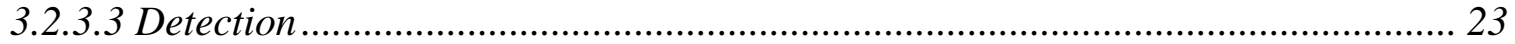

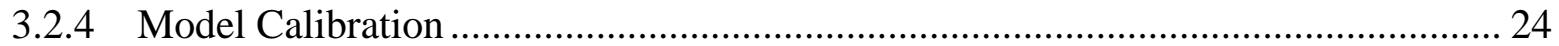

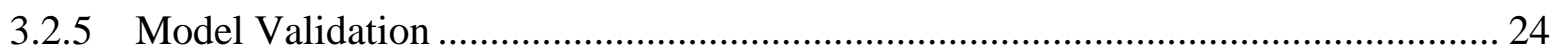

3.3 MODEL DEVELOPMENT FOR PEDESTRIAN PRIORITY ALGORITHM ................. 25

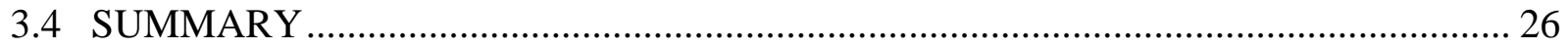

4.0 PEDESTRIAN PRIORITY ALGORITHM DEVELOPMENT.................................. 27

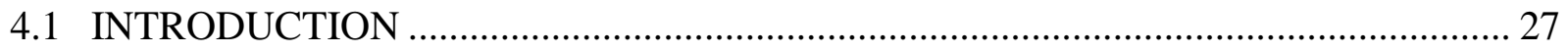

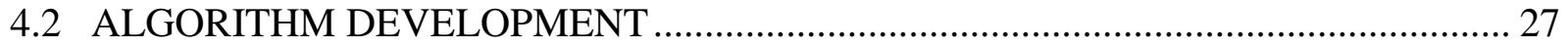

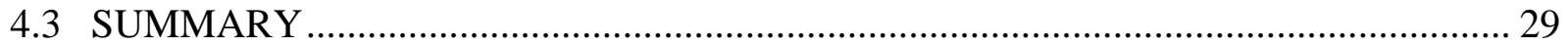

5.0 PEDESTRIAN CONTROL STRATEGIES.................................................................... 30

5.1 SIMULATION COMPARISONS WITH VALIDATED DATA..................................... 30

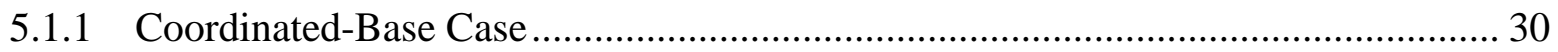

5.1.2 Removal of Coordination (free operation)........................................................ 30

5.1.3 Leading Pedestrian Interval .................................................................................. 32

5.1.3.1 Leading Pedestrian Interval on the Minor-Street Phases..................................... 32

5.1.3.2 Leading Pedestrian Interval on the Major-Street Phases....................................... 33

5.1.3.3 Leading Pedestrian Interval on Both Approaches.................................................. 34

5.1.4 Exclusive Pedestrian Phase ............................................................................................ 35 


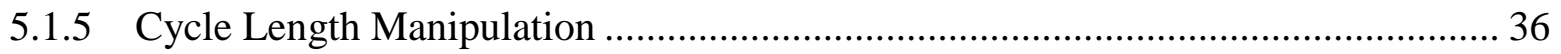

5.2 PEDESTRIAN PRIORITY ALGORITHM SIMULATION ……………………............. 38

5.2.1 Comparison of Algorithm and PPOPs .................................................................... 39

5.2.2 Algorithm Simulation with Validated Data ................................................................... 39

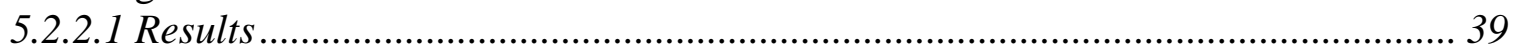

5.2.3 Algorithm Simulation with Non-Validated Data..................................................... 40

5.2.3.1 Results ...................................................................................................... 41

5.2.3.2 Sensitivity Analysis of Vehicle Extension Timers................................................. 43

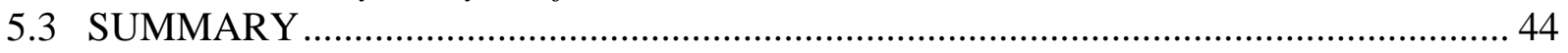

6.0 DEPLOYMENT OF PEDESTRIAN PRIORITY ALGORITHM................................ 45

6.1 IDENTIFICATION OF SITES FOR DEPLOYMENT ………….................................... 45

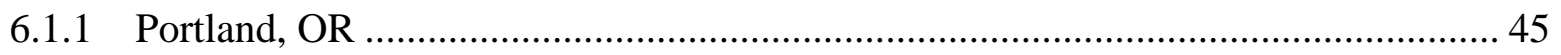

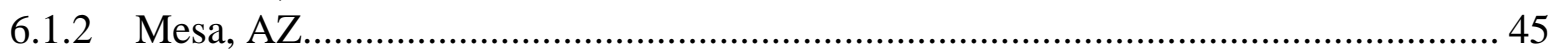

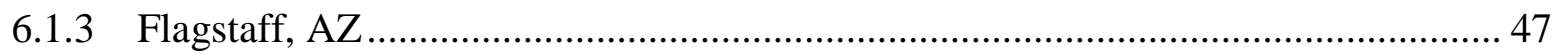

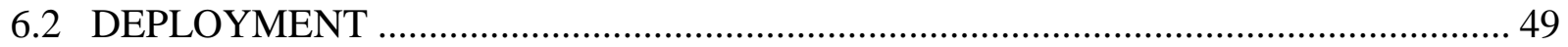

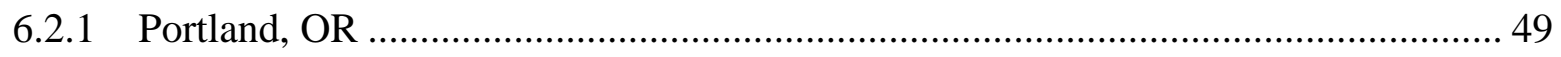

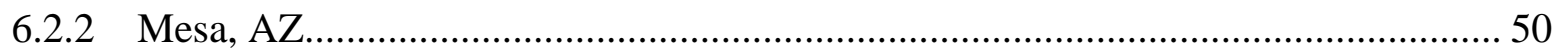

6.2.2.1 Field Deployment I ........................................................................................ 50

6.2.2.2 Algorithm Platform Change ............................................................................... 51

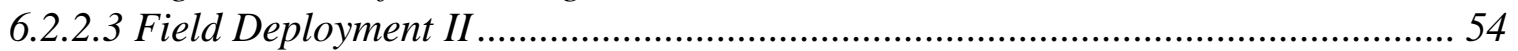

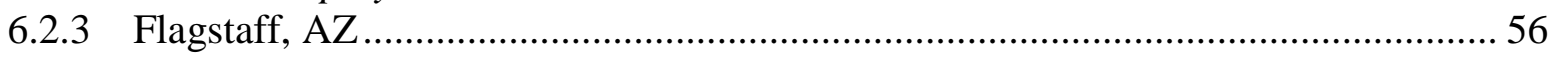

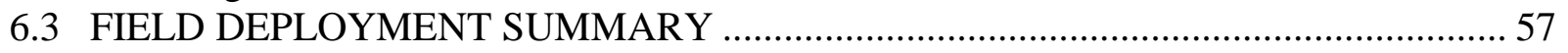

7.0 CONCLUSIONS AND RECOMMENDATIONS...................................................5

7.1 SIMULATION RESULTS ………………………................................................. 58

7.1.1 Ranking of Existing Control Strategies ................................................................... 59

7.1.2 Pedestrian Priority Algorithm Development and Field Deployment.......................... 60

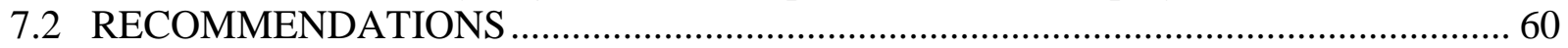

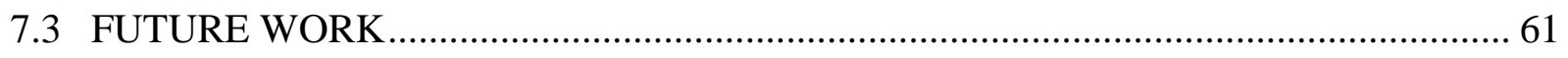

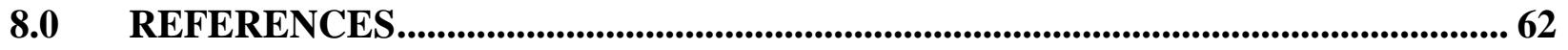

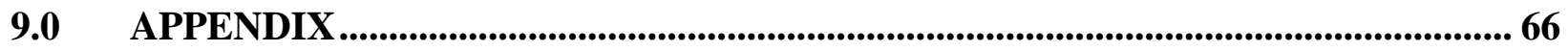

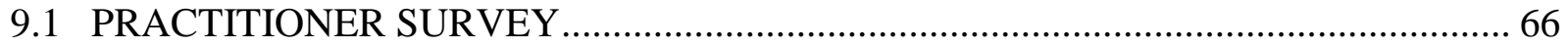

\section{LIST OF TABLES}

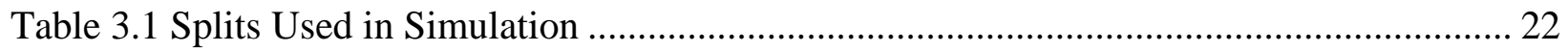

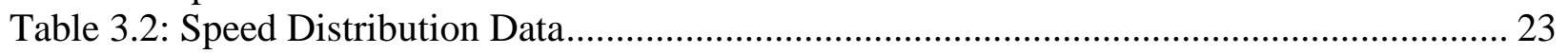

Table 3.3 GEH Criteria for Model Validation ................................................................................. 25

Table 5.1 Average Delays from Coordinated Operation (Base Case) .............................................. 30

Table 5.2 Average and Percent Delays from Free Operation ........................................................ 31

Table 5.3 Average and Percent Difference in Delays Due to LPI on Minor Street Phases........... 33

Table 5.4 Average and Percent Difference in Delays due to LPI on Major-Street Phases............ 34

Table 5.5 Average and Percent Difference in Delays due to LPI on Major and Minor- Street

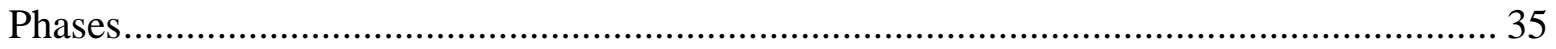

Table 5.6 Average and Percent Difference in Delay due to Exclusive Pedestrian Phase.............. 35 
Table 5.7: Percent Difference in Delay for Cycle Length Manipulation at SE 119th Avenue..... 37

Table 5.8: Percent Difference in Delay for Cycle Length Manipulation at SE 122nd Avenue.... 37

Table 5.9: Percent Difference in Delay for Cycle Length Manipulation at SE 130th Avenue..... 37

Table 5.10 Pedestrian Priority Algorithm Simulation Results with Validated Data .................. 40

Table 5.11 Comparison of Delays with and without Algorithm using Validated Data............... 40

Table 5.12 Simulation Results, Absolute Values.............................................................. 42

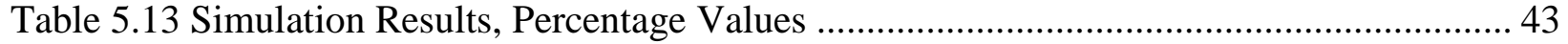

Table 6.1 Portland Deployment, Pedestrian Data ................................................................. 50

Table 6.2: Mesa Deployment, Pedestrian Data..................................................................... 55

Table 6.3: Mesa Deployment, Travel Time Data ................................................................ 55

Table 6.4: Flagstaff Deployment, Pedestrian Data ................................................................. 56

Table 7.1 Ranking of Control Strategies based on Major-Street Vehicle Delay ........................ 59

Table 7.2 Ranking of Control Strategies based on Minor-Street Pedestrian Delay..................... 59

Table 9.1: Practitioner Survey, Abbreviated Results................................................................. 66

\section{LIST OF FIGURES}

Figure 2.1 Ring Barrier Diagram for Leading Pedestrian Intervals........................................ 11

Figure 2.2 Ring Barrier Diagram for Exclusive Pedestrian Phase.......................................... 12

Figure 2.3 Ring Barrier Diagram for Actuated-Coordinated Operation ..................................... 14

Figure 2.4 Transportation Hierarchy from Portland, OR .................................................. 15

Figure 3.1 Simulation Site Location in Portland, OR ....................................................... 18

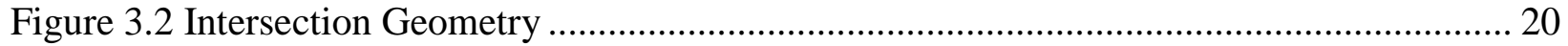

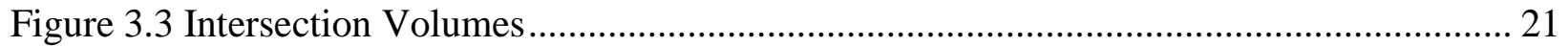

Figure 3.4 Detector Layout ....................................................................................... 24

Figure 3.5 Division Street Corridor Volumes used in the Pedestrian Priority Algorithm

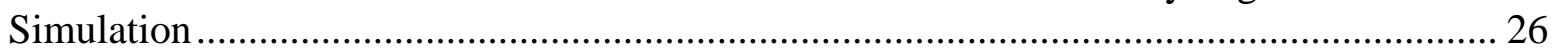

Figure 4.1 Pedestrian Priority Algorithm Flowchart ......................................................... 28

Figure 5.1 Percent Difference in Delay per Person, listed by Phase at SE 119th Avenue ........... 31

Figure 5.2 LPI on Minor Approach Only ........................................................................ 32

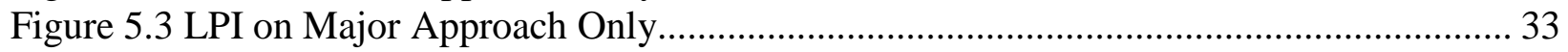

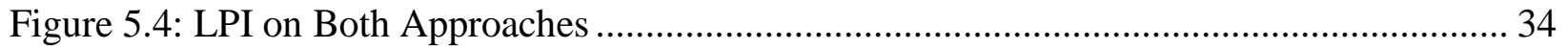

Figure 6.1 Location Map: Brown Road HAWK, Mesa, AZ ................................................. 46

Figure 6.2 Site Overview, Brown Road HAWK, Mesa, AZ .................................................... 47

Figure 6.3 Location Map: N. Beaver and Forest, Flagstaff, AZ .............................................. 48

Figure 6.4 Site Overview, N. Beaver and Forest, Flagstaff, AZ ............................................ 49

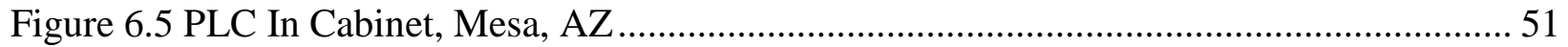

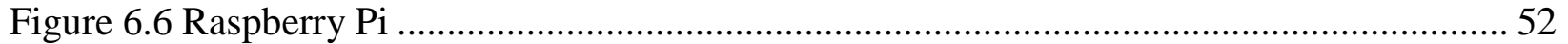

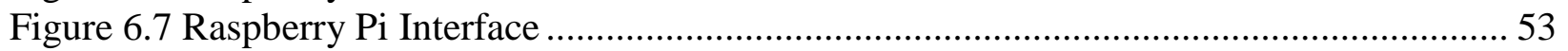

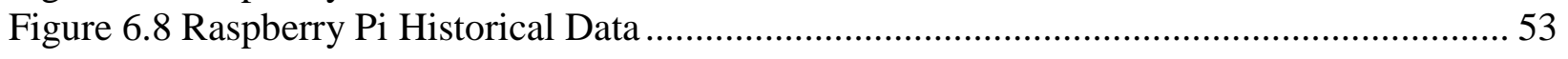




\section{EXECUTIVE SUMMARY}

The goal of signal timing at an intersection should be to separate conflicting movements in time, maximizing safety and efficiency for all users. In many jurisdictions, however, signal timing objectives have traditionally focused on allowing vehicle progression and reducing vehicular delay and stops. While these are important considerations in many contexts, other users (especially pedestrians) deserve similar focus and control strategies. Recent updates to the Highway Capacity Manual (HCM, 2010) have included specific multimodal delay modeling techniques offering a bit more accommodation to pedestrians, but still remain heavily vehiclecentric. While strategies such as an exclusive pedestrian phase and leading pedestrian intervals can help improve the safety of pedestrian operations, legacy service of pedestrians requires that they still must wait for "their turn" - which at times means they experience delays much in excess of those that would be deemed acceptable for a motor vehicle at the same location. Excessive delay can lead to pedestrian frustration, noncompliance and, ultimately, decreased safety. In the North American context, there is limited research on incorporating alternative pedestrian treatments at signalized intersections.

This project builds on past research completed at Portland State University by exploring pedestrian signal timing control strategies, including a concept of pedestrian priority which may be warranted when pedestrian demand is low and vehicular demand is moderate. Using a software-in-the-loop (SITL) simulation, strategies such as coordination, actuated-coordination, free operation, short cycle lengths, leading pedestrian interval (LPI), Barnes Dance and a pedestrian priority algorithm were evaluated to understand the operational impacts of the various treatments. The findings revealed that free operation was most beneficial for minor-street pedestrian delays, while traditional coordination was beneficial for major-street vehicle delays. While safety-focused strategies such as LPI increased vehicle delays and showed no change for pedestrian delays, Barnes Dance increased delays for all users. Implementation of the pedestrian priority algorithm at intersections in Portland, OR, Mesa, AZ, and Flagstaff, AZ, revealed that the algorithm was successful in changing the signal controller operational plan based on realtime field inputs, which resulted in reduction of pedestrian delay during the off-peak periods.

This research is novel in that its overall goal goes beyond simply accommodating pedestrians at signalized intersections to actually encouraging walking by providing fieldimplementable solutions for reducing pedestrian delays. These findings may have nationwide appeal, particularly for cities that are looking to create safe, sustainable streets capable of accommodating multiple modes, which are an integral component in the development of livable communities. 


\subsection{INTRODUCTION}

Walking as a transportation mode is associated with a number of benefits ranging from reductions in congestion and emission levels to improvements in personal health. Therefore, many communities across the United States are eager to increase walk mode shares. A safe and desirable walking environment is critical to the development of healthy and sustainable communities. According to the 2009 National Household Travel Survey, an estimated 42 billion walking trips occur in the U.S. each year, amounting to 10.9 percent of all trips (Pucher et al., 2011).

Most of these walking trips occur in urban areas and 67 percent of these trips are less than one mile in length. In urban areas, pedestrian crossings may occur either at signalized intersections or mid-block. Legacy signal timing policies at intersections have prioritized vehicular movements, often leading to large and sometimes unnecessary delays for pedestrians. Because pedestrian trips are short, delays at signalized intersections can affect pedestrians disproportionately compared to auto trips. Several studies have shown that delay is a key factor in pedestrian noncompliance (Dunn and Pretty, 1984; TRB, 2010; Wang et al., 2011; Vallyon et al., 2011) and the Highway Capacity Manual has stated that delays greater than 30 seconds are associated with increased frustration and risky behaviors (Dunn and Pretty, 1984) (Houten et al., 2006), (HCM, 2010).

Existing strategies for pedestrians such as the leading pedestrian interval (LPI) and exclusive pedestrian phase (also known as Barnes Dance) are primarily safety related. With increased focus on nonmotorized transportation modes, there is a critical need for research on efficiency-based pedestrian signal control strategies. Options such as the use of shorter cycle lengths, actuated-coordinated timing and free operation have been used but in a very limited fashion.

The goals of this research study are twofold: a) assess the efficiency impacts of existing strategies - coordination, leading pedestrian intervals, excusive pedestrian phase, cycle length manipulation and free operation on all users at an intersection using a microsimulation platform and b) develop and implement a pedestrian priority algorithm. A simulated corridor consisting of three intersections was developed in VISSIM, and each strategy was simulated and compared with the base coordinated case using the ASC/3 software-in-the-loop signal controller software. Using the logic processor capability within the ASC/3 software, the pedestrian priority algorithm was developed, tested and deployed in three locations - Portland, OR, Mesa, AZ, and Flagstaff, AZ.

The remainder of this report is organized in the following manner. A detailed literature review of the existing control strategies is presented in Chapter 2. Also included in Chapter 2 are findings from a brief practitioner survey that was conducted to understand the state of practice with respect to use and deployment of pedestrian control strategies. A description of the simulation model development for evaluating pedestrian control strategies is presented in Chapter 3, followed by a description of the pedestrian priority algorithm development in Chapter 4. The results of the simulation of the various pedestrian control strategies are presented in Chapter 5. Results from the field deployment of the pedestrian priority algorithm are presented in Chapter 6. The report wraps up with conclusions and recommendations in Chapter 7. 


\subsection{BACKGROUND}

There has been limited research on control strategies for pedestrians at signalized intersections. Control strategies can generally be divided into two categories: safety related and efficiency related. The primary goal of safety-focused control strategies is to improve pedestrian safety by reducing pedestrian-vehicle conflicts. Examples of such strategies are the leading pedestrian interval (LPI) and exclusive pedestrian phase (EPP, also known as Barnes Dance). Efficiencyrelated control strategies aim to reduce delays for pedestrians primarily via signal timing changes. Examples of efficiency control strategies include cycle length manipulation, permissive period changes and pedestrian priority. Historically, these have received less attention in the literature.

This chapter aims to synthesize past literature pertaining to the following control strategies: leading pedestrian interval, exclusive pedestrian phase, cycle length manipulation, permissive window changes and pedestrian priority. The goal of the literature review is to identify critical gaps in existing literature and highlight areas where additional research may be warranted.

\subsection{SIGNAL TIMING CONTROL STRATEGIES}

The purpose of signal timing at an intersection is to separate the conflicting movements in time. A properly designed and timed signal is expected to provide a range of benefits such as maximizing flow at an intersection, reducing severity and frequency of certain types of crashes, allowing orderly and efficient movement of people, and providing appropriate levels of accessibility for pedestrians and side street traffic (Koonce et al., 2008). The prioritization of modes within the signal timing process depends on regional goals and policies.

Traditionally, signal timing policies have prioritized vehicular movements along the major streets with strategies such as coordination and adaptive signal control. Along certain corridors, buses are also prioritized via the implementation of transit priority. Coordinated signal timing for bicycles along critical corridors is an emerging concept, designed to reduce their stops and travel times (Taylor and Mahmassani, 2000). However, pedestrians are typically not considered in the prioritization process. Pedestrians are often viewed as a detriment to traffic flow and are accommodated in a way that ensures least disruption to the flow of vehicles.

At signalized intersections, pedestrians are typically served using concurrent signal phasing, which allows them to cross the street along with the parallel vehicle movements. In this phasing, turning vehicles are expected to yield to pedestrians. Strategies such as LPI and EPP have emerged primarily as measures to improve pedestrian safety while crossing. Efficiencyrelated control strategies such as cycle length and permissive window manipulation are less studied and warrant more research. Each of these strategies is discussed further below.

\subsubsection{Leading Pedestrian Interval}

Leading pedestrian interval (LPI) refers to a signal control strategy by which pedestrians are provided with an exclusive walk signal for a few seconds, prior to the parallel vehicular green indication. In a typical situation a pedestrian Walk signal illuminates for several seconds before the corresponding vehicle signal, thereby providing the pedestrians with greater visibility by 
allowing them to enter the intersection before the turning vehicles. After the first few seconds, the vehicular green indication for the parallel movement is served and the operation is similar to concurrent timing. Figure 2.1 shows the ring barrier diagram for the LPI. In Figure 2.1, pedestrian phases 2 and 6 have a LPI.

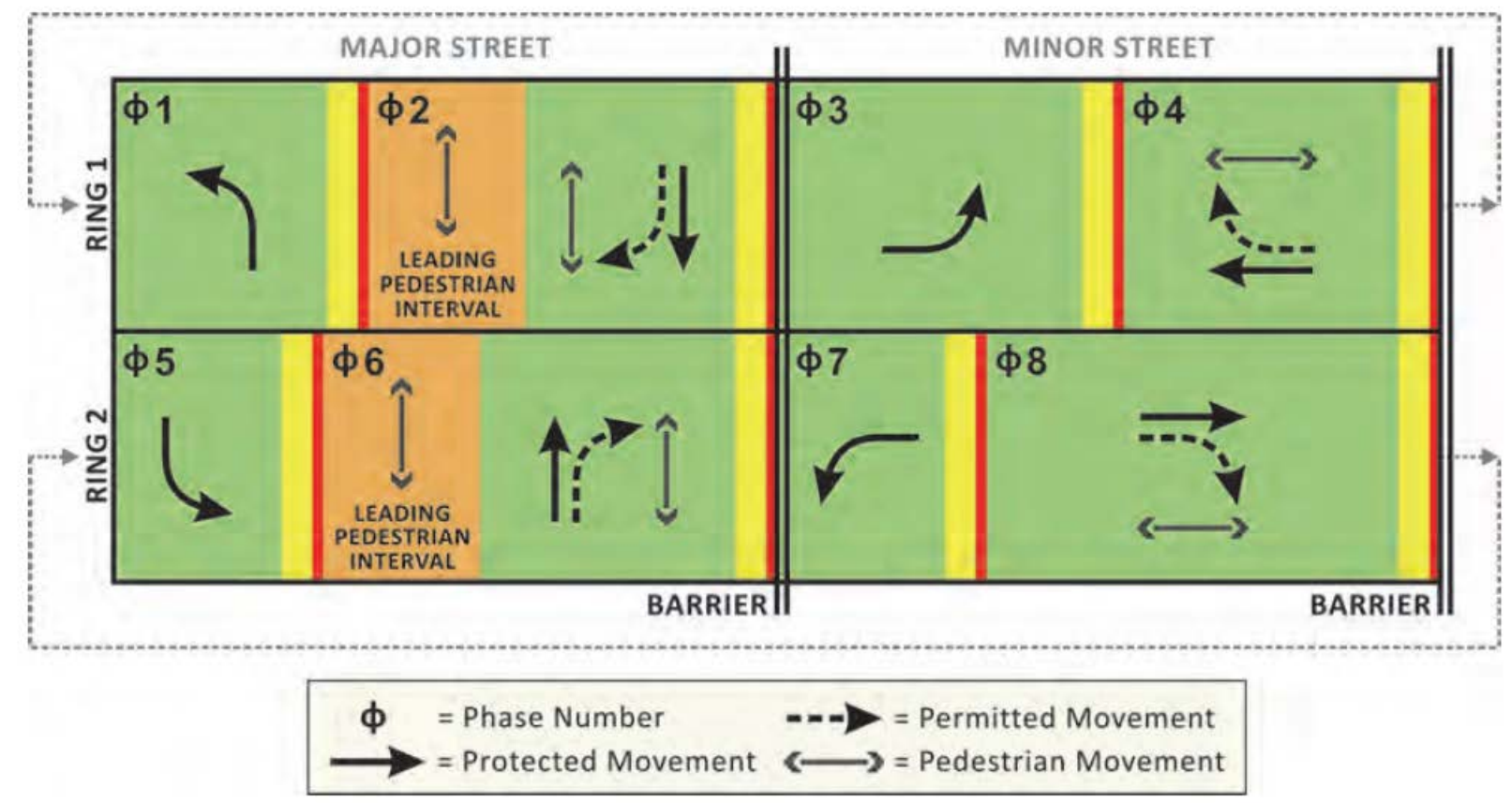

Figure 2.1 Ring Barrier Diagram for Leading Pedestrian Intervals

(Source: Signal Timing Manual, Second Edition)

The advantages of LPI are primarily safety related; studies have reported reduced conflicts between pedestrians and turning vehicles (Houten et al., 2006; Zegeer et al., 2002; Turner, 2000). One study also reported a reduction in pedestrians yielding the right of way to turning vehicles (Fayish and Gross, 2010). Finally, one study created a set of guidelines for LPI implantation for the city of Toronto (Saneinejad and Lo, 2015). In addition to actual safety improvements, LPIs may also improve perceptions of safety. Delay, as defined by the HCM, for both vehicles and pedestrians may be affected as well; vehicle delay may increase due to loss of green time for adjacent vehicles, while for pedestrians it may increase due to higher cycle length (Hubbard et al., 2007; King, 1999).

\subsubsection{Exclusive Pedestrian Phase}

An exclusive pedestrian phase (EPP), also known as a Barnes Dance or a pedestrian scramble, is a type of phasing in which pedestrians are permitted exclusive use of the intersection including lateral and diagonal crossings while all vehicular traffic is stopped. Figure 2.2 shows the ring barrier diagram for the exclusive pedestrian phase, which is served after the other phases have been served. 


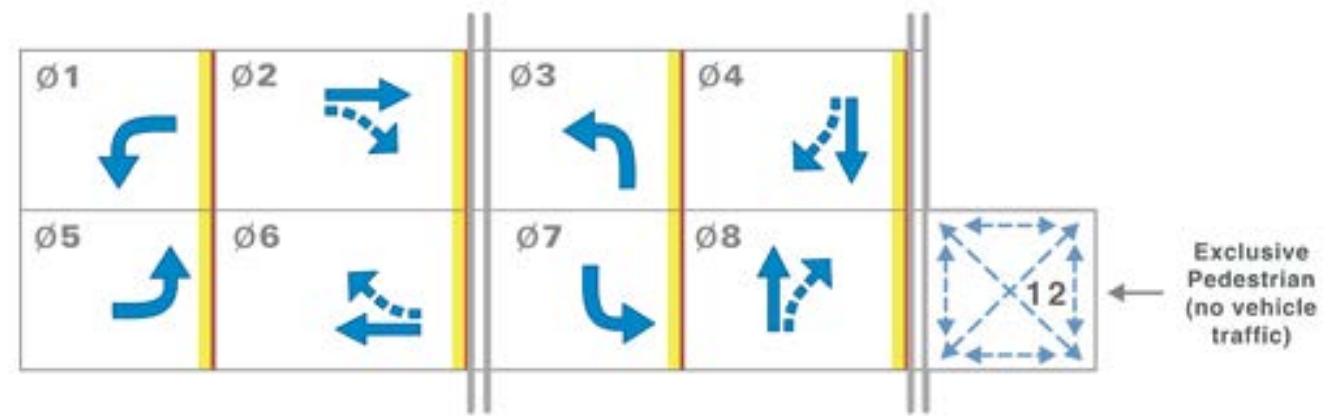

Figure 2.2 Ring Barrier Diagram for Exclusive Pedestrian Phase

(Source: Signal Timing Manual, $1^{\text {st }}$ Edition)

The Walk signal for all crosswalks is displayed simultaneously. While this phasing eliminates conflicts for pedestrians, it increases both vehicular and pedestrian delays due to increased cycle length. A few studies have documented increased pedestrian noncompliance due to the increased delays as a result of EPP implementation (Abrams and Smith, 1977; Zegeer et al., 1985; Zaidel and Hocherman, 1987, Gårder, 1989; Bechtel et al., 2004; Kattan et al., 2009).

\subsubsection{Cycle Length Manipulation}

Cycle length in signal timing refers to the time taken for a complete sequence of signal indications (Koonce et al., 2008). Cycle length is an important signal timing parameter especially for coordinated signal systems. The HCM provides an equation to estimate pedestrian delay based on cycle length and effective green time for pedestrians (TRB, 2010). Research has shown that, in general, shorter cycle lengths benefit pedestrians. leading to lower delay (Ishaque and Noland, 2005; Ishaque and Noland, 2007; Vallyon et al., 2011; Kothuri et al., 2013). Other guides such as the NACTO's Urban Street Design Guide and the PEDSAFE also recommend the provision of shorter cycle lengths to encourage signal compliance and increase efficiency (NACTO, 2013; FHWA, 2013).

\subsubsection{Permissive Period Change}

Permissive period is one of many signal timing settings in the controller. According to the Traffic Signal Timing Manual, permissive period refers to the period of time during the coordinated cycle in which calls on the conflicting (non-coordinated) phases will result in phase transition from coordinated to non-coordinated phase (Koonce et al., 2008). Permissive period values are typically auto calculated by the signal controller. Similarly, the permissive point is the first point of time in the coordinated phase when the controller is able to switch to the non-coordinated phase when a call is placed on the subject phase (de Castro-Neto, 2005). As such, the permissive point indicates the start of the permissive period.

Very limited research exists on permissive period changes and the resulting impacts on delays for vehicles and pedestrians. Using hardware-in-the-loop simulation, de-Castro Neto et al. studied the impacts on average vehicle delay for non-coordinated phases resulting from three different coordination modes that use varying permissive periods (fixed vs. simultaneous) and traffic volumes. Their findings revealed that the three modes performed similarly when traffic volumes were moderate-high. However, during low-volume conditions, the coordination mode 
whose permissive period closed later in the cycle resulted in lowest delay for the noncoordinated phases (de Castro-Neto, 2005).

Kothuri et al. studied the impacts of increased permissive periods for pedestrians at a half signal location in Portland, OR (Kothuri et al., 2013). Their findings revealed that increasing the permissive period resulted in statistically significant lower pedestrian delay. In addition, the largest tested increase in permissive period produced the lowest average delay for pedestrians. However, this research did not test the impacts of the increased permissive period on major street vehicular delay. It is conceivable that the increased permissive periods impact coordination and, therefore the overall impacts on all modes resulting from permissive period changes need to be better understood.

\subsubsection{Actuated-Coordinated Operation}

Actuated-coordinated operation is a method of coordinated operation where the coordinated movements, typically phases 2 and 6 , are allowed to gap out. The time released by this gap out is then available to serve other users during the successive cycle. Figure 2.3 a illustrates actuated-coordinated operation within the ring barrier diagram (RBD) using the terminology employed by the field controller used in the subsequent sections of this research. In this example, Phases 2 and 6 are the coordinated phases, and there is a 100-second cycle length equally divided between all phases. Figure 2.3 a shows the base RBD with two of the three actuated-coordinated mode parameters identified above the coordinated movements (fixed and extensible periods). In this controller, the value SPLT EXT (split extension) identifies the length of time within the full split that is extensible (this is calculated back from the yield point). After the fixed period has passed, the coordinated phases are only held green for active vehicles (extensible period). In this example, the SPLT EXT value is set to 15s, creating a 15s extensible period. The termination of the extensible period can be made more or less aggressive through selection of the extension timer value (the third parameter for actuated-coordinated operation) and by using (or not using) certain features such as simultaneous gap out or lane-by-lane detection (Sharma et al., 2007, Smaglik et al., 2007).

In Figure $2.3 \mathrm{~b}$, the termination of the platoon on the coordinated phase has resulted in gap-out termination 5 s into the extensible period (dashed lines indicate where phases would have terminated had they timed to their original force off points in Figure $2.3 \mathrm{a}$ ). This coordinated phase terminated early because either the entire platoon was served during the fixed portion of the coordinated phase, or the platoon extended past the fixed phase and the headway exceeded a critical maximum headway programmed to ensure most of the platoon is served. The time remaining from this early termination can be used to serve other users, including minor-phase pedestrians, earlier and reduce user delay. While research has been performed on the impacts of actuated-coordinated operation on vehicular movements (Day et al., 2008), its effects on pedestrian operations have not been quantified. 


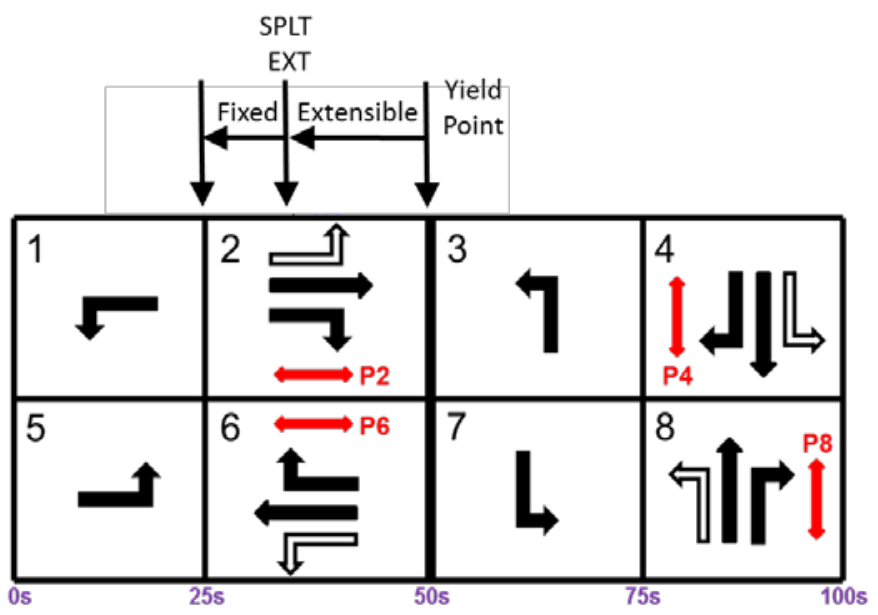

a) Base ring barrier diagram with several actuated-coordinated parameters

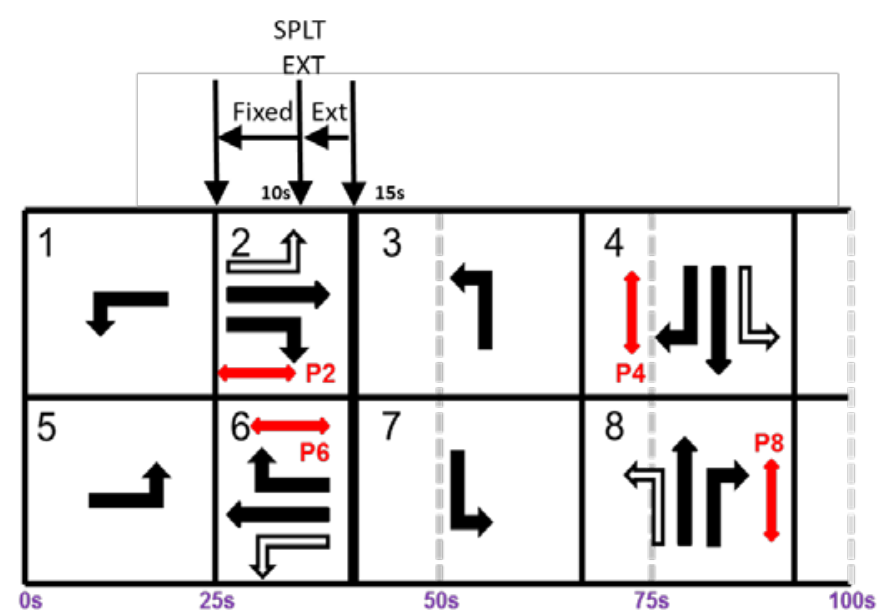

b) Gap-out termination 5s into extensible period allows for early termination

\section{Figure 2.3 Ring Barrier Diagram for Actuated-Coordinated Operation}

The critical maximum headway is directly related to the extension timer for the coordinated phase, and along with the duration of the fixed period and the extensible period, controls how much of the platoon is served, and therefore how much additional time can be made available for other users. Actuated-coordinated operation as described above is one of the algorithm-driven operational scenarios evaluated with simulation in this paper, and while settings for all three parameters of actuated-coordinated operation are not explored, a sensitivity analysis is performed on gap extension timer values to determine their impact on user delay. 


\subsubsection{Pedestrian Priority}

Traditionally, vehicles at signalized intersections are prioritized using signal timing practices. One such example is transit priority, which has been well documented in the literature (Balke, 2000; Furth and Muller, 2000; Skabardonis, 2000; Baker et al., 2002; Liu et al., 2003; Byrne et al., 2005; Smith et al., 2005; Skabardonis and Geroliminis, 2008; Ma et al., 2010; Head, 1998). However, in the United States, the provision of priority for pedestrians has not been traditionally considered in signal timing policy. In Europe, pedestrian priority zones have been implemented in certain areas (Heydecker and Robertson, 2009). Historically, strategies for prioritizing pedestrians include reducing speed limits, improving the streetscape, road diets and other geometric modifications (Heydecker and Robertson, 2009). Other examples of pedestrian prioritization include master plan-level thinking such as the concept of a transportation hierarchy (See Figure 2.4), which in cities like Portland, OR, is used to give pedestrians priority at both the planning level and the street level (Anderson et al., 2015).

He et al. recently developed a multimodal priority control system that is able to service multiple priority requests simultaneously (He et al., 2014). With this system, pedestrians and transit vehicles were able to send priority requests to the controller. A mathematical optimization model with real-time actuation control was developed and tested in VISSIM. The underlying assumption is that vehicle-to-infrastructure (v2i) communication is available for the various traffic modes. Compared to traditional coordination approach with transit priority, the multimodal traffic signal priority model was able to reduce bus and pedestrian delays while achieving similar car delays.

To the best of our knowledge, no other studies pertaining to pedestrian priority and signal timing exist. Therefore, there is a need for more research pertaining to pedestrian priority development and implementation.

\section{Transportation hierarchy for people movement}
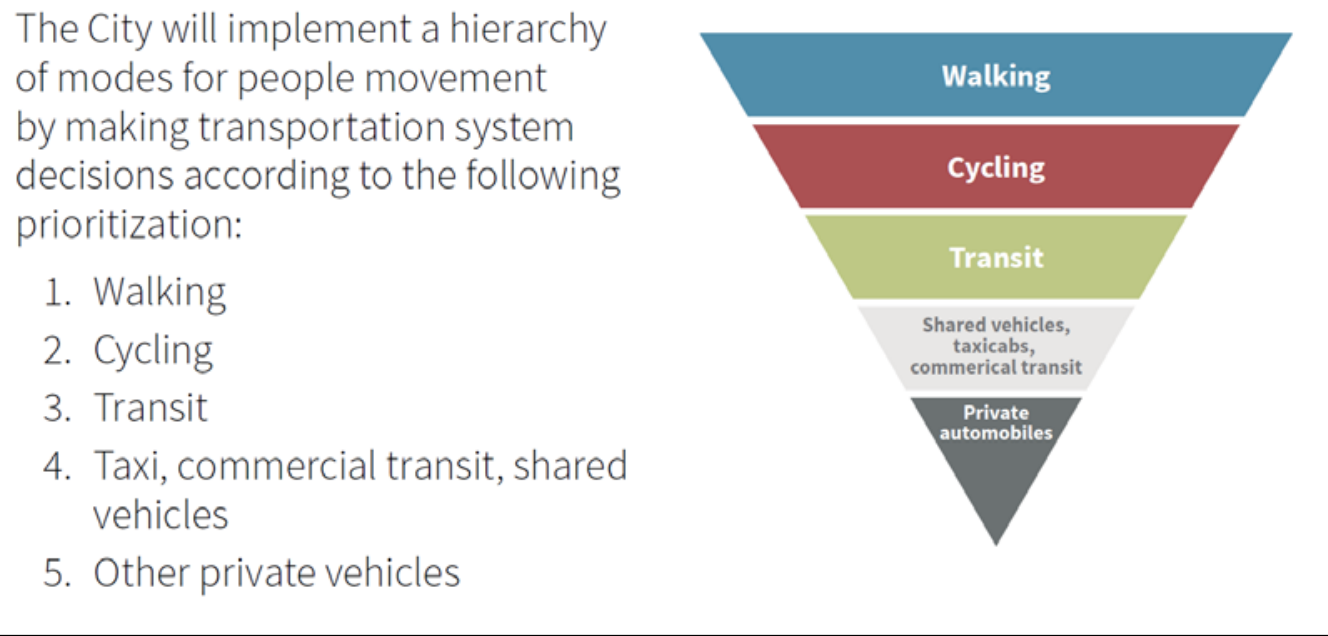

Figure 2.4 Transportation Hierarchy from Portland, OR (Anderson et al., 2015) 


\subsection{PRACTITIONER SURVEY}

A survey of practitioners was taken in order to gain insight into the current state of practice regarding pedestrian-related signal timing practices. A total of eight practitioners belonging to different agencies across the country were sent an email-based survey comprised of five questions during fall 2014. The intent of the questions was to determine what specific signal control strategies were being employed that prioritize pedestrians. Additional questions also sought to understand the tradeoffs of such strategies, any issues faced during their implementation, and if any documentation existed regarding the adopted strategies.

Of the practitioners surveyed, four responded (Table 9.1 in the Appendix shows the detailed responses). From the respondents several similarities were noticed: The majority of those who responded employed some type of pedestrian prioritization, with LPI being the most common, while some agencies employed no strategies that prioritize pedestrians. Documentation about the treatments was noticeably absent from the majority of respondents and there were few issues experienced during implementation.

The results of the survey indicate that agencies and practitioners are familiar with the concepts involved in pedestrian prioritization, have specific plans in place to address some of the needs of pedestrians, and have experienced little if any issues in the implementation of such strategies.

\subsection{SUMMARY}

This literature review summarizes the available research on the various signal timing-related pedestrian treatments. The review revealed that pedestrian treatments are primarily viewed via the safety lens and efficiency-related control strategies have been less of a priority. Safetyfocused strategies such as LPI and EPP reduce the conflicts between pedestrians and vehicles but have not reduced delays experienced by pedestrians. Existing literature also revealed that shorter cycle lengths are better for pedestrians in terms of delay reduction, and the actuated-coordinated operation has not been studied in relation to pedestrian operations. Some preliminary studies on permissive window manipulations revealed that increasing the length of the window resulted in lower pedestrian delays for the non-coordinated phase. However, more research is needed to understand the feasibility regimes for that treatment and its impact on all modes. Priority for pedestrians is rarely provided in practice, and additional research is warranted on this treatment as well. 


\subsection{SIMULATION DEVELOPMENT}

This chapter describes the microsimulation modeling framework in VISSIM and analyzes the impacts on all modes as a result of changes to signal controller operation based on the various strategies. This chapter will discuss the specifics of the modeling process as well as the source of the data used as inputs. First the development of the model will be discussed, which includes the network creation, the data collection methods, the calibration of the network, and finally the validation of the models. The chapter concludes with an explanation of the models' results and their implications and relevance to the project as a whole.

\subsection{BACKGROUND}

A number of tools have been developed for analyzing traffic and are typically grouped into analytical and simulation models. Analytical models use mathematical formulations to determine traffic states (capacity, density, speed, delay and queuing) on facilities (Akçelik, 2007). These tools are specifically suited for analyzing small-scale facilities. Simulation models are often used to model traffic flows in a network. These models can be multimodal in nature and are used to model the interactions between different modes on a transportation network. These tools are useful in evaluating design alternatives and for decision-making purposes. There are three categories of simulation models - macroscopic, mesoscopic and microscopic models. In macroscopic models, the simulation takes place on a section basis, without explicitly considering individual vehicles. Some well-known examples of macroscopic simulation models are PASSER, SYNCHRO, TRANSYT and TRANSYT7F. Mesoscopic models are a blend of macroscopic and microscopic models. Microsimulation models model the movement of individual vehicles in the traffic stream based on car-following and lane-changing models. The most popular among these are PARAMICS, AIMSUN, VISSIM, SIMTRAFFIC and CORSIM.

Microsimulation models are being increasingly used as an analysis tool worldwide. The advantages of microsimulation models are their ability to model system-wide impacts of alternatives and various geometric configurations. While these models can provide detailed statistics, there are a few issues worth noting. These models often require large amounts of data and the accuracy of data inputs into the simulation model affects the precision of results. These models also need to be properly calibrated and validated to yield accurate results. Some degree of user skill is required to build a representative model.

Each of the physical aspects must be created within the microsimulation model itself, whether those be hardware or software. These are referred to as "in-the-loop" systems, which are the mathematical models of the hardware/software that are used to represent the hardware/software within the simulation itself. In this research, VISSIM microsimulation software was used to model the interactions between vehicles, pedestrians and bicycles on an urban street network to evaluate the impacts of various signal control strategies to prioritize pedestrians. The following sections describe the steps taken in model development, calibration and validation. 


\subsection{GENERAL SIMULATION MODEL DEVELOPMENT}

A simulation model was developed in VISSIM to test the impacts of different strategies on the user mix. Data that was required for the construction of the models was gathered by researchers via field observations, taken from video, or from Google Maps ${ }^{\circledR}$ and Street View ${ }^{\circledR}$. The broad steps taken in the modeling process are:
1. Site selection
2. Network development
3. Data collection
4. Network calibration
5. Network validation

\subsubsection{Site Selection}

The selection of the site for simulation was based on a few criteria such as availability of newer signal controllers (Type 2070), moderate pedestrian volumes, and fully instrumented intersections which provided the necessary detection and agency preference. The specific intersections were chosen based on discussions with the Portland Bureau of Transportation, which put forth specific site recommendations based on the city's needs for pedestrian safety improvements along the corridor due to the high crash rates involving pedestrians.

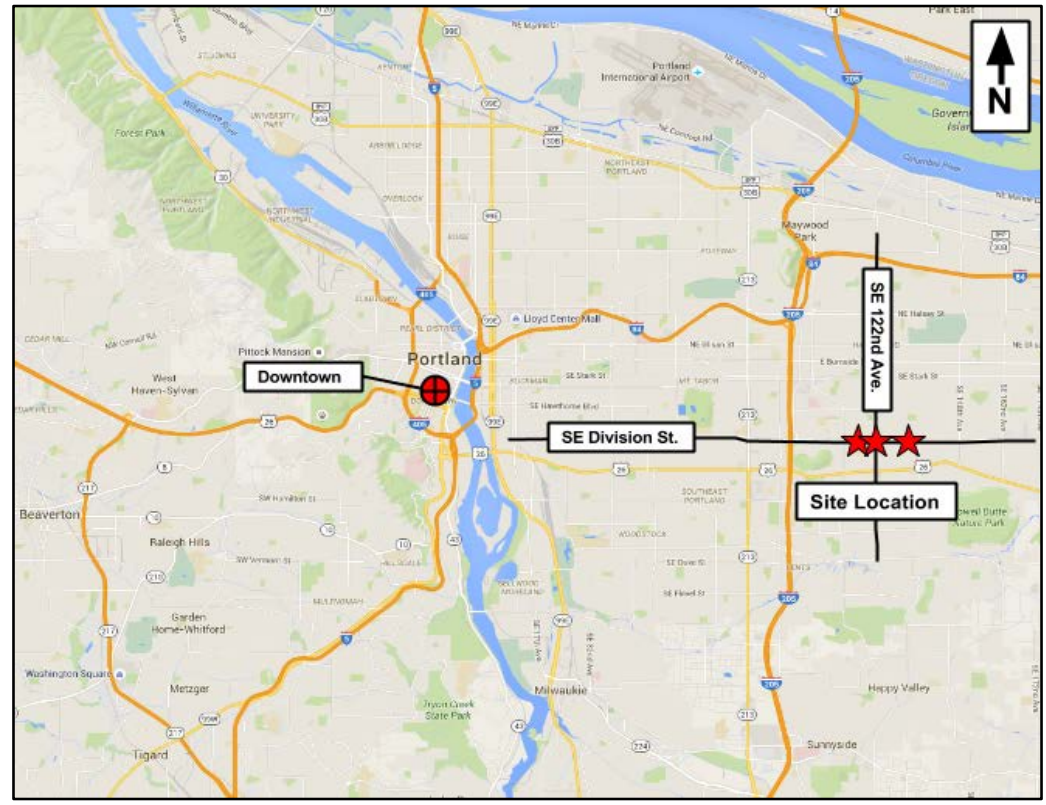

Figure 3.1 Simulation Site Location in Portland, OR

Division Street is a major east-west arterial corridor in Portland, OR, carrying approximately 18,000 vehicle trips per day. Three intersections were chosen for simulation analysis along Division Street and these were located in southeast Portland. The intersections chosen were SE $119^{\text {th }}$ Avenue, SE $122^{\text {nd }}$ Avenue and SE $130^{\text {th }}$ Avenue along SE Division Street (see Figure 3.1). 
This stretch of the corridor was chosen because the intersection at SE $122^{\text {nd }}$ Avenue and SE Division Street is a test-bed intersection for the Portland Bureau of Transportation's Signal and Street Lighting Division for evaluating new technologies. This intersection was equipped with a variety of detection technologies and afforded the possibility of field deployment of the strategies developed in this study. In addition, the intersection of SE $122^{\text {nd }}$ and SE Division Street was identified as a high-crash location (Portland Bureau of Transportation 2014). A total of 64 crashes involving pedestrians were reported between 2000 and 2009 along SE $122^{\text {nd }}$ Avenue, with over half of them occurring at signalized intersections (Portland Bureau of Transportation 2014).

\subsubsection{Data Collection}

Underlying all the simulation programs are the detailed data required to run the models. The different types of data required are geometry (lengths, lanes), volume data by user type, speeds and signal timing data. Data collection in each of these categories is discussed further below.

\subsubsection{Geometry}

Along the stretch of the corridor that was chosen for the simulation, Division Street has two lanes in each direction, with additional turn lanes at the intersections. A bicycle lane is also present along SE Division Street. SE $119^{\text {th }}$ Avenue and SE Division Street is a T-intersection, with one travel lane in each direction on SE $119^{\text {th }}$ Avenue. SE $122^{\text {nd }}$ Avenue has two through lanes and additional right- and left-turn lanes in the north- and southbound directions. SE $130^{\text {th }}$ Avenue has one traffic lane in each direction. Figure 3.2 shows the geometry at the three intersections. The lane lengths and widths were measured using Google satellite images. 


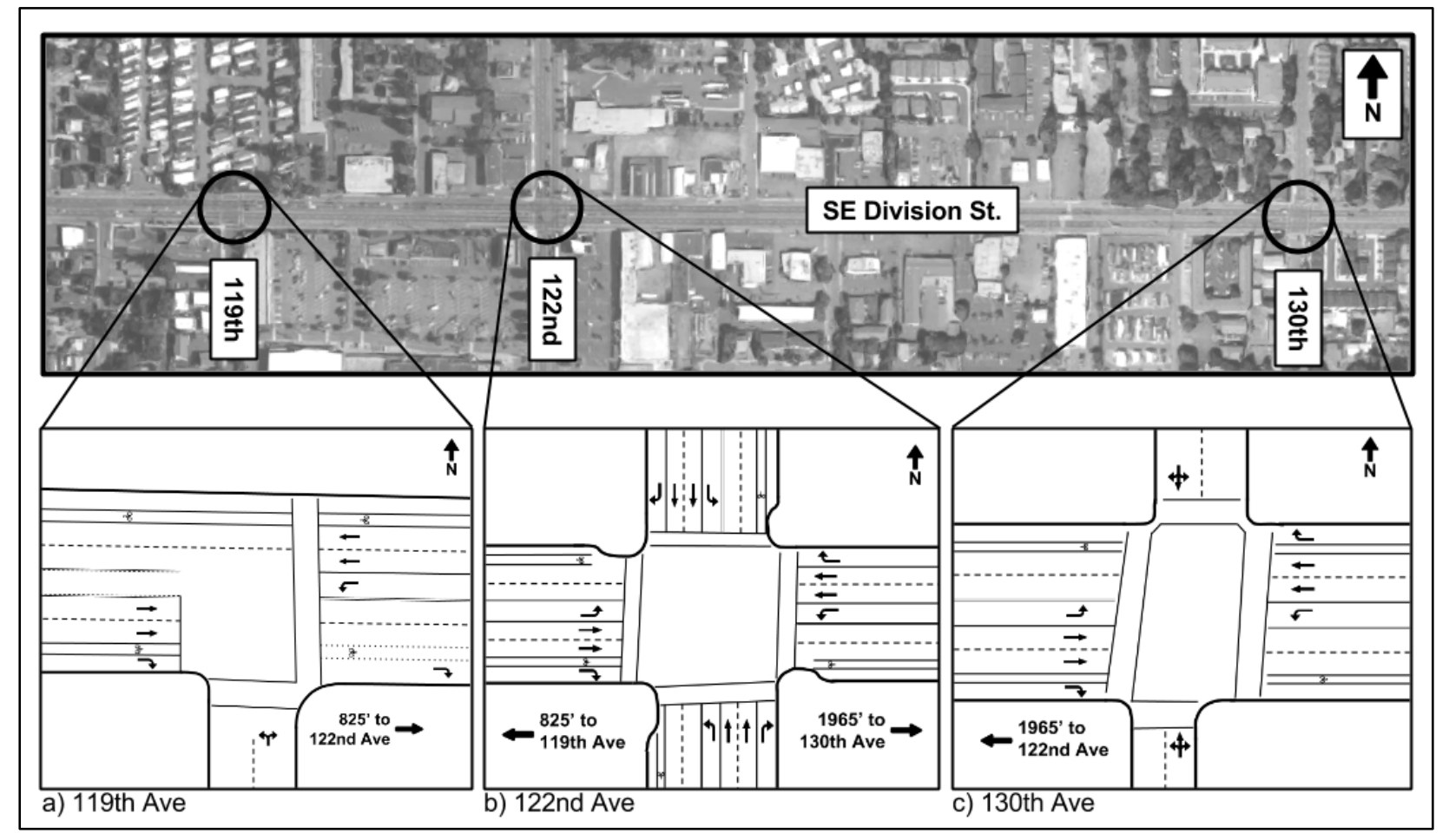

Figure 3.2 Intersection Geometry

\subsubsection{Volume Data}

All volume data was obtained from a vendor, Quality Counts (QC), who collected data using pneumatic tube counters set along the roadway in September 2015.The data that was collected included the following categories: turning movement volumes; bicycle, pedestrian and vehicle volumes; and vehicle speeds. Figure 3.3 shows the volumes and turning movement counts at each of the intersections. 


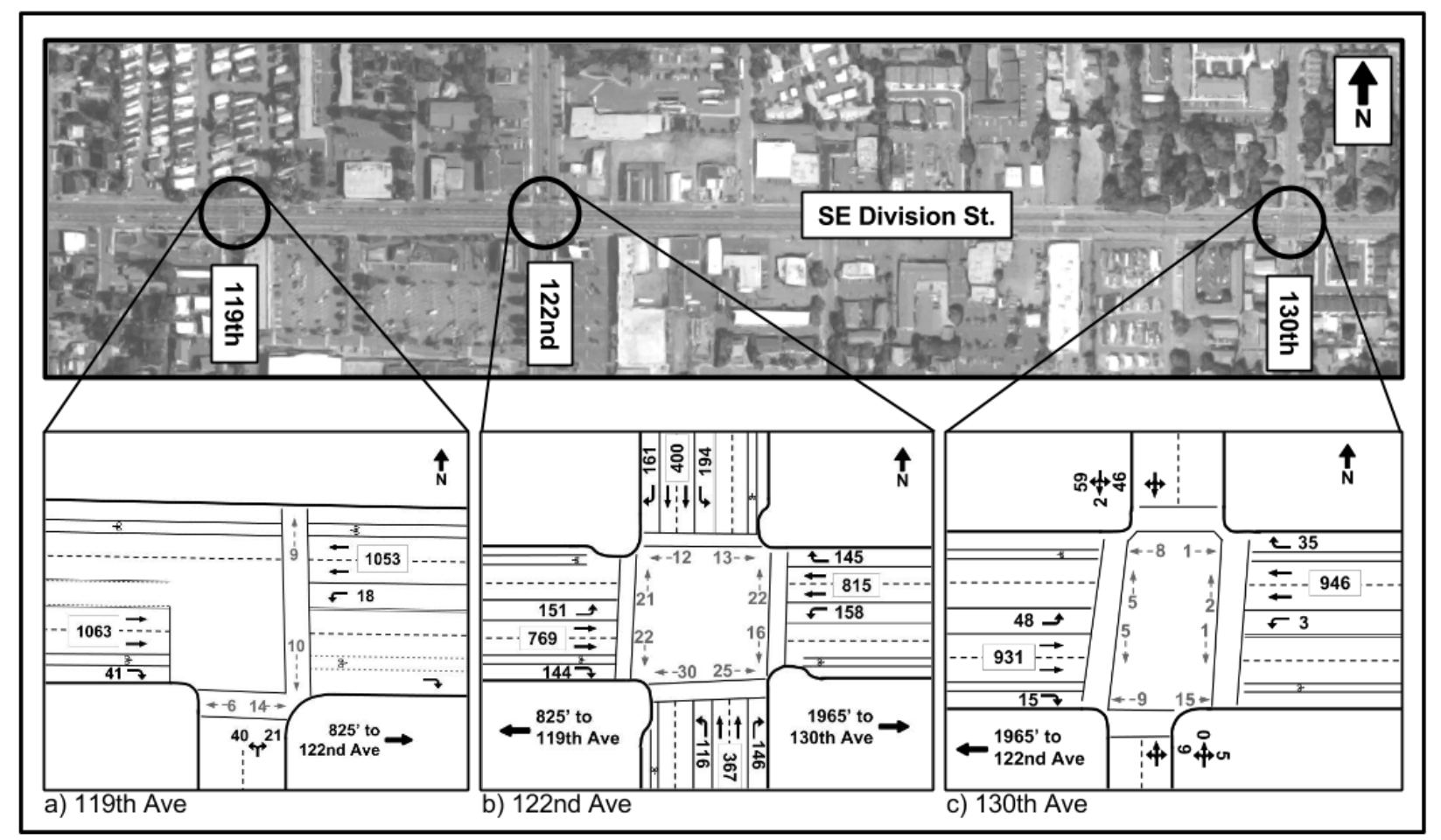

Figure 3.3 Intersection Volumes

\subsubsection{Vehicle Composition}

All vehicle composition data was obtained from QC, and included the following categories: peak-hour factors, percent heavy trucks, as well as movements of pedestrians and bicyclists. This data was coded into VISSIM with specific attributes applied to each mode.

For passenger cars each vehicle was assumed to be of single occupancy, and default driving behaviors were used. Default driving behavior parameters were also used for heavy vehicles, but the volumes came from the pneumatic tube counts and were coded as percentages of the total volume, which was between 3-10 percent for the three intersections. No transit vehicles were used in the study. Bicycle volumes were also from QC data and were low at all three intersections. Finally, pedestrian volumes were from QC data as well, with a minor change; the QC data only specified number of pedestrians that used a particular crosswalk, but did not give details on which direction the pedestrian was traveling (i.e., only pedestrians using the south crosswalk, but not how many crossed eastbound or westbound). In order to resolve this, the video-based counts that the researches had previously obtained were re-examined for specific pedestrian movements, and the ratio of directional split was then applied to the QC data, creating volumes for each movement. 


\subsubsection{Signal Timing}

Signal timing data was obtained from PBOT, which included all existing signal timing and detector layout plans for the three intersections. The signal timing plans included controller status (coordinated/free), cycle lengths, offsets, and volume/density information.

In its current state, the intersection of Division and $122^{\text {nd }}$ Avenue was operating in free mode. However, in order to implement a pedestrian priority algorithm, the intersection was set in coordination with the adjacent intersections of $119^{\text {th }}$ and $130^{\text {th }}$ avenues. To that end, traffic modeling software Synchro ${ }^{\circledR}$ was used (in conjunction with PBOT staff help) to create a coordinated timing plan for Division and $122^{\text {nd }}$. A cycle length of 110 seconds was chosen for coordination with adjacent intersections based on the time-of-day schedule.

Table 3.1 below shows the cycle length, splits and offsets that were used in the modeling of the coordination scheme. Splits for the intersections of SE Division and SE $119^{\text {th }}$ and SE $130^{\text {th }}$ were field derived, whereas the splits for the intersection of SE $122^{\text {nd }}$ and SE Division were determined using Synchro along with some engineering judgment.

Table 3.1 Splits Used in Simulation

\begin{tabular}{c|cccccccccc}
\hline Phase & 01 & 02 & 03 & 04 & 05 & 06 & 07 & 08 & Offset & Cycle Length \\
\hline 119th Ave & 13 & 69 & - & - & - & 82 & - & 28 & 27 & 110 \\
122nd Ave & 19 & 41 & 15 & 35 & 17 & 43 & 21 & 29 & 0 & 110 \\
130th Ave & 16 & 65 & - & 29 & 16 & 65 & - & 29 & 89 & 110 \\
\hline
\end{tabular}

The simulation model used in this study employed ASC/3 signal controller software, which was available as software-in-the-loop for VISSIM. The ASC/3 software was different than the Voyage signal controller software on Type 2070 signal controllers, present in the field. However, tests were performed to compare the performance metrics between the ASC/3 controllers and the RBC controller (which was closest in performance to Voyage). The comparison tests revealed that the metrics compared well (percent differences in delay and traffic volumes between the two models were within 6 percent in most cases). All timing and detection plans obtained from PBOT were adapted to the ASC/3 platform. Pedestrian movements were simplified to only intersection crossings in order to focus on the delay at intersections; to that end, no movements along the corridor were simulated.

\subsubsection{Network Development}

The network development for the simulation model was based on Google Earth satellite imagery. Further description is provided below. 


\subsubsection{Lane Widths}

The lane width for each travel lane was coded as 11 feet. Bicycle lanes were coded as 5 feet and pedestrian crosswalks were coded as two links, each with a width of 5 feet. All of the widths were obtained from measurements using Google Earth imagery.

\subsubsection{Speeds}

Speed values in VISSIM are assigned based on a distribution defined by the user. Table 3.2 shows the speeds and distribution values.

Table 3.2: Speed Distribution Data

\begin{tabular}{|l|l|}
\hline Link or Mode & Speeds and Distribution Bounds \\
\hline Auto + HGV along SE Division St & $35 \mathrm{mph}( \pm 2 \mathrm{mph})$ \\
\hline Auto + HGV along SE $122^{\text {nd }}$ Ave & $35 \mathrm{mph}( \pm 2 \mathrm{mph})$ \\
\hline Auto + HGV along SE $119^{\text {th }}$ Ave. & $25 \mathrm{mph}( \pm 2 \mathrm{mph})$ \\
\hline Auto + HGV along SE $130^{\text {th }}$ Ave. & $25 \mathrm{mph}( \pm 2 \mathrm{mph})$ \\
\hline Auto + HGV Right Turns & $9 \mathrm{mph}( \pm 2 \mathrm{mph})$ \\
\hline Auto + HGV Left Turns & $15 \mathrm{mph}( \pm 2 \mathrm{mph})$ \\
\hline Pedestrians & $4 \mathrm{mph}( \pm 1 \mathrm{mph})$ \\
\hline Bicycles & $10 \mathrm{mph}( \pm 2 \mathrm{mph})$ \\
\hline
\end{tabular}

All speed distributions were linear in nature (as opposed to polynomial). Defaults settings were retained for all other parameters such as driving and walking behavior, acceleration distributions, and other base-level options.

\subsubsection{Detection}

The intersections used in the modeling were equipped with inductive loop detectors on all approaches. Detection plans were obtained from PBOT-supplied signal timing plans, along with any volume density parameters related to the detectors. Figure 3.4 shows the detection scheme at the three intersections, with individual detectors shown in yellow. The model did, however, contain several changes to the PBOT in-field scheme. These include:

- The multiple stop-bar loops (in series) in the left-turn pockets and on the minor approaches used by PBOT were replaced by one large loop of the same size for simplification. 


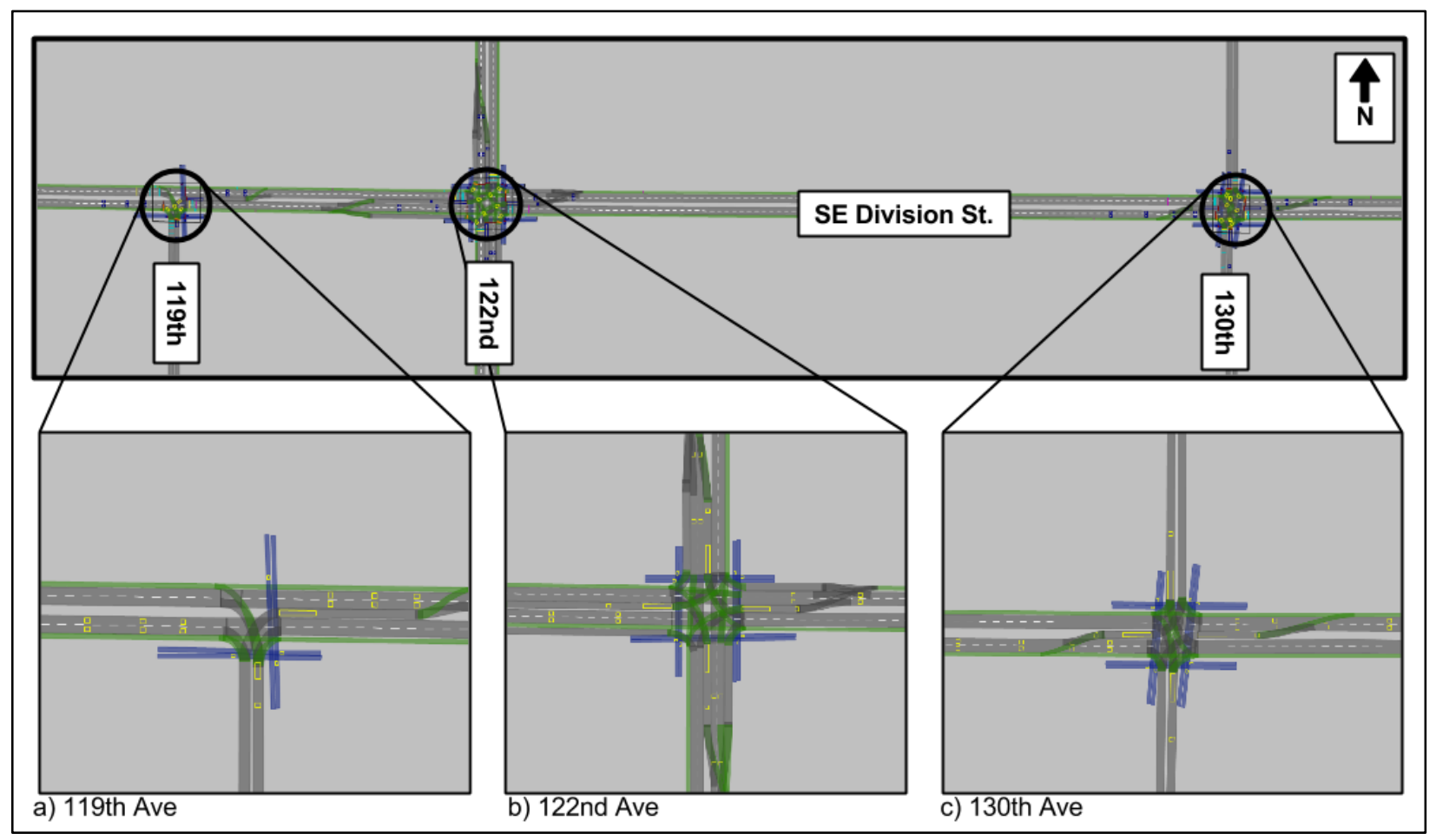

Figure 3.4 Detector Layout

- Each individual detector was linked to the controller separately rather than linking pairs in a series. This was done because the virtual controller does not have the physical ports that facilitate the in-series wiring.

\subsubsection{Model Calibration}

Calibration of models is performed to ensure that the model accurately reflects the real-world attributes desired for correct operation. This is done through the systematic adjustment of the many parameters that are user defined, as well as through an understanding of the nuance of how the particular program uses those parameters to arrive at its outputs. Calibration also involves finding and removing errors and ensuring that the outputs meet certain user-defined standards. No calibration was performed for our network.

\subsubsection{Model Validation}

In order to calibrate the models, simulation input and output volumes are compared to assess how closely they match each other. The Oregon Department of Transportation (ODOT) recommends the GEH formula as the metric that should be used to compare traffic volumes within the simulation to those from the real world. The formula is given by:

$$
G E H=\sqrt{\frac{2(m-c)^{2}}{m+c}}
$$


where,

$\mathrm{m}=$ output traffic volume from simulation model (vph)

$\mathrm{c}=$ input traffic volume $(\mathrm{vph})$

The ODOT VISSIM protocol report provides guidance on acceptable values for GEH statistic (ODOT, 2011). The criteria are listed in Table 3.3.

Table 3.3 GEH Criteria for Model Validation

\begin{tabular}{l|l}
\hline Value of Statistic & Criteria \\
\hline GEH $<5.0$ & Acceptable fit \\
$5.0<=$ GEH $<=10.0$ & Caution: possible model error or bad data \\
GEH $>10.0$ & Unacceptable \\
\hline
\end{tabular}

(Source: ODOT, Protocol for VISSIM Simulation, June 2011)

ODOT recommends that GEH statistics should be calculated for all intersection turns and mainline links and for traffic volumes at all entry and exit locations for each model and the criteria presented in Table 3.3 be used to assess the validity of the model results.

Results of the GEH analysis revealed GEH $<5.0$ for all links, meaning all data was considered to be acceptable.

\subsection{MODEL DEVELOPMENT FOR PEDESTRIAN PRIORITY ALGORITHM}

The same base simulation model for the Division Street network was used to evaluate the pedestrian priority algorithm. Two sets of models were used to simulate the impacts of the pedestrian priority algorithm. Due to the timing of this simulation (conducted in time to meet the TRB 2016 paper submission deadline), there were several notable changes. First, at the time of this simulation, traffic volumes from QC were not yet available. Instead, Portland State University researchers collected three-hour traffic volumes at each of the intersections between 10 a.m.-1 p.m. using video cameras. These were used to populate the simulation model that was used to analyze the algorithm results. Second, while this model and its signal timing were developed and calibrated with real-world data, this model has not been validated to actual field conditions (Smaglik et al., 2011; Smaglik et al., 2008). All comparisons that come from the results of these simulations were internally compared. This model is referred to as the model with non-validated data. Later on, the algorithm was also rerun on the model with validated data. The results from both these efforts are presented in Chapter 5. 


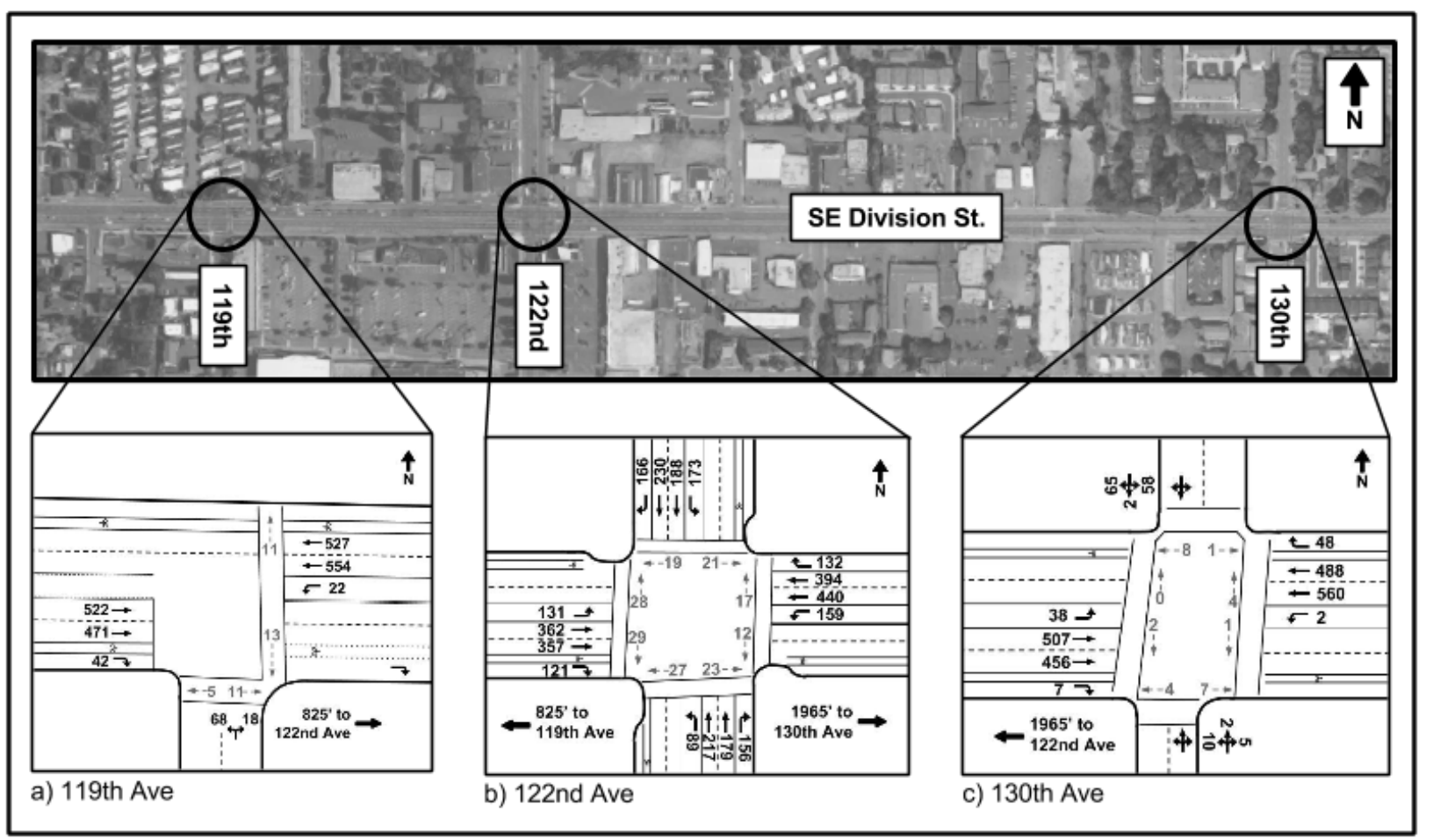

Figure 3.5 Division Street Corridor Volumes used in the Pedestrian Priority Algorithm Simulation

\subsection{SUMMARY}

In this chapter, the steps undertaken to build a microsimulation model using VISSIM software including site selection, data collection to gather inputs, network development, model calibration and validation - were described. Three intersections along the Division Street corridor in Portland, OR, were simulated. The objective of the model-building exercise was to use it to evaluate the various pedestrian control strategies. The next chapter details the development of the pedestrian priority algorithm. 


\subsection{PEDESTRIAN PRIORITY ALGORITHM DEVELOPMENT}

\subsection{INTRODUCTION}

This chapter proposes and analyzes an algorithm designed to prioritize pedestrian service under certain traffic conditions. The algorithm analyzes field data and changes the active operational strategy to match conditions in the field. The goal is to automatically select a strategy that matches the policy objective based on data that can be readily collected in the field with equipment commonly used by traffic signal practitioners.

\subsection{ALGORITHM DEVELOPMENT}

The use of the existing traffic signal controller to implement signal timing plans that prioritize pedestrians is considered advantageous from a maintenance standpoint. For this reason, the algorithm developed in this work uses an onboard logic processor within a traffic controller to allow the controller to switch into a pedestrian priority operational plan (PPOP) based upon volume over a specified time interval (Econolite's ASC/3 controller was used in this work). The following pseudocode generically presents the algorithm.

\section{IF OPERATIONAL PLAN $=X$ \\ AND VEHICULAR VOLUME < THRESHOLD during last $T$ minutes THEN INITIATE PEDESTRIAN PRIORITY OPERATIONAL PLAN ELSE CONTINUE OPERATIONAL PLAN $X$}

The logic processor is only able to test and modify certain parameters within the controller. For monitoring volumes, this controller can make decisions based upon NTCIP-stored vehicle volumes. Since there is a limit of 204.7 seconds per NTCIP log period, a series of delays and logic flags are used to extend the duration of time monitored ( $T$ in the above pseudocode) to a preferred amount of time. The desired threshold for volume is dependent upon characteristics at the intersections in question. Prior work by Kothuri showed that pedestrian responsive strategies may be most applicable during coordination, when major-street vehicle volumes are moderate $(0.5<$ v/c < 0.8) and minor-street pedestrian volumes are low or moderate (Kothuri et al., 2015). Volumes are monitored for the movements selected by the user (typically the through movements for the major approaches), and the controller will switch into the PPOP if the volumes are below the target threshold for the desired volume collection period. Figure 4.1 is a flowchart showing the general steps of the algorithm. 


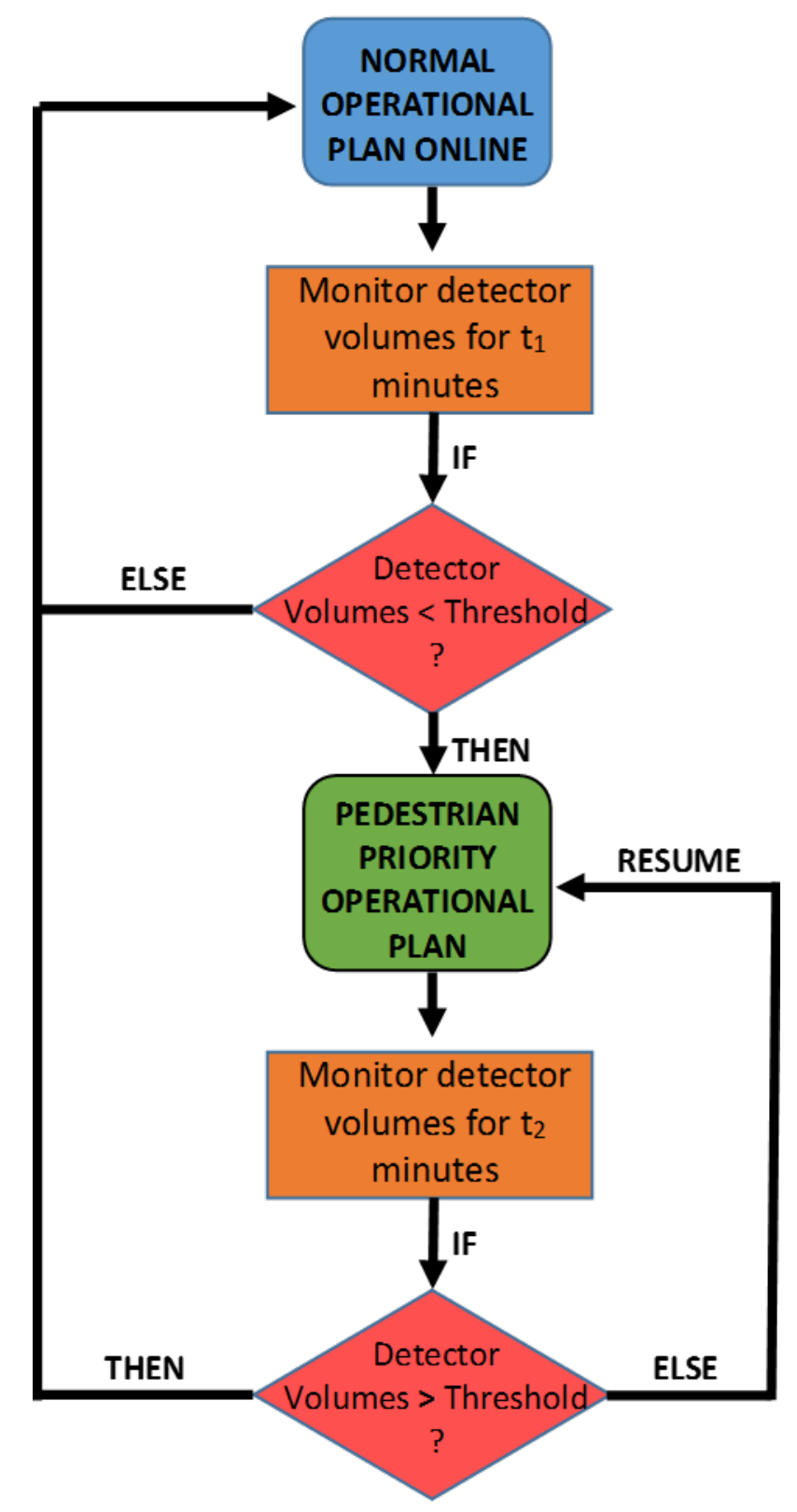

Figure 4.1 Pedestrian Priority Algorithm Flowchart

Within the logic processor of the controller, the operational plan can be selected based upon the outcome of a test. The operational plan is used to assign the timing plan (MIN \& MAX greens, VEH EXT, etc.) and in coordination plan along with other associated options. Therefore, within the logic processor the user can define which operational plan to switch to when vehicle volumes are below the desired threshold. This is identified as the pedestrian priority operational plan (PPOP) in Figure 4.1. Depending on user preferences, the PPOP could shorten the cycle length, change the permissive periods, or adjust coordination settings to reduce the delay experienced by 
minor-phase pedestrians. While in the PPOP, the logic processor continues to monitor volume to either keep the PPOP in action, or change back to the normal plan. The amount of time between possible operational plan changes is user definable to avoid hopping back and forth between plans too quickly. The following sections will evaluate the impact that the employment of this algorithm has on user delay.

\subsection{SUMMARY}

The objective of this chapter was to present the development of a traffic responsive algorithm to change the operational plan of a traffic signal to a plan which is favorable to pedestrians when vehicular volumes drop below a certain threshold. Once the user-defined volume threshold has been met, any of the user-specified efficiency strategies listed above can be implemented until the volume conditions are no longer met. The next chapter presents the results from the simulation models analyzed in this work. 


\subsection{PEDESTRIAN CONTROL STRATEGIES}

Using the simulation model previously developed, this chapter explores the impacts of various pedestrian control strategies on all users. The various strategies tested in this study include removal of coordination (free operation), leading pedestrian interval, exclusive pedestrian phase, cycle length manipulation, pedestrian priority algorithm, and actuated-coordinated operation. Each of these treatments was compared to a base case, which was standard coordination at all three intersections. These treatments are described further below.

\subsection{SIMULATION COMPARISONS WITH VALIDATED DATA}

As was noted earlier, simulation comparisons in this work were carried out on two different sets of data: validated and non-validated. The following subsections discuss the results from simulations conducted with field-validated data.

\subsubsection{Coordinated-Base Case}

The base case model consisted of the three intersections in the previously developed simulation model $-119^{\text {th }}$ Avenue, $122^{\text {nd }}$ Avenue, and $130^{\text {th }}$ Avenue - operating in coordination with each other. The signal timing parameters for $119^{\text {th }}$ Avenue and $130^{\text {th }}$ Avenue were field derived, whereas coordinated signal timing for $122^{\text {nd }}$ Avenue was developed using Synchro ${ }^{\mathrm{TM}}$ signal timing software. The offsets were adjusted in the field based on engineering judgment. The cycle length at each of these intersections was 110 seconds.

Table 5.1 shows the average delays for autos, heavy vehicles, bicycles and pedestrians at the three intersections, based on averages obtained from 10 simulation runs in VISSIM. Overall delays show wide variation, ranging from 5.34 seconds for all users at $119^{\text {th }}$ Avenue to 26.5 seconds at $122^{\text {nd }}$ Avenue. Among all the users, at all three intersections, pedestrians have the highest magnitude of delay.

Table 5.1 Average Delays from Coordinated Operation (Base Case)

\begin{tabular}{l|rrrrrr}
\hline & Int & All (s) & Bike (s) & Ped (s) & HGV (s) & Car (s) \\
\hline Coord & $119^{\text {th }}$ & 5.34 & 3.59 & 27.34 & 5.67 & 4.89 \\
& $122^{\text {nd }}$ & 26.50 & 21.44 & 40.17 & 26.56 & 25.82 \\
& 130 th & 8.31 & 17.12 & 19.45 & 8.85 & 8.01 \\
\hline
\end{tabular}

\subsubsection{Removal of Coordination (free operation)}

In free operation, each intersection operates independently of the adjacent intersections. The advantage of free operation is that individual intersections can be optimized without consideration of other signals, thus allowing greater flexibility and responsiveness (Urbanik et al., 2015). Good detection on all approaches is necessary for high operational and safety performance (Koonce et al., 2008). 
In this scenario, all three intersections were operated in free mode. Table 5.2 shows the average delays obtained for all users as well as the percent differences (in parentheses) compared to the base (coordinated case).

Table 5.2 Average and Percent Delays from Free Operation

\begin{tabular}{l|lccccc}
\hline & Int & All (s) & Bike (s) & Ped (s) & HGV (s) & Car (s) \\
\hline \multirow{2}{*}{ Free } & 119th & $6.66(25 \%)$ & $5.27(47 \%)$ & $-14.39(-47 \%)$ & $7.22(27 \%)$ & $6.48(33 \%)$ \\
& 122nd & $-24.3(-8 \%)$ & $-19.49(-9 \%)$ & $-38.46(-4 \%)$ & $-24.61(-7 \%)$ & $-23.59(-9 \%)$ \\
& 130th & $-7.27(-13 \%)$ & $-9.77(-43 \%)$ & $-17.63(-9 \%)$ & $7.16(-19 \%)$ & $-7.04(-12 \%)$ \\
\hline
\end{tabular}

Table 5.2 shows that reductions in delay were obtained at the intersections of 122nd Avenue and 130th Avenue for all users, while 119th Avenue saw increased delay for all modes except pedestrians when the signal was operating free compared to the base coordinated case. In order to understand the reason for the increase in delay at the intersection of SE 119th Avenue, the data was explored further.

Figure 5.1 shows the percent difference in delay between the free operation and coordinated-base case for the different phases at $119^{\text {th }}$ Avenue. The graph shows that while the free scenario reduced delay on the minor-street phase $(8)$, it increased delay on the major-street phases $(2,6)$ when compared to the base case, thereby resulting in an overall increase in delay. Additionally, as this was a T-intersection, with only four phases and considerably more traffic on the major street than the minor street, the decrease in delays on the minor street was undermined by the increased delays on the major street.

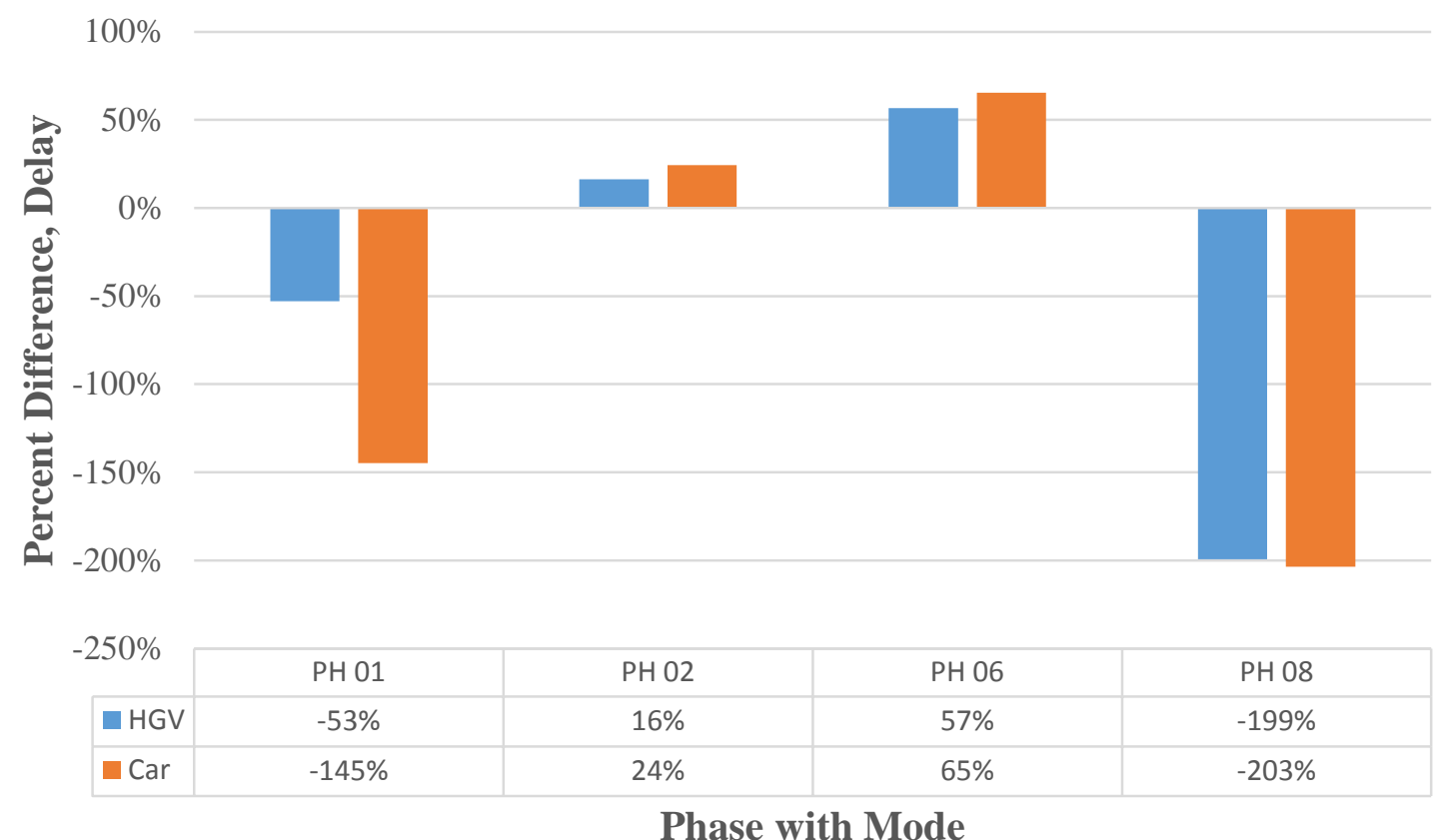

Figure 5.1 Percent Difference in Delay per Person, listed by Phase at SE 119th Avenue 


\subsubsection{Leading Pedestrian Interval}

In order to study the impacts of LPI on intersection performance, three scenarios were constructed: LPI on minor approach (SE 119th, SE 122nd and SE 130th avenues) only; LPI on major approach (SE Division Street) only; and LPI on both major and minor approaches. The resulting simulation results were compared with the base case coordinated model in order to understand the impacts. Specifically, delay per person was examined. The results of each LPI scenario (major, minor, and both) will be examined in-depth below.

\subsubsection{Leading Pedestrian Interval on the Minor-Street Phases}

The LPI was applied to only the minor approach of all three intersections in the study corridor (phases 4 and 8). Figure 5.2 shows the LPI treatment for pertinent crosswalks (shown as dashed lines) in a simplified version for a single intersection along the corridor.

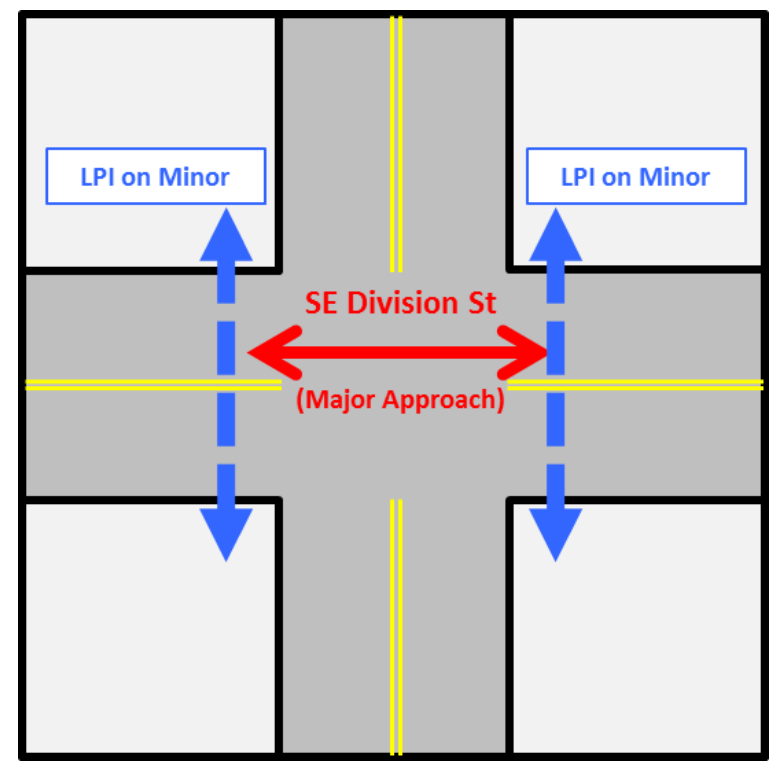

Figure 5.2 LPI on Minor Approach Only

Results of the simulation were compared to the base case coordinated model. Table 5.3 shows the difference in average delays when compared to the base case with the percent difference in delay shown in parentheses for LPI on the minor-street pedestrian phases only. 
Table 5.3 Average and Percent Difference in Delays Due to LPI on Minor Street Phases

\begin{tabular}{l|ccccc}
\hline & All (s) & Bike (s) & Ped (s) & HGV (s) & Car (s) \\
\hline 119th & $0.05(1 \%)$ & $0.02(1 \%)$ & $0(0 \%)$ & $-0.07(-1 \%)$ & $0.05(1 \%)$ \\
122nd & $0.72(3 \%)$ & $0.47(2 \%)$ & $0.06(0 \%)$ & $0.99(4 \%)$ & $0.74(3 \%)$ \\
130th & $-0.17(-2 \%)$ & $0.09(1 \%)$ & $-0.34(-2 \%)$ & $-0.47(-5 \%)$ & $-0.16(-2 \%)$ \\
\hline
\end{tabular}

The results, in general, reveal slight increases in delay resulting from the implementation of LPI on the minor street for the intersections of SE $119^{\text {th }}$ and SE $122^{\text {nd }}$ avenues compared to the base case. These results are intuitive as the LPI implementation leads to lost time for vehicles, which results in increased delay. On the other hand, average overall delays were slightly lower at the intersection of SE $130^{\text {th }}$ Avenue.

\subsubsection{Leading Pedestrian Interval on the Major-Street Phases}

The LPI was applied to major street pedestrian phases (SE Division Street) of all three intersections in the study corridor (phases 2 and 6). Figure 5.3 shows the crossings along which LPI was applied (indicated by dashed lines) for a single intersection along the corridor.

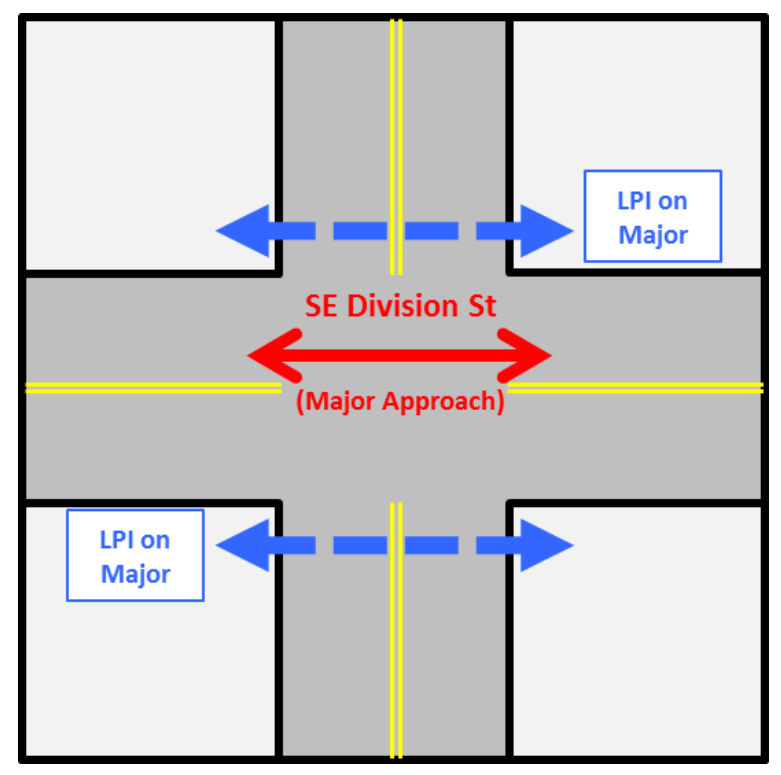

Figure 5.3 LPI on Major Approach Only

Results of the simulations were compared to the base case coordinated model using the percent difference in delay. Table 5.4 shows the difference in average delays when compared to the base case, with the percent difference in delay shown in parentheses for LPI on the major street pedestrian phases only. 
Table 5.4 Average and Percent Difference in Delays due to LPI on Major-Street Phases

\begin{tabular}{l|ccccc}
\hline & All & Bike & Ped & HGV & Car \\
\hline 119th & $0.8(15 \%)$ & $0.25(7 \%)$ & $0(0 \%)$ & $0.65(11 \%)$ & $0.82(17 \%)$ \\
122nd & $1.2(5 \%)$ & $0.28(1 \%)$ & $-0.01(0 \%)$ & $1.53(6 \%)$ & $1.24(5 \%)$ \\
130th & $0.78(9 \%)$ & $0.1(1 \%)$ & $-0.12(-1 \%)$ & $-0.56(-6 \%)$ & $0.87(11 \%)$ \\
\hline
\end{tabular}

Overall results showed delay increased at all three intersections, but LPI had little to no impact on pedestrian delay when compared to the base case. The increase in delay is driven primarily by the increase in auto delay on the major street which experiences the lost time due to the LPI implementation on the major-street pedestrian phases.

\subsubsection{Leading Pedestrian Interval on Both Approaches}

The LPI treatment was applied to both the major- and minor-street phases of all three intersections in the study corridor (phases 2, 4, 6, and 8). Figure 5.4 shows a simplified version for a single intersection along the corridor.

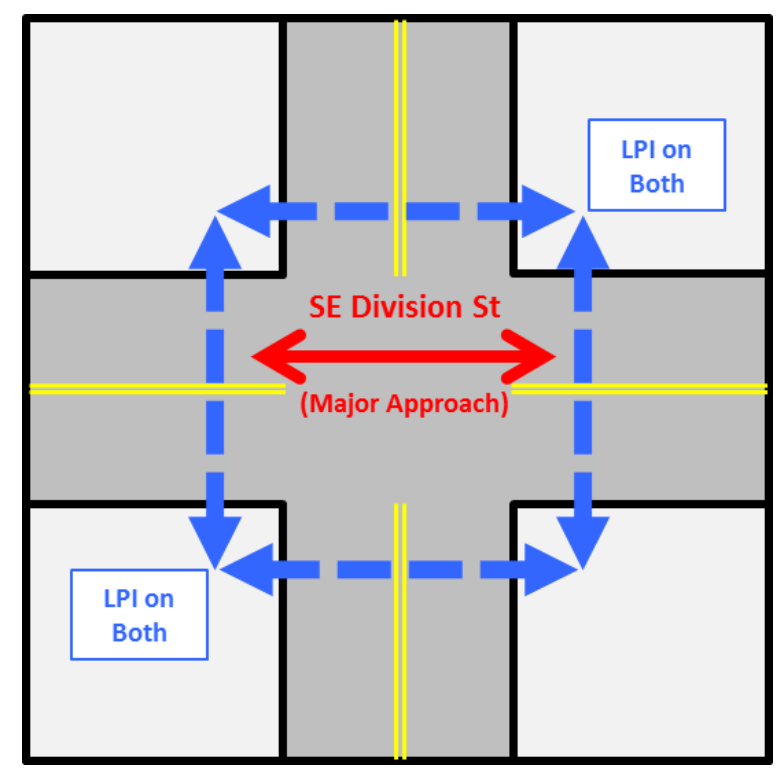

Figure 5.4: LPI on Both Approaches

Results of the simulations were compared to the base case coordinated model using the percent difference in delay across modes. Table 5.5 shows the average and percent difference in delay between the base case coordinated model and the current model using LPI treatment for both major- and minor-street pedestrian phases. 
Table 5.5 Average and Percent Difference in Delays due to LPI on Major and MinorStreet Phases

\begin{tabular}{l|ccccc}
\hline & All & Bike & Ped & HGV & Car \\
\hline 119th & $0.84(16 \%)$ & $0.22(6 \%)$ & $0(0 \%)$ & $0.63(11 \%)$ & $0.87(18 \%)$ \\
122nd & $1.83(7 \%)$ & $1.07(5 \%)$ & $0.08(0 \%)$ & $2.29(9 \%)$ & $1.9(7 \%)$ \\
130th & $0.87(10 \%)$ & $0.19(1 \%)$ & $-0.33(-2 \%)$ & $-0.39(-4 \%)$ & $0.96(12 \%)$ \\
\hline
\end{tabular}

Overall results show increased delay when all modes are considered. However, little to no change was observed for pedestrian delay when compared to the base case.

\subsubsection{Exclusive Pedestrian Phase}

Because the test corridor used in this study did not have high pedestrian volumes in reality, for this scenario the pedestrian volumes were increased to understand the impacts of the exclusive pedestrian phase on user delay. For this analysis, the exclusive pedestrian-phase timing while in coordination was developed using Synchro traffic modeling software, which has built-in functionality specifically to deal with exclusive pedestrian phases. This treatment was applied only to the intersection of SE Division Street and SE 122nd Avenue, and was coded such that all pedestrian movements occurred only during the exclusive pedestrian phase. Additionally, due to the length of the diagonal crossing at this intersection, the total time needed for the exclusive pedestrian phase was 34 seconds (4 sec Walk + 30 sec Flashing Don’t Walk). Cycle length was altered from 110 seconds to 155 seconds in order to accommodate the exclusive pedestrian phase splits.

Since the exclusive pedestrian phase is generally used in areas with high pedestrian volumes, the number of pedestrians used in the simulation was altered, as was noted earlier. Three different pedestrian volume scenarios were tested: 200, 400, and 600 pedestrians per hour (base case volumes were 161 pedestrians per hour). The results of the simulations were then compared to the base case scenario. Table 5.6 shows the results of the comparison with the average delays in seconds and the percent difference in delays in parentheses.

Table 5.6 Average and Percent Difference in Delay due to Exclusive Pedestrian Phase

\begin{tabular}{l|ccccc}
\hline Peds/hr & All & Bike & Ped & HGV & Car \\
\hline 200 & $22.57(85 \%)$ & $30.08(140 \%)$ & $35.77(89 \%)$ & $22.69(85 \%)$ & $21.95(85 \%)$ \\
400 & $23.67(89 \%)$ & $30.21(141 \%)$ & $34.86(87 \%)$ & $22.92(86 \%)$ & $22.08(86 \%)$ \\
600 & $25.43(96 \%)$ & $30.27(141 \%)$ & $34.54(86 \%)$ & $22.96(86 \%)$ & $22.12(86 \%)$ \\
\hline
\end{tabular}

The results of the simulations show that the addition of an exclusive pedestrian phase significantly increased delay across the modes when compared to the base case for all pedestrian volume scenarios. These results are intuitive as the addition of an exclusive pedestrian phase increases cycle length, which results in increased delay for all modes. Therefore, from an 
efficiency perspective, the exclusive pedestrian phase is less desirable due to increased delays all around.

\subsubsection{Cycle Length Manipulation}

The goal of this exercise was to understand the impacts of various cycle lengths on overall user delay as well as pedestrian delay. Due to the geometry of the intersections and PBOT standard minimums for FDW, the cycle length could not go below 70 seconds. Additionally, a maximum bound of 130 seconds was chosen. A range of potential cycle lengths were chosen from 70-130 seconds in 10-second increments (110 seconds was the same as the base case and was therefore excluded). Phases 02 and 06 remained in rest-in-walk.

For each cycle length (70, 80, 90, 100, 120, and 130 seconds), offsets and splits were obtained using Synchro. The obtained splits and offsets for each cycle length were input into VISSIM for all three intersections, and 10 simulation runs were implemented for each cycle length scenario.

Results were analyzed by examining trends in the VISSIM outputs and comparing the percent difference in average delays for each tested cycle length scenario with the 110-second base case.

Tables 5.7, 5.8 and 5.9 show the percent difference in delay per person when compared to the base case. These tables show that for lower cycle lengths (70-90 seconds), average delays on the major (coordinated) approach are higher when compared to the base case. This could be attributed to the queue not being cleared due to shorter green times. On the other hand, shorter cycle lengths contribute to lower delays on the minor street approach. Pedestrian delays on the minor-street phase reduce as a function of lower cycle lengths. 
Table 5.7: Percent Difference in Delay for Cycle Length Manipulation at SE 119th Avenue

\begin{tabular}{|c|c|c|c|c|}
\hline Cycle Length & \multicolumn{4}{|c|}{ Phase } \\
\hline (seconds) & $2 / 6$ & 8 & Ped 2 & Ped 4/8 \\
\hline 70 & $29 \%$ & $-54 \%$ & $19 \%$ & $-44 \%$ \\
\hline 80 & $22 \%$ & $-40 \%$ & $9 \%$ & $-34 \%$ \\
\hline 90 & $24 \%$ & $-28 \%$ & $10 \%$ & $-19 \%$ \\
\hline 100 & $6 \%$ & $-24 \%$ & $16 \%$ & $-11 \%$ \\
\hline 120 & $7 \%$ & $16 \%$ & $10 \%$ & $11 \%$ \\
\hline 130 & $-88 \%$ & $17 \%$ & $21 \%$ & $20 \%$ \\
\hline
\end{tabular}

Table 5.8: Percent Difference in Delay for Cycle Length Manipulation at SE 122nd Avenue

\begin{tabular}{lr|rlrr}
\multicolumn{2}{l|}{ Cycle Length } & \multicolumn{4}{|c}{ Phase } \\
\hline (seconds) & & $2 / 6$ & $4 / 8$ & Ped 2/6 & Ped 4/8 \\
& 70 & $15 \%$ & $-37 \%$ & $11 \%$ & $-35 \%$ \\
& 80 & $8 \%$ & $-35 \%$ & $0 \%$ & $-44 \%$ \\
& 90 & $16 \%$ & $-29 \%$ & $9 \%$ & $-28 \%$ \\
& 100 & $6 \%$ & $-13 \%$ & $-2 \%$ & $-6 \%$ \\
& 120 & $1 \%$ & $13 \%$ & $2 \%$ & $11 \%$ \\
& 130 & $2 \%$ & $20 \%$ & $-8 \%$ & $16 \%$ \\
\hline
\end{tabular}

Table 5.9: Percent Difference in Delay for Cycle Length Manipulation at SE 130th Avenue

\begin{tabular}{|c|c|c|c|c|}
\hline \multirow{2}{*}{$\begin{array}{l}\text { Cycle Length } \\
\text { (seconds) }\end{array}$} & \multicolumn{4}{|c|}{ Phase } \\
\hline & $2 / 6$ & $04 / 08$ & Ped 2/6 & Ped 4/8 \\
\hline 70 & $26 \%$ & $-93 \%$ & $-1050 \%$ & $-61 \%$ \\
\hline 80 & $-8 \%$ & $-37 \%$ & $-4 \%$ & $-22 \%$ \\
\hline 90 & $-56 \%$ & $-35 \%$ & $-22 \%$ & $-26 \%$ \\
\hline 100 & $-99 \%$ & $-12 \%$ & $-20 \%$ & $-9 \%$ \\
\hline 120 & $2 \%$ & $15 \%$ & $-3 \%$ & $9 \%$ \\
\hline 130 & $18 \%$ & $-48 \%$ & $-122 \%$ & $8 \%$ \\
\hline
\end{tabular}


Table 5.7 shows the aforementioned trends, with two exceptions:

1. There is a sudden drop in percent difference of average delay at the 130-second cycle length, which is caused by the westbound (Phase 06) movement. Note that Phase 06 is the least restricted movement at this intersection (T-intersection, and duration of phase 02 is dependent on the duration of phase 01). At 130 seconds of cycle length, phase 06 receives an additional 10 seconds of green time compared to the 120 -second cycle length, and a total of 20 seconds compared to the base case (110 seconds). This extra time helps to reduce the delays at the intersection for $\mathrm{PH} 06$ which, when compared to the base case at the 130-second cycle length, results in the dramatic drop seen in the table.

2. There is a steady increase in delay for the major approach phase 02 around the 110second mark, which is against the expected decreasing trend. This appears to be the result of the increased cycle length allocated to phases 08 and 01 , which are the only two phases that conflict with pedestrian phase 02 . Any time gained by phases 08 or 01 can result in increased delay for pedestrian phase 02 .

Table 5.9 shows no consistent trend in pedestrian delays for pedestrian phases 2 and 6 as compared to the base case. This appears to be due to low pedestrian volumes for pedestrian phases 2 and 6; the majority of the simulation runs had one or zero pedestrians, meaning that any delay values were overly influenced by the single pedestrian who used the facility. This implied that the single pedestrian who used the crossing either arrived at the right time and crossed quickly (without delay), or they arrived at the wrong time in the cycle and were made to wait, resulting in the wide variation in the results. Phases 4 and 8, however, showed the expected trend.

The results of the simulations, when compared to the base case for all pedestrian volume scenarios, showed that the cycle length manipulation significantly increased delay along the major (coordinated) phases, although that increase in delay decreased as a function of the cycle length. The minor phases delay was significantly reduced at low cycle lengths, but that changed as a function of cycle length until eventually delay began to increase at the higher cycle lengths. These results are expected, as the longer cycle lengths will allocate more of the split time to the major (coordinated) phase, thereby increasing delay on the minor phase. Unfortunately, low user volumes at SE $119^{\text {th }}$ and SE 130th caused some of the results to be inconclusive.

\subsection{PEDESTRIAN PRIORITY ALGORITHM SIMULATION}

As was noted earlier, simulation comparisons in this work were carried out on two different sets of data: validated and non-validated. The following subsections discuss the results from simulations conducted with non-validated data.

The simulation work in this section was undertaken with a dual purpose. First, the authors desired to see the impact of implementing various PPOPs on user delay, and second, to observe the hypothetical impacts of terminating an actuated-coordinated phase early through selection of extension timer values. 


\subsubsection{Comparison of Algorithm and PPOPs}

To test the impacts of a PPOP employed with the traffic-responsive algorithm, the first step was to develop a base timing plan to which the other strategies would be compared. Data for all comparisons was collected from operations at SE $122^{\text {nd }} /$ SE Division. Pertinent characteristics of the base timing plan are:

- Coordination along SE Division Street with a cycle length of 110 seconds. The exact plan was selected through Synchro 9.0 analysis using a comparison of the Synchro Performance Index and natural cycle lengths observed in the field during free operation (during the same time period).

- For the validated model, full field detection was used during the simulation. For the nonvalidated model, detection within the simulation is reduced from actual field detection, but ample enough to drive all strategies.

- SE $122^{\text {nd }} /$ SE Division characteristics:

o Stop detection present on all left-turn movements.

o Advance detection present on all through movements.

o Pedestrian service for phases $2 / 6$ is coordinated rest-in-walk.

o Pedestrian service for phases $4 / 8$ is actuated.

o Pedestrian volumes on 2/6 are as shown in Figure 3.5, while pedestrian volumes on $4 / 8$ were selected to actuate a pedestrian call roughly every four cycles. This was done to approximate low to moderate side-street pedestrian activity. For the validated model, the field observed volumes were used.

\subsubsection{Algorithm Simulation with Validated Data}

The validated base model of the Division Street corridor was used to study the impacts of the pedestrian priority algorithm. The pedestrian priority operational plan was to drop into free mode from coordination when the threshold was met. The thresholds were chosen after reviewing the 24-hour volume profile along the corridor. Three scenarios were compared using this model.

1. Coordinated-base

2. Free using the responsive algorithm (Coordinated-base when PPOP not active)

3. Free

Additionally, a sensitivity analysis was conducted on the threshold value used in the algorithm. Four values of the threshold were simulated as shown below.

1. 18 vehicles in three minutes

2. 19 vehicles in three minutes

3. 20 vehicles in three minutes

4. 21 vehicles in three minutes

\subsubsection{Results}

Table 5.10 shows the results of the simulation using the validated data. The results show that using the algorithm and dropping into free operation did reduce the overall delay by 4 percent when compared to coordinated-base case delay across all users. Overall pedestrian delay did 
increase by 1 percent for the free-with-algorithm scenario when compared to the coordinatedbase case. Operating the intersection purely in free mode reduced the overall delay by 8 percent, indicating that while free operation is preferred from a delay-reduction perspective, it may not always be feasible to operate the intersection in free mode at all times. In such cases, the algorithm provides a feasible alternative of reducing overall delays compared to the base case.

Table 5.10 Pedestrian Priority Algorithm Simulation Results with Validated Data

\begin{tabular}{l|lllll}
\hline Scenario & All & $\begin{array}{l}\text { Avg. Vehicle } \\
\text { Delay (s) }\end{array}$ & $\begin{array}{l}\text { Avg. Heavy } \\
\text { Vehicle Delay } \\
(\mathrm{s})\end{array}$ & $\begin{array}{l}\text { Avg. Pedestrian } \\
\text { Delay (s) }\end{array}$ & $\begin{array}{l}\text { Avg. Bike Delay } \\
(\mathrm{s})\end{array}$ \\
\hline $\begin{array}{l}\text { Coordinated- } \\
\text { Base }\end{array}$ & 26.5 & 25.82 & 26.56 & 40.17 & 21.44 \\
$\begin{array}{l}\text { Free with } \\
\begin{array}{l}\text { Algorithm } \\
\text { Free }\end{array}\end{array}$ & 25.51 & 24.66 & 27.49 & 40.49 & 21.12 \\
\hline
\end{tabular}

Table 5.11 shows the comparison of delays using the validated model. The average vehicle delay reduced compared to the base coordinated case for the free-with-algorithm and free scenarios. Comparing the pedestrian delays across phases, it was observed that while the free-withalgorithm scenario contributed to increased delay for pedestrian phases 2 and 6 by 13 percent, it reduced pedestrian delay by 9 percent for pedestrian phases 4 and 8 when compared to the base coordinated case. The free scenario also followed similar trends as the free-with-algorithm, but the reduction in pedestrian delay for phases 4 and 8, was higher (24 percent), when compared to the base case.

Table 5.11 Comparison of Delays with and without Algorithm using Validated Data

\begin{tabular}{l|ccc}
\hline \multicolumn{1}{c|}{ Scenario } & $\begin{array}{c}\text { Avg. Veh } \\
\text { Delay (s) }\end{array}$ & $\begin{array}{c}\text { Avg. Ped Delay } \\
2 / 6(\mathrm{~s})\end{array}$ & Avg. Ped Delay 4/8 (s) \\
\hline Coordinated (Base) & 25.82 & 29.84 & 49.96 \\
Free with Algorithm & 24.66 & 33.63 & 45.55 \\
Free & 23.59 & 38.46 & 37.86 \\
\hline
\end{tabular}

\subsubsection{Algorithm Simulation with Non-Validated Data}

The compared scenarios for the algorithm simulation using the non-validated data were the following ${ }^{1}$ :

1. Coordinated-base

2. Actuated-coordinated using the responsive algorithm (coordinated-base when PPOP not active).

a. SPLT EXT values of 15s were used for each ring (this was all that was available after accounting for Ped Recall). Note: Ped Recall used with actuatedcoordinated operation does not rest-in-walk. It serves Walk and Ped Clear as it would in an actuated setting

3. Free using the responsive algorithm (coordinated-base when PPOP not active)

4. Free

\footnotetext{
${ }^{1}$ Note: This analysis was undertaken to meet the TRB 2016 paper deadline; it was completed in addition to the agreed upon project workplan.
} 
Each simulation was 75 minutes long with 15 minutes for network population and 60 minutes for data collection. In order to activate the traffic-responsive algorithm, the volumes on the E/W links were varied per the following:

- 15 minutes at high volume (v/c value 0.20 greater than observed in field)

- 30 minutes at low volume (v/c value 0.20 less than observed in the field)

- 30 minutes at high volume (v/c value 0.20 greater than observed in the field)

In scenarios 2 and 3 above, the PPOP was active for roughly 30 minutes of the monitored 60minute period. Each scenario was run 10 times with different random seed values for each simulation (the same 10 random seeds were used across each scenario).

\subsubsection{Results}

Table 5.12 and Table 5.13 show the comparative results of the simulation in absolute and percentage values, with the scenario comparison in Table 5.12 a and Table 5.13 a and an extension timer comparison in Table $5.12 \mathrm{~b}$ and Table $5.13 \mathrm{~b}$. For the scenario comparison, the coordinated scenario is the base case and all comparisons are relative to the base. It was observed that either scenario including free operation significantly decreased average vehicle delay, while the scenario with actuated-coordinated operation had no significant difference. This is not surprising as it is common for coordinated operation to result in higher average vehicle delay for all users than other strategies. Travel times NB and SB were significantly reduced with any free operation, while travel times EB and WB increased with any free operation significantly in all cases except for free-with-algorithm. From a pedestrian standpoint, delay increases significantly on phases 2 and 6, but this is to be expected as the base case serves pedestrians with rest-in-walk (Flashing Don't Walk terminates with green termination) while the other strategies serve pedestrians on 2 and 6 with a defined walk period (7 seconds) followed by pedestrian clearance, with the pedestrian indication dwelling in solid Don't Walk until the next Walk indication. For pedestrians in phases 4 and 8, all strategies resulted in a decrease in pedestrian delay, with the free strategy seeing a significant difference (32.7 percent decrease in delay from the base case). This, along with the fact that both free strategies show a significant decrease in average vehicle delay, indicate that free may be a valid option to reduce minor-phase pedestrian delay without negatively impacting vehicular delay. The actuated-coordinated strategy reduced pedestrian delay on phases 4 and 8 by 3.3 percent, albeit not significantly, and left average vehicle delay essentially unchanged ( 0.7 percent increase). With more aggressive settings, the actuatedcoordinated strategy may yield significant differences. 
Table 5.12 Simulation Results, Absolute Values

\begin{tabular}{|c|c|c|c|c|c|c|c|}
\hline Scenario & $\begin{array}{l}\text { Avg. } \\
\text { Veh } \\
\text { Delay } \\
\text { (s) }\end{array}$ & $\begin{array}{c}\text { Avg. Ped } \\
\text { Delay } \\
2 / 6 \text { (s) }\end{array}$ & $\begin{array}{c}\text { Avg. Ped Delay } \\
\text { 4/8 (s) }\end{array}$ & $\begin{array}{l}\text { Avg. } \\
\text { TT } \\
\text { (s) } \\
\text { (EB) }\end{array}$ & $\begin{array}{c}\text { Avg. } \\
\text { TT } \\
\text { (s) } \\
\text { (WB) }\end{array}$ & $\begin{array}{l}\text { Avg. } \\
\text { TT } \\
\text { (s) } \\
\text { (NB) }\end{array}$ & $\begin{array}{l}\text { Avg. } \\
\text { TT } \\
\text { (s) } \\
\text { (SB) }\end{array}$ \\
\hline $\begin{array}{l}\text { Coordinated- } \\
\text { (Base) }\end{array}$ & 26.55 & 25.43 & 44.95 & 100.71 & 90.61 & 94.79 & 90.77 \\
\hline $\begin{array}{l}\text { Actuated- } \\
\text { Coordinated }\end{array}$ & 26.73 & $36.45 *$ & 43.45 & 101.98 & 90.99 & 94.81 & 91.28 \\
\hline $\begin{array}{l}\text { Free-with- } \\
\text { Algorithm }\end{array}$ & $25.11^{*}$ & $28.44 *$ & 41.28 & 102.25 & 99.93* & $87.69 *$ & 84.39* \\
\hline Free & $22.81^{*}$ & $32.87 *$ & $30.25 *$ & 104.25* & 107.62* & 77.73* & $74.50 *$ \\
\hline
\end{tabular}

a) Scenario comparison

\begin{tabular}{|c|c|c|c|c|c|c|c|c|}
\hline $\begin{array}{c}\text { Vehicle } \\
\text { Extension } \\
\text { Timer } \\
\text { (s) }\end{array}$ & $\begin{array}{l}\text { Avg. } \\
\text { Overall } \\
\text { Delay } \\
\text { (s) }\end{array}$ & $\begin{array}{l}\text { Avg. Veh } \\
\text { Delay (s) }\end{array}$ & $\begin{array}{l}\text { Avg. Ped } \\
\text { Delay } \\
2 / 6 \text { (s) }\end{array}$ & $\begin{array}{l}\text { Avg. Ped Delay } \\
\text { 4/8 (s) }\end{array}$ & $\begin{array}{c}\text { Avg. } \\
\text { TT } \\
\text { (s) } \\
\text { (EB) }\end{array}$ & $\begin{array}{c}\text { Avg. } \\
\text { TT } \\
\text { (s) } \\
\text { (WB) }\end{array}$ & $\begin{array}{l}\text { Avg. } \\
\text { TT } \\
\text { (s) } \\
\text { (NB) }\end{array}$ & $\begin{array}{l}\text { Avg. } \\
\text { TT } \\
\text { (s) } \\
\text { (SB) }\end{array}$ \\
\hline 0 & 26.74 & 26.14 & 48.07 & 38.33 & $104.89 *$ & 89.76 & 94.69 & 90.28 \\
\hline 0.5 & 26.73 & 26.14 & 48.08 & 38.33 & 104.89* & 89.76 & 94.70 & 90.26 \\
\hline 1.0 & 26.73 & 26.91 & 48.14 & 38.44 & 104.86* & 89.64 & 94.63 & 90.37 \\
\hline 1.5 & 26.65 & 26.04 & 48.08 & 38.86 & 104.13* & 89.53 & 94.70 & 90.33 \\
\hline 2.0 & 26.70 & 26.07 & 48.27 & 39.59 & 103.50* & 89.44 & 94.84 & 90.68 \\
\hline 2.5 & 26.75 & 26.11 & 48.60 & 41.66 & $102.92 *$ & 89.58 & 95.09 & 90.57 \\
\hline 3.0 & 26.68 & 26.04 & 48.64 & 42.57 & 101.98 & 89.19 & 95.23 & 90.68 \\
\hline 3.5 (Base) & 26.57 & 25.94 & 48.49 & 42.19 & 101.08 & 89.16 & 94.99 & 90.51 \\
\hline
\end{tabular}

b) Extension timer value sensitivity analysis 
Table 5.13 Simulation Results, Percentage Values

\begin{tabular}{lcccrrrr}
\hline \multicolumn{1}{c}{ Scenario } & $\begin{array}{c}\text { Avg. } \\
\text { Veh } \\
\text { Delay }\end{array}$ & $\begin{array}{c}\text { Avg. } \\
\text { Ped } \\
\text { Delay } \\
\mathbf{2 / 6}\end{array}$ & $\begin{array}{c}\text { Avg. } \\
\text { Ped } \\
\text { Delay } \\
\mathbf{4 / 8}\end{array}$ & $\begin{array}{c}\text { Avg. } \\
\text { TT } \\
\text { (EB) }\end{array}$ & $\begin{array}{c}\text { Avg. } \\
\text { TT } \\
\text { (WB) }\end{array}$ & $\begin{array}{c}\text { Avg. } \\
\text { TT } \\
\text { (NB) }\end{array}$ & $\begin{array}{r}\text { Avg. } \\
\text { TT } \\
\text { (SB) }\end{array}$ \\
\hline Actuated-Coordinated & 0.7 & 43.3 & -3.3 & 1.3 & 0.4 & 0.0 & 0.6 \\
\hline Free-with-Algorithm & -5.4 & 11.8 & -8.2 & 1.5 & 10.3 & -7.5 & -7.0 \\
\hline Free & -14.1 & 29.3 & -32.7 & 3.5 & 18.8 & -18.0 & -17.9 \\
\hline
\end{tabular}

a) Scenario comparison

\begin{tabular}{|c|c|c|c|c|c|c|c|c|}
\hline $\begin{array}{c}\text { Vehicle } \\
\text { Extension } \\
\text { Timer }\end{array}$ & $\begin{array}{l}\text { Avg. } \\
\text { Overall } \\
\text { Delay }\end{array}$ & $\begin{array}{l}\text { Avg. } \\
\text { Veh } \\
\text { Delay }\end{array}$ & $\begin{array}{c}\text { Avg. } \\
\text { Ped } \\
\text { Delay } \\
2 / 6\end{array}$ & $\begin{array}{c}\text { Avg. } \\
\text { Ped } \\
\text { Delay } \\
4 / 8\end{array}$ & $\begin{array}{l}\text { Avg. } \\
\text { TT } \\
\text { (EB) }\end{array}$ & $\begin{array}{l}\text { Avg. } \\
\text { TT } \\
\text { (WB) }\end{array}$ & $\begin{array}{l}\text { Avg. } \\
\text { TT } \\
\text { (NB) }\end{array}$ & $\begin{array}{l}\text { Avg. } \\
\text { TT } \\
\text { (SB) }\end{array}$ \\
\hline 0 & $0.6 \%$ & $0.8 \%$ & $-0.9 \%$ & $-9.1 \%$ & $3.8 \%$ & $0.7 \%$ & $-0.3 \%$ & $-0.3 \%$ \\
\hline 0.5 & $0.6 \%$ & $0.8 \%$ & $-0.8 \%$ & $-9.1 \%$ & $3.8 \%$ & $0.7 \%$ & $-0.3 \%$ & $-0.3 \%$ \\
\hline 1.0 & $0.6 \%$ & $3.7 \%$ & $-0.7 \%$ & $-8.9 \%$ & $3.7 \%$ & $0.5 \%$ & $-0.4 \%$ & $-0.2 \%$ \\
\hline 1.5 & $0.3 \%$ & $0.4 \%$ & $-0.8 \%$ & $-7.9 \%$ & $3.0 \%$ & $0.4 \%$ & $-0.3 \%$ & $-0.2 \%$ \\
\hline 2.0 & $0.5 \%$ & $0.5 \%$ & $-0.5 \%$ & $-6.2 \%$ & $2.4 \%$ & $0.3 \%$ & $-0.2 \%$ & $0.2 \%$ \\
\hline 2.5 & $0.7 \%$ & $0.7 \%$ & $0.2 \%$ & $-1.3 \%$ & $1.8 \%$ & $0.5 \%$ & $0.1 \%$ & $0.1 \%$ \\
\hline 3.0 & $0.4 \%$ & $0.4 \%$ & $0.3 \%$ & $0.9 \%$ & $0.9 \%$ & $0.0 \%$ & $0.3 \%$ & $0.2 \%$ \\
\hline
\end{tabular}

b) Extension timer value sensitivity analysis

\subsubsection{Sensitivity Analysis of Vehicle Extension Timers}

Selection of a critical maximum allowable headway (CMAH) based upon operational objectives would result in using actuated-coordinated operation with values for the extensible period and extension timer chosen through a mathematical process. To emulate the impact that this type of operation may have on user delay and using the simulation network developed in this work, a sensitivity analysis was undertaken on the vehicle extension timer value to observe the change in user delay with more (or less) aggressive CMAH settings. For this comparison, pedestrian recall with no rest-in-walk was used on phases 2/6 (pedestrian service on 4/8 was actuated) and extension timers on 2/6 were varied between 3.5 seconds (base case) and 0.0 second in halfsecond increments (given that Division Street is a $35 \mathrm{mph}$ roadway, dilemma zone impacts were not considered in this analysis). Pedestrian volumes were the same as in the scenario comparison; vehicle volumes were as collected in the field and were not varied during the simulation period.

For the extension timer comparison, the base case was the scenario with vehicle extension timer value of 3.5 seconds. As expected we see an increase in travel times on EB and WB, significantly on EB with extension timer values of 2.5 seconds or lower (0.9-3.8 percent increase compared to base case). Travel times on NB and SB were roughly unchanged. Average vehicle delay across the intersection did increase when the extension timer value dropped, though not significantly. This is not surprising as lower extension timer values on the coordinated phase will increase delay on that phase, and with the large vehicle volumes this can increase the overall delay. For pedestrians, while there were no significant differences, pedestrian delay on phases 4 
and 8 dropped almost four seconds from the base case to the 0.0 second extension value timer (decrease of 9.1 percent). This, combined with an average vehicle delay increase of only 0.20 seconds ( 0.6 percent) between these strategies, shows that manipulation of phase termination through platoon dispersion techniques may be a promising method to reduce minor phase pedestrian delays with negligible impacts on vehicle delays.

\subsection{SUMMARY}

In this chapter, pedestrian control strategies such as leading pedestrian interval, exclusive pedestrian phase (Barnes Dance), free operation, cycle length manipulation, and pedestrian priority algorithm were tested in a simulation model to assess their efficiency impacts on all users. The average delays across modes for each of these strategies were compared to the base case coordinated model. Following were the key findings.

- For free operation, overall delays across all users decreased at $122^{\text {nd }}$ Avenue and $130^{\text {th }}$ Avenue, while at $119^{\text {th }}$ Avenue delay increased compared to the base coordinated operation. Pedestrian delays, however, decreased at all three intersections compared to the base case, indicating that free operation may be employed as a strategy, especially when the objective is to reduce delays for minor-street pedestrian phases.

- Implementation of LPI for the minor-street pedestrian phases increased overall delays slightly, due to lost time incurred by the vehicular traffic. However, pedestrian delays did not show much change. Implementation of LPI for the major-street pedestrian phases increased delays by a larger amount, while pedestrian delays did not experience much change when compared to the base coordinate delays. Implementation of LPI on both major- and minor-street pedestrian phases increased delays overall, without much change to pedestrian delays.

- Implementation of an exclusive pedestrian phase at $122^{\text {nd }}$ Avenue and Division Street only increased delays substantially overall and for all modes at this intersection. Overall delays also increased as a function of increased pedestrian volume.

- Results from the cycle length manipulation analysis showed that as cycle lengths were shortened delays for minor street vehicular and pedestrian phases decreased, while corresponding delays on the major street increased. At higher cycle lengths, overall delays and pedestrian delays across major and minor street phases increased when compared to the base coordinated case, indicating that shorter cycle lengths are ideal for lowering pedestrian delays for minor-street pedestrian movements.

- The scenario analysis with the pedestrian priority algorithm showed that employing free operation with the algorithm or without was an effective method of reducing minor street pedestrian delay while also decreasing average intersection vehicular delay. Vehicle extension timer sensitivity analysis showed that reducing the extension timer of an actuated-coordinated phase can reduce minor street pedestrian delay without increasing overall vehicle delay.

- The vehicle extension sensitivity analysis showed that shortening the extension timer of an actuated-coordinated phase can reduce the minor street pedestrian delay without increasing overall vehicle delay. Percent reductions for the minor street pedestrian phase varied from 1.3 to 9.1 percent, with a reduction in the vehicle extension timer from the base case of 3.5 seconds to 0.0 second. 


\subsection{DEPLOYMENT OF PEDESTRIAN PRIORITY ALGORITHM}

This chapter presents the process followed for site identification for the field deployment of the pedestrian priority algorithm and the results from the deployment. Three intersections, one each in the cities of Portland, OR, Mesa, AZ, and Flagstaff, AZ, were chosen for deployment.

\subsection{IDENTIFICATION OF SITES FOR DEPLOYMENT}

The research team sat down with practitioners from each of the three deployment cities to discuss deployment locations. For Portland, the natural fit was that of the one simulated for reasons discussed earlier. For the Arizona sites, criteria such as need for coordination, pedestrian demand, and general operational characteristics were topics that were pertinent to the discussion, to be detailed in the subsequent sections.

\subsubsection{Portland, OR}

Portland, OR, with an estimated population of 600,000, is the largest city in the Portland metropolitan region, which has a population of 2.35 million. The city of Portland operates over 1,000 traffic signals and is a leader in accommodating non-motorized transportation modes at the various intersections.

Based on conversations with city personnel, the intersection of Division Street and $122^{\text {nd }}$ Avenue was chosen for deployment. This intersection was not ideal for deployment, as the volumes of traffic on Division Street and $122^{\text {nd }}$ Avenue are similar. However, this intersection was chosen based on city personnel preference and because it was previously used as the basis for simulation and therefore the impacts were known. Ideally for the pedestrian priority algorithm, the chosen intersection would have greater volume of traffic on the major street and lower volume on the minor street, and thus provide the signal controller with the ability to activate the algorithm only when the major street traffic volume falls below a certain threshold. The geometric and operational characteristics of this intersection have been described extensively in Chapter 3 and therefore will not be repeated here.

\subsubsection{Mesa, AZ}

Mesa is a city of nearly 500,000 residents in the eastern side of the valley of the Phoenix metropolitan area, in which over 4 million people reside. The city operates 453 traffic signals, many in various modes of coordination, as the city is roughly a grid with major roadways spaced one mile apart, and minor collectors on the half-mile spacing in between. Mesa personnel indicated that providing coordination to their citizens is important when justified, but that they were open to experimenting with other operations during periods of lower volume. They noted that pedestrians are generally ok with waiting a bit longer to be served when volumes are high, but with lower volumes they get impatient and are more likely to violate the signal.

Based upon this, the location agreed upon by the team and Mesa personnel was that of $262 \mathrm{E}$. Brown Road, where a pedestrian hybrid beacon (PHB), formerly known as a HAWK (High- 
Intensity Activated Crosswalk Beacon), is located. This location was selected for several reasons. First, the roadway on which it is located, Brown Road, is a half-mile minor collector roadway. As such, Mesa was comfortable dropping this intersection out of coordination during certain times of the day. Second, this PHB provides access between an elderly home and a grocery store / strip mall, so it was believed that there would be ample activations. To verify, a log of pedestrian calls was pulled and approximately 50 calls were placed on a daily basis. Lastly, probe data collection devices (Bluetooth technology) were located at the adjacent intersections, allowing the team to collect travel time data along the one-mile segment both before and after. Figure 6.1 shows the location of the PHB within the city while Figure 6.2 shows an overview of the site and the surrounding network.

This site is within a coordinated network and Mesa has fiber communication to the site as well as the other intersections in this system. Control and timing settings at this location can be changed remotely through Mesa's CENTRACS system. An Econolite ASC/3 controller operates the PHB using special logic contained within the on-board logic processor. Mesa installed Econolite Terra cameras for each approach to provide count capability for driving the algorithm. The PHB is operated by pushbutton.

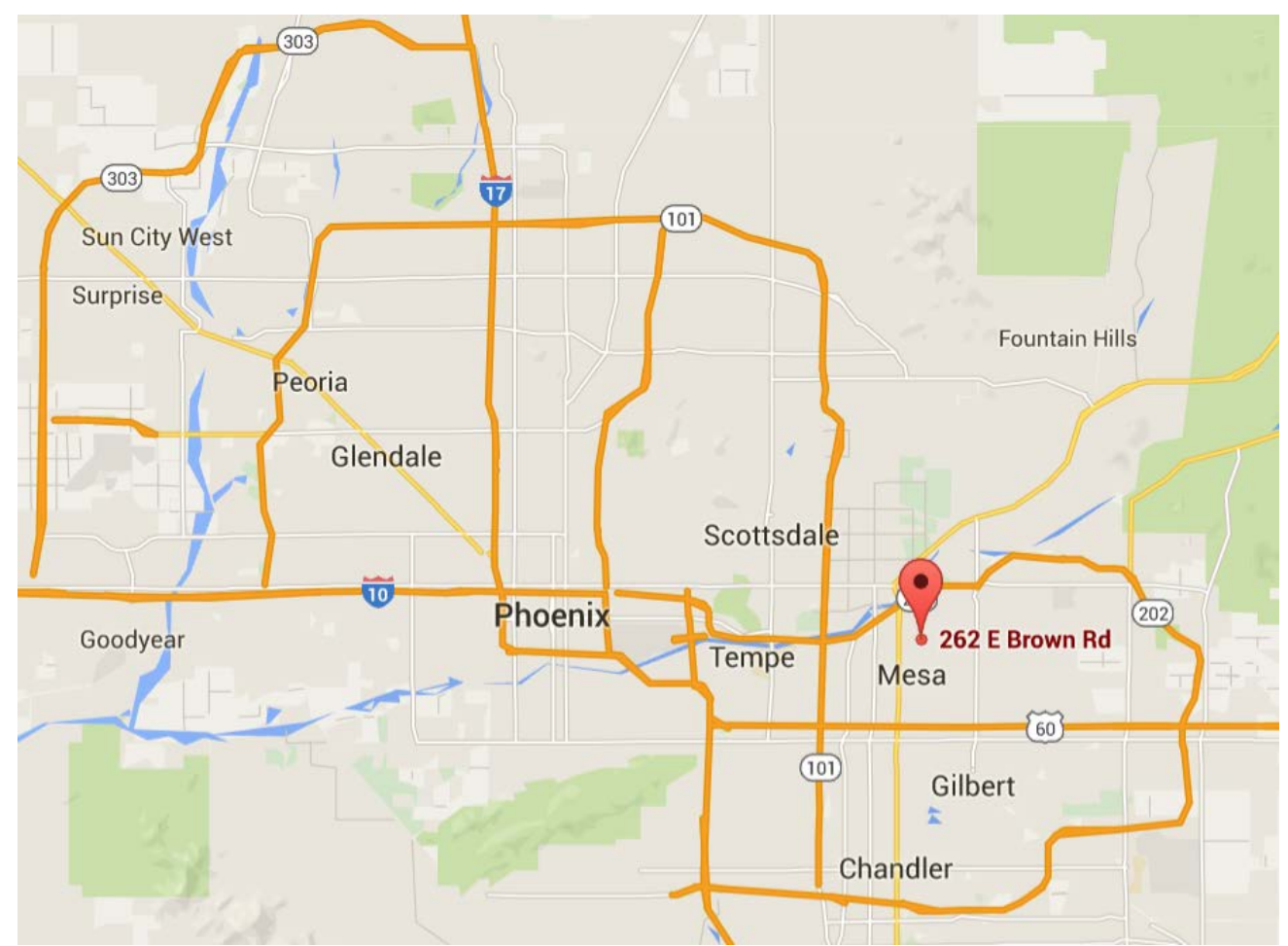

Figure 6.1 Location Map: Brown Road HAWK, Mesa, AZ 


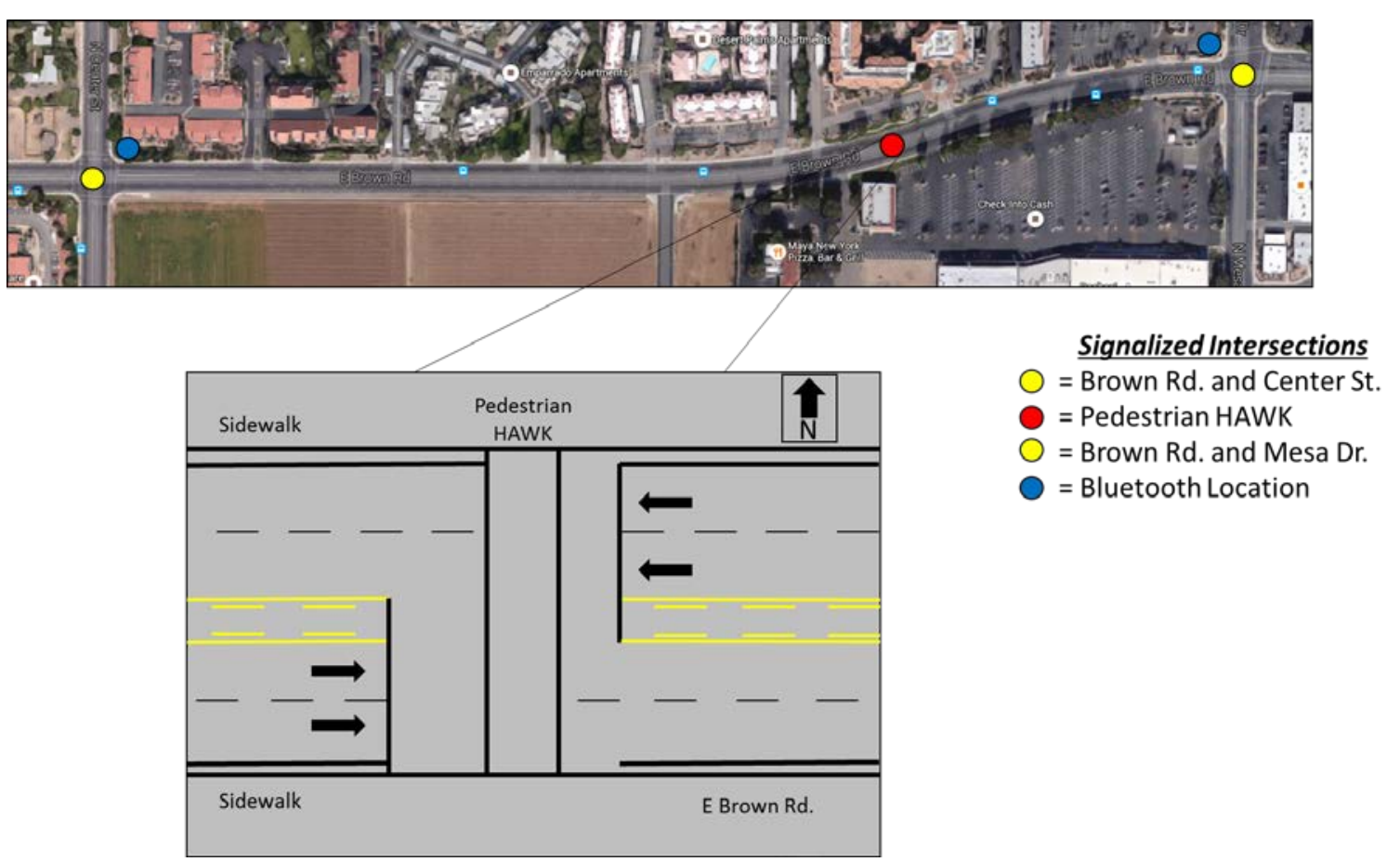

Figure 6.2 Site Overview, Brown Road HAWK, Mesa, AZ

\subsubsection{Flagstaff, AZ}

The city of Flagstaff (CoF) has approximately 69,000 residents in the mountains of northern Arizona. The city operates 50 traffic signals with several coordinated systems. CoF personnel indicated that providing coordination to their citizens is important when justified, similar to Mesa, but that reducing delay for all users was of significance due to the various users who are present at many of their signalized intersections. As such, Flagstaff was willing to experiment with leaving coordination during certain times of the day in an attempt to reduce delay for pedestrians.

The location agreed upon by the team and CoF personnel is that of N. Beaver and Forest avenues, located on the north side of the city. This location was selected for several reasons. First, the intersection operates in coordination during certain times of the day. Second, there is moderate pedestrian movement at this intersection due to the residential area north of the location and the hospital, high school, and university located immediately a half mile and one mile south of the intersection, respectively. Figure 6.3 shows the location of the intersection within the city while Figure 6.4 shows an overview of the site and the surrounding network, including the locations of temporary Bluetooth travel time data collection equipment.

As mentioned earlier, this site is within a coordinated network; however, there is no communication to the site. As such, it operates via time of day with the adjacent locations. At the request of the research team, an Econolite ASC/3 controller was installed at the intersection to allow the team to operate the pedestrian priority algorithm. Detection at the site is provided 
by an Econolite Terra camera on each approach, with the capability of providing vehicle counts for input to the pedestrian priority algorithm. Pedestrian pushbuttons are located at all approaches.

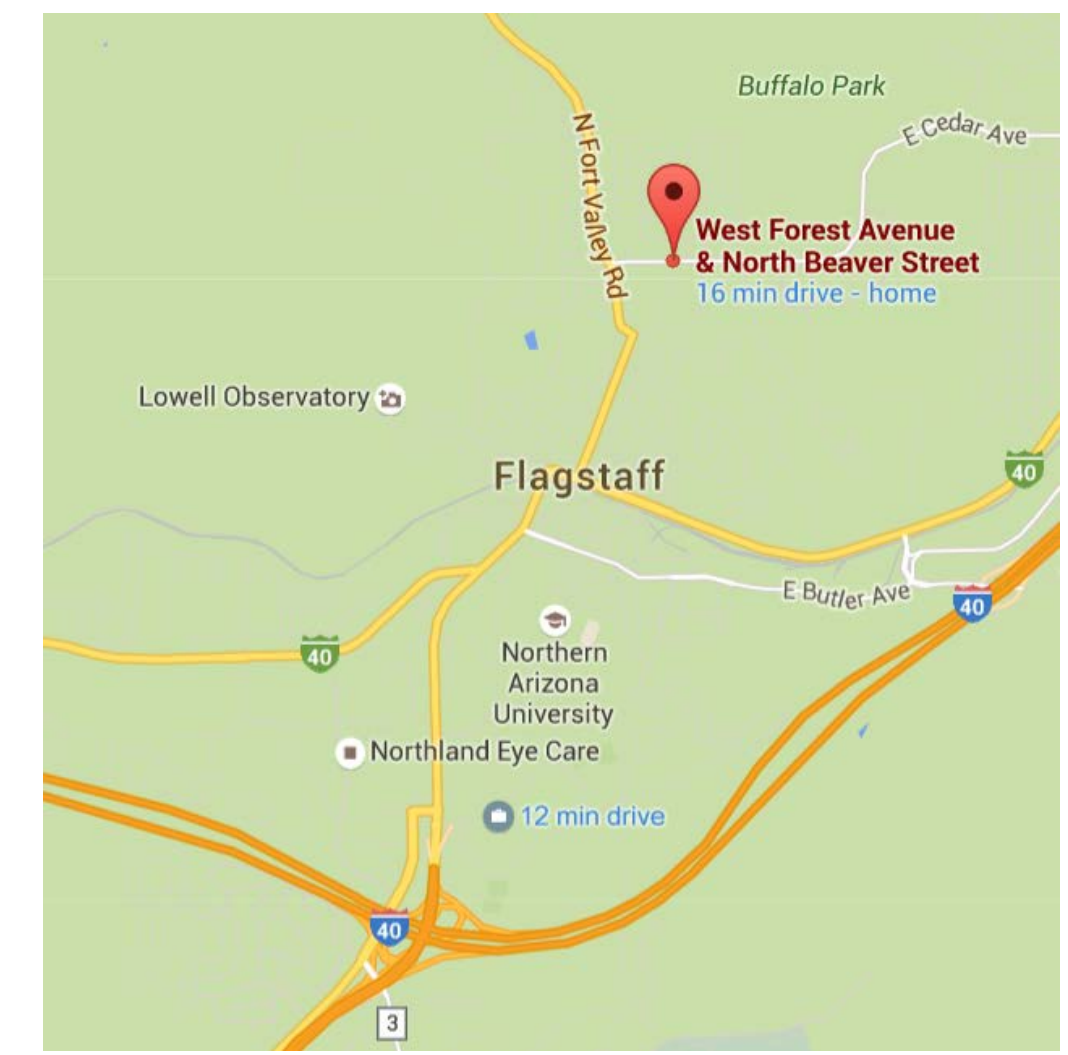

Figure 6.3 Location Map: N. Beaver and Forest, Flagstaff, AZ 


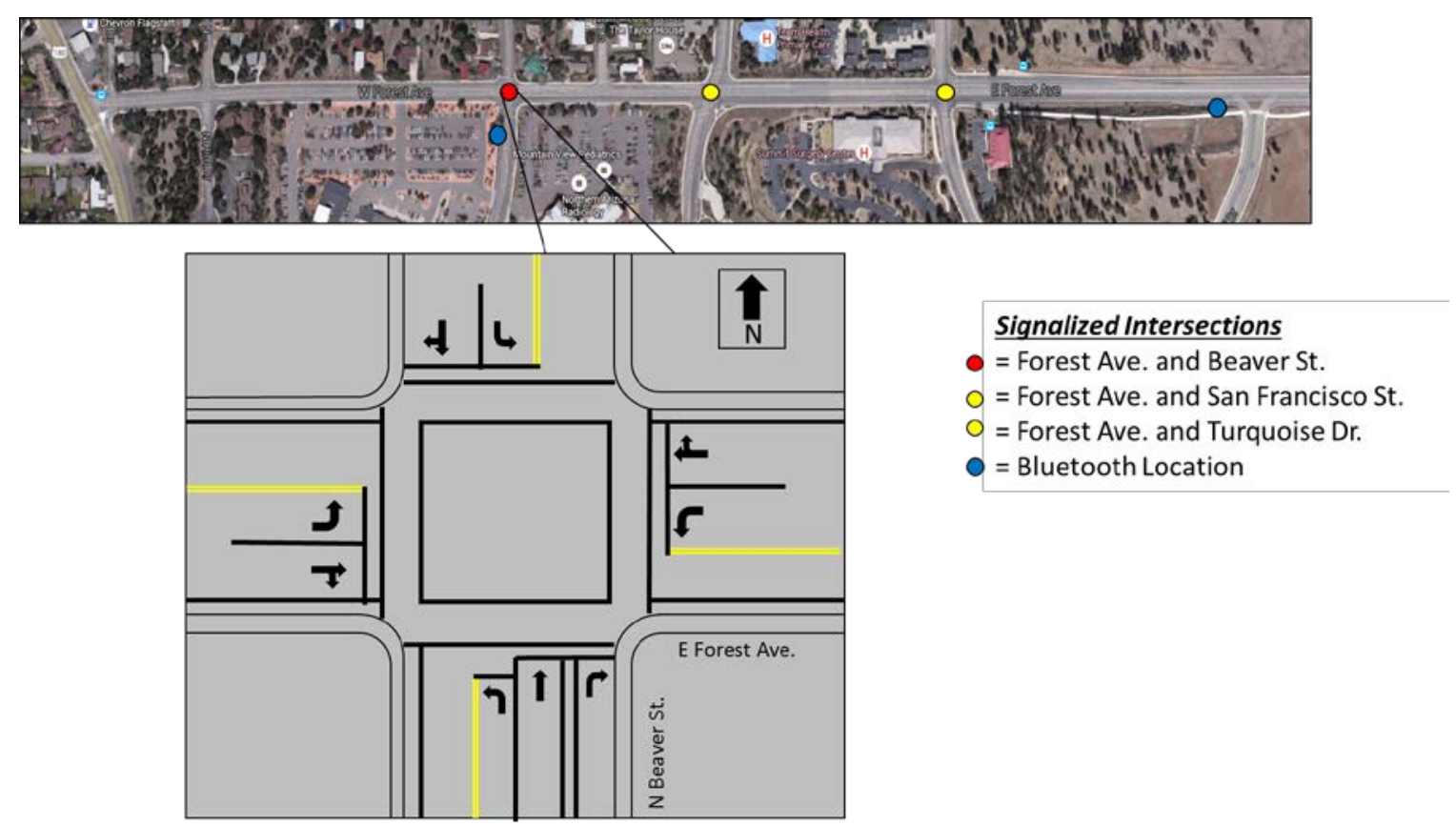

Figure 6.4 Site Overview, N. Beaver and Forest, Flagstaff, AZ

\subsection{DEPLOYMENT}

\subsubsection{Portland, OR}

Initially, the intersection of SE Division Street and SE $122^{\text {nd }}$ Avenue was equipped with a Type 2070 signal controller with Voyage software by Northwest Signal and was operating in a free mode. However, during algorithm development, the 2070 signal controller was replaced with an ASC/3 signal controller and placed in coordination with the adjacent intersections. The controller was replaced by PBOT for reasons external to this project.

To identify the threshold for the pedestrian priority algorithm, the research team analyzed the 24-hour pneumatic tube counts that were collected for this intersection for a previous research study. The threshold was chosen such that the algorithm would be enabled during the vehicle off-peak hours when pedestrian demand would be higher, such as the hours between 10 a.m.-1 p.m. The operational plan chosen was to switch the mode of operation from coordinated to free when the algorithm was enabled.

Due to unforeseen delays arising from swapping out the signal controller, the after data was collected first during the week of May 23-27, 2016. The algorithm was turned off in June and after data was collected during the week of June 20-24, 2016. 
Table 6.1 shows the results from the Portland deployment. When the entire time period was considered, pedestrian delay decreased 6 percent for phase 4 and 4 percent for phase 8 . During the off-peak period between 10 a.m. and 3 p.m., observed delay reductions were 2 percent and 8 percent for phases 4 and 8 , respectively.

Table 6.1 Portland Deployment, Pedestrian Data

\begin{tabular}{llclc}
\hline Results & \multicolumn{3}{c}{ Ped 4 } & \multicolumn{2}{c}{ Ped 8 } \\
& $\mathrm{n}$ & Avg. Ped Delay & $\mathrm{n}$ & Avg. Ped Delay \\
\hline Without Algorithm (All Day) & 1604 & $0: 00: 51$ & 1617 & $0: 00: 51$ \\
With Algorithm (All Day) & 1590 & $0: 00: 48$ & 1602 & $0: 00: 49$ \\
Without Algorithm (10:00 -13:00) & 285 & $0: 00: 51$ & 283 & $0: 00: 53$ \\
With Algorithm (10:00 - 13:00) & 229 & $0: 00: 50$ & 273 & $0: 00: 49$ \\
\hline
\end{tabular}

\subsubsection{Mesa, AZ}

\subsubsection{Field Deployment I}

The research team and Mesa staff analyzed a 24-hour volume count at the HAWK location and decided upon a volume threshold that should roughly activate the algorithm between the hours of 10 a.m. and 3 p.m., after 7 p.m., and before 6 a.m. It was decided that the operational plan that the controller would drop into when prioritizing pedestrian service was free, as this would provide the greatest delay reduction for the pedestrians at the site. Mesa staff also liked this selection for the operational plan because they had tried both coordinated and free operation at various signalized trail crossings within the city and had found that, as expected, each choice satisfied a different group of users.

In October 2015, the team began collecting before data, including probe data from the adjacent Bluetooth sensors along with pedestrian delay information in a manner consistent with that used at the Portland site using the ASC/3 data logger. Shortly after the team commenced collecting the before data set, a contractor began working along Brown Road, reducing it to one lane in each direction. The decision was made to proceed as planned and adapt the settings of the algorithm. However, the team ran into numerous problems in trying to activate the algorithm in the field. NAU staff was successful in bench testing the Mesa controller database in the lab at NAU, but when implemented at the field location the controller would operate in free all the time. After a number of troubleshooting sessions it was determined that the use of CENTRACS to upload the controller database to the field was the likely culprit, as that was the only difference between how the databases were changed at NAU and the field location. 


\subsubsection{Algorithm Platform Change}

Even though this was a relatively major setback in the field deployment, the staff at the city of Mesa suggested trying to implement the algorithm with a programmable logic controller (PLC) as opposed to using the onboard logic processor of the ASC/3. This solution has the added benefit of being vendor neutral, in that it could be deployed at other locations regardless of the color of the control box. Figure 6.5 shows staff at Mesa testing the PLC in their test cabinet at their Traffic Management Center (TMC).

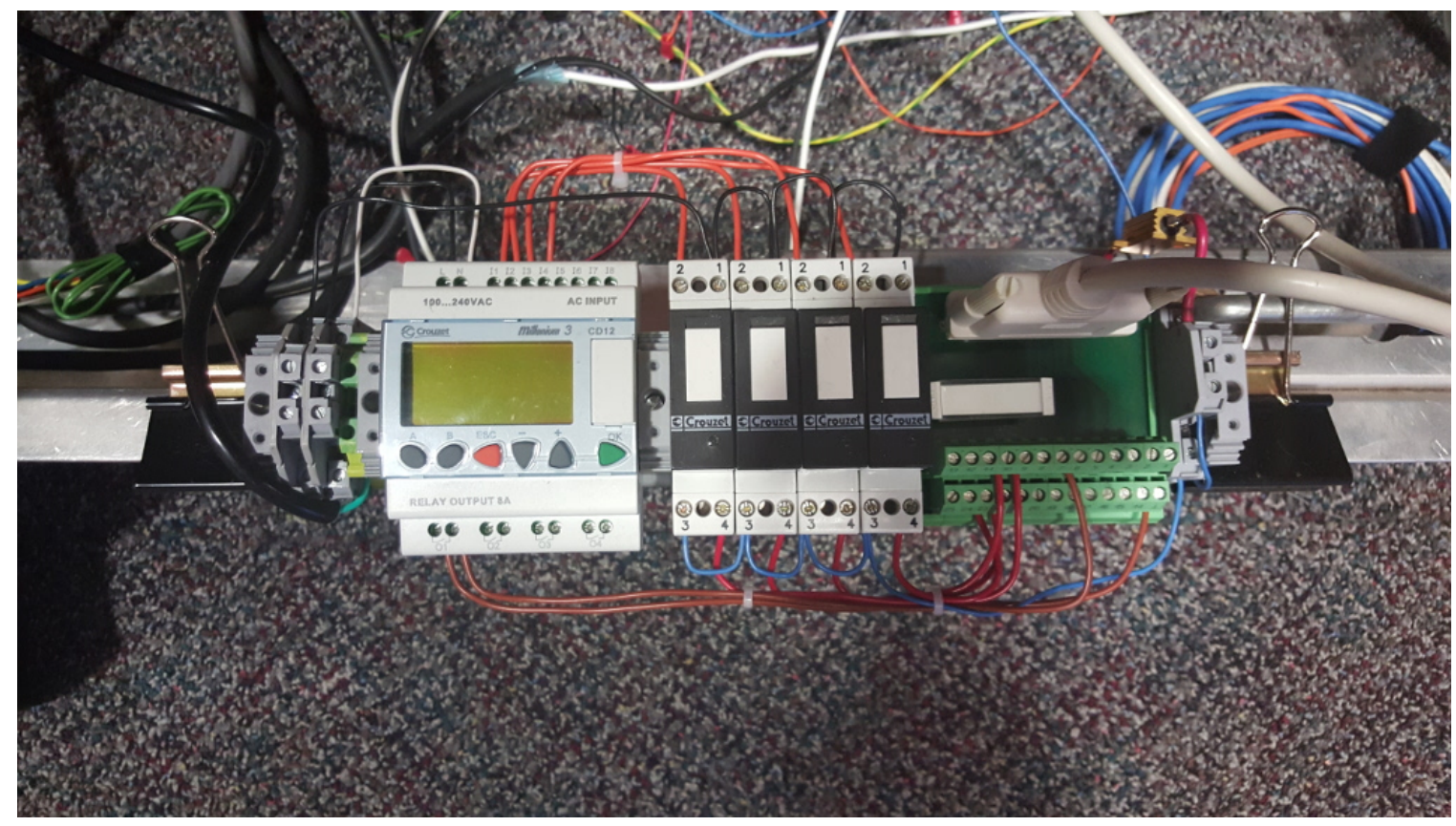

Figure 6.5 PLC In Cabinet, Mesa, AZ

After experimenting with the PLC, Mesa staff decided that a better solution would be to use a Raspberry Pi to perform the logic. A Raspberry Pi is a small, electronically flexible handheld computing device that can be programmed to perform logical functions ranging from very basic to rather advanced. The PLC solution required several different connections to the control cabinet as well as several controller settings to make the count outputs of the detectors available to the PLC. The Raspberry Pi would only require one connection to the controller through the ethernet port. This meant that the device could be deployed locally or remotely if there was communication to the site. In addition, the PLC and all of its required relays cost about $\$ 350$ while the Raspberry Pi device is roughly \$50. Figure 6.6 shows the Raspberry Pi device in the test cabinet at Mesa. 


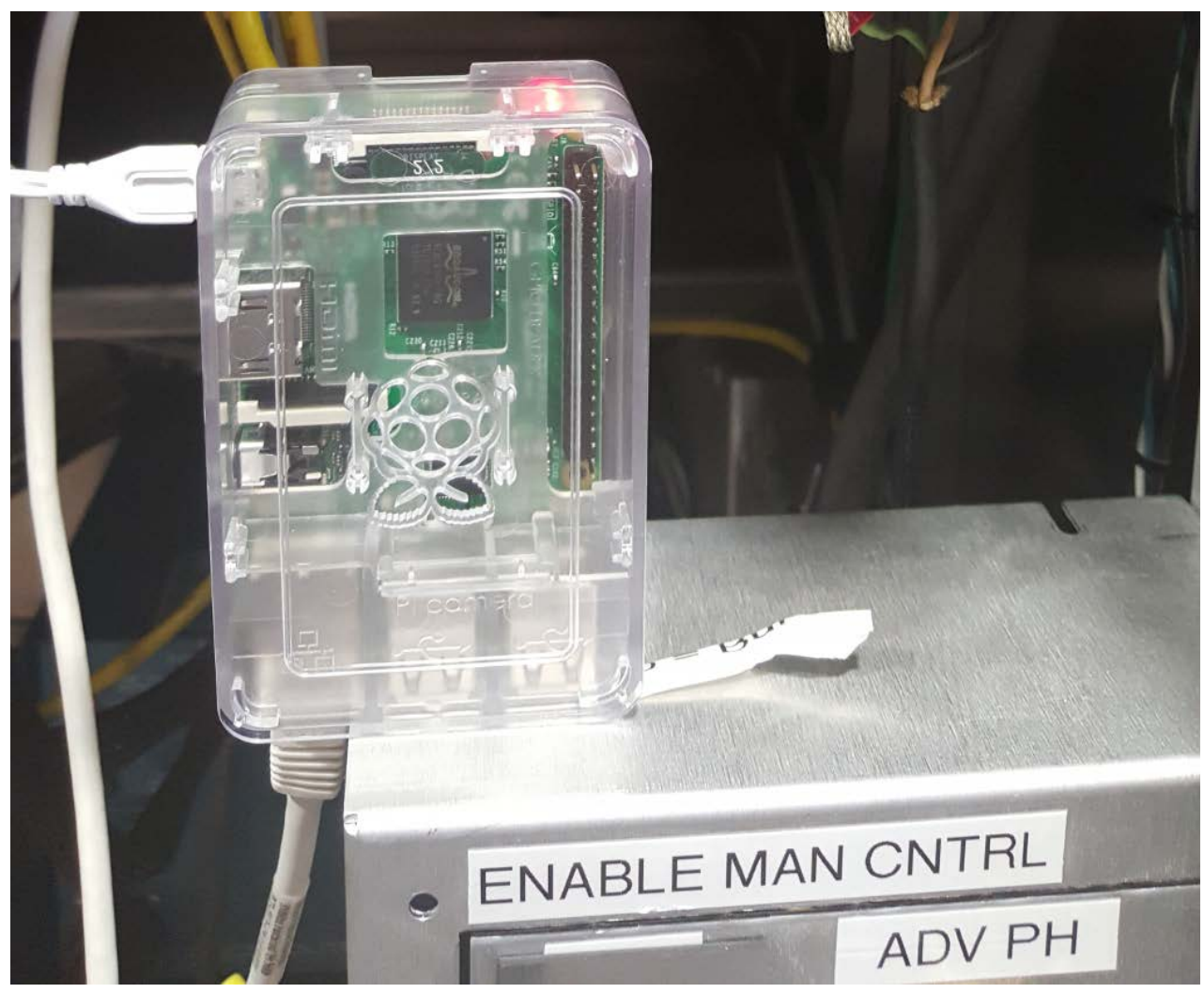

Figure 6.6 Raspberry Pi

The Raspberry Pi communicates directly with the controller using the National Transportation Communications for Intelligent Transportation System Protocol (NTCIP). It directly polls detectors of interest and determines when to implement the pedestrian priority operational plan, which is also implemented through NTCIP communications. All of the logic is programmed though Python programming language, with NetXMS used for the user interface. Figure 6.7 shows a screenshot of the NetXMS interface, while Figure 6.8 shows an example of the historical data available through that interface. 


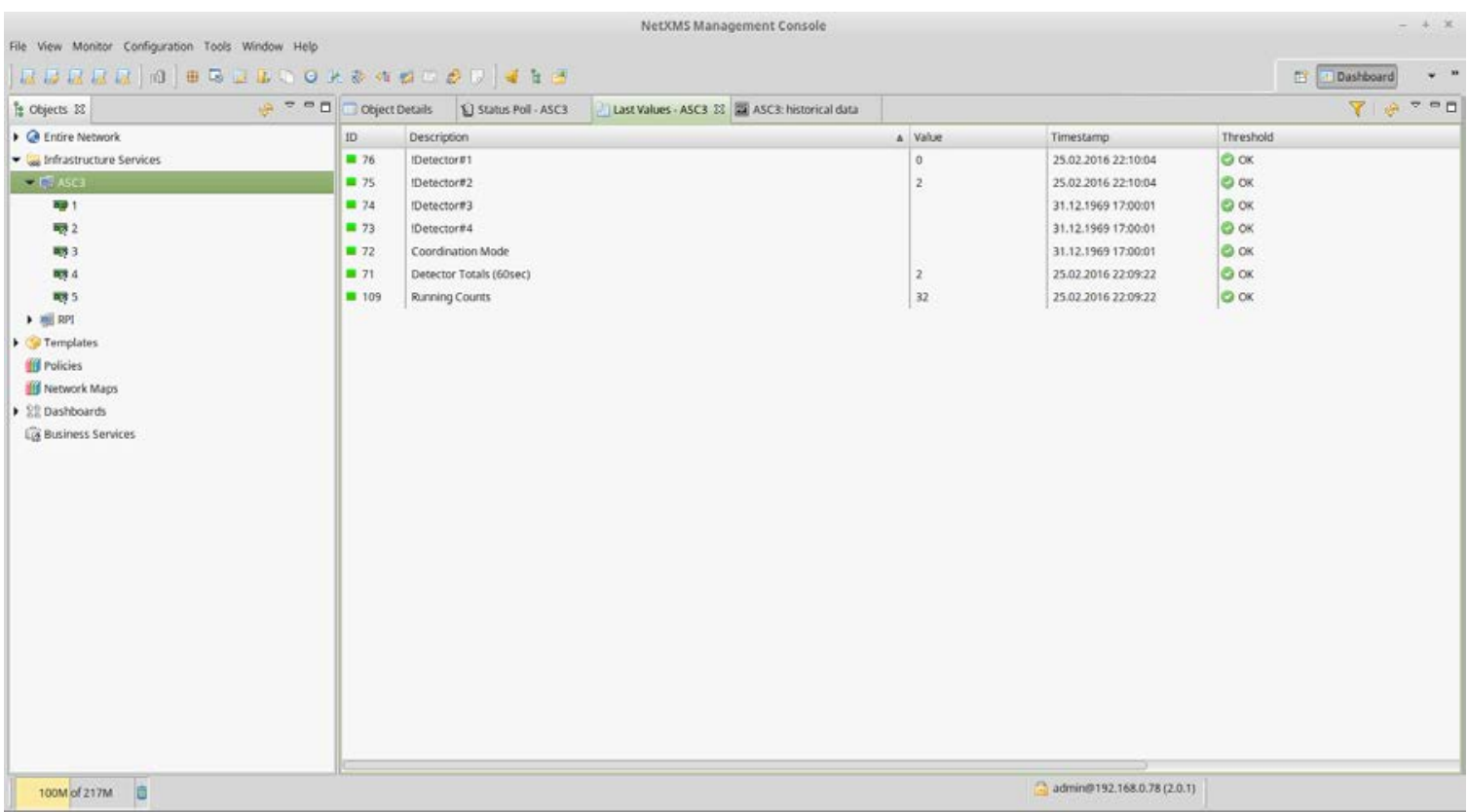

Figure 6.7 Raspberry Pi Interface

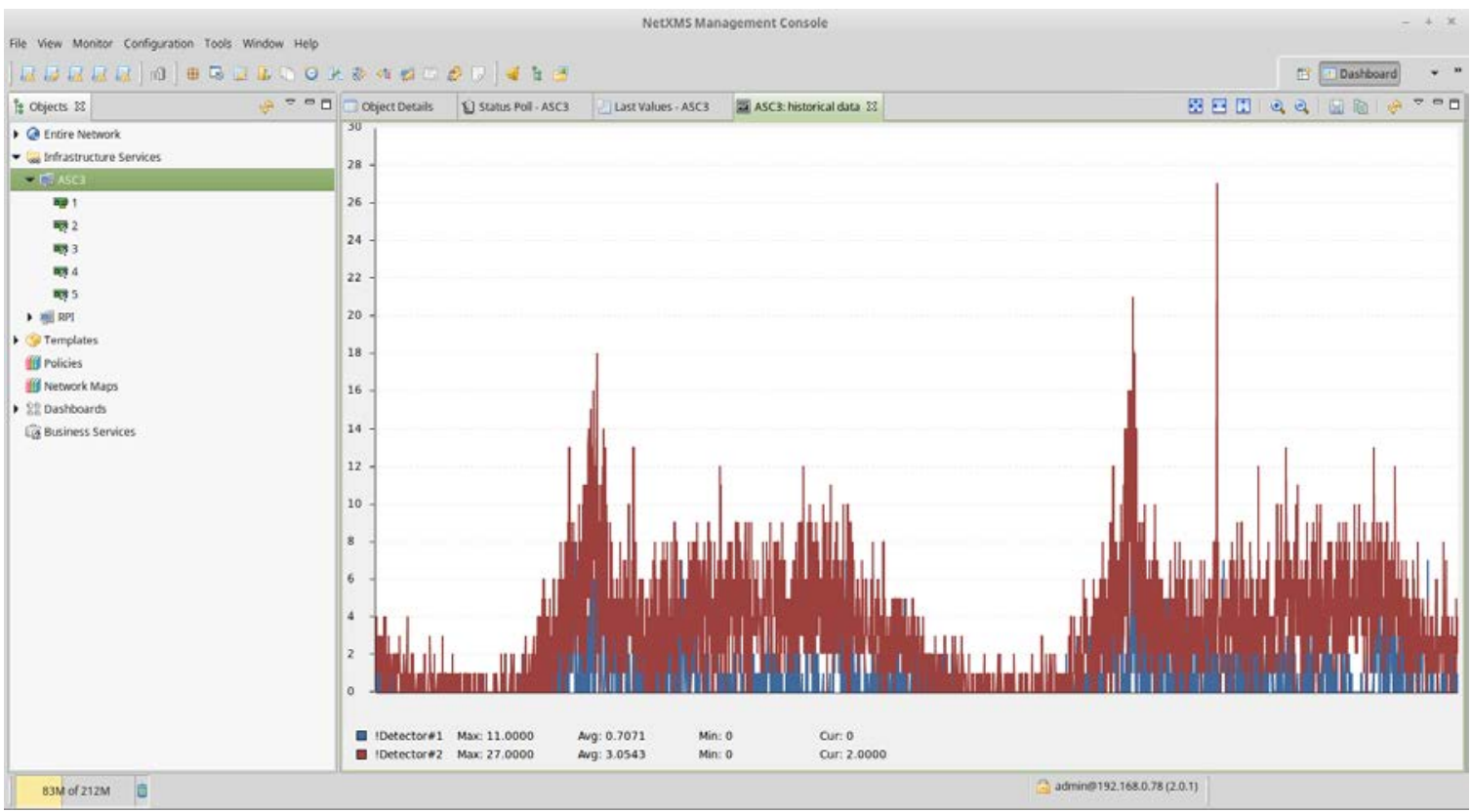

Figure 6.8 Raspberry Pi Historical Data 


\subsubsection{Field Deployment II}

In order to use the Raspberry Pi to adjust the operational plan based upon vehicular volumes, data was collected during the months of April and May of 2016. Two weeks of before data (April 12-19 and May 6-13) were collected along with two weeks of after data (April 19-May 4). Given the challenges with data collection experienced during the previous fall, the research team decided to collect one week of before and then one week after to ensure that everything was functioning properly. Once this was established, an additional week of after and then before data was collected. For the before data, the Raspberry Pi was connected to the controller and monitoring detector volumes; however, the lines of code that would change the operational plan based upon vehicular volumes were disabled. After the first week of before data, research and city staff evaluated the volume profile provided by the Raspberry Pi, observing a plot similar to that shown in Figure 6.8, to select a threshold volume (as was done in Section 6.2.2.1). Given the character of the location, and the desire to greatly reduce the pedestrian delay when the PPOP was active, Mesa opted for free operation within the PPOP, the most aggressive option.

As was noted earlier, data collected for analysis included travel times between the adjacent signalized intersections using Bluetooth monitoring and pedestrian delay using data from the onboard event-based data logger of the ASC/3 (Smaglik et al., 2007). This logger has been shown to be a powerful method to develop real-time performance measures showcasing a variety of items (Day et al., 2014). Two of the items logged by the device are the time when a pedestrian call is placed (the first time the button is pushed) as well as when the Walk indication illuminates (Sturdevant et al., 2012). Subtracting the time of the former from the time of the latter provides a metric for pedestrian delay.

Table 6.2 summarizes the pedestrian delay for the before-and-after data for weekdays during the data collection periods. The left-hand column lists the different time-of-day plans as well as the cycle length for each call. The center column lists the count of pedestrian calls during each timing plan bin across the two-week period. The right-hand column lists average pedestrian delay, calculated as described above, for each timing plan bin. As was noted earlier, the times of day when delay improvement could be affected were between 10 a.m.-3 p.m. and 7 p.m.-6 a.m., corresponding to the 0630-1500, 1830-0000 and 000-0630 timing plans. During the 0630-1500 bin, average pedestrian delay dropped from 49.1s to 22.0s, a delay decrease of 55 percent. For the overnight bins, the percentage decrease was 41 percent and 76 percent for the evening and morning bins, respectively. 
Table 6.2: Mesa Deployment, Pedestrian Data

\begin{tabular}{l|rc}
\hline & Count of Pedestrians Call & Avg. Pedestrian Delay \\
\hline Two weeks, before (weekdays) & 13 & \\
0000-0630 (C=90) & 330 & $00: 54.1$ \\
0630-1500 (C=100) & 200 & $00: 49.1$ \\
1500-1830 (C=110) & 153 & $00: 50.9$ \\
1830-0000 (C=90) & & $00: 44.4$ \\
Two weeks, after (weekdays) & 7 & \\
0000-0630 (C=90) & 317 & $00: 13.0$ \\
0630-1500 (C=100) & 169 & $00: 22.0$ \\
$1500-1830(C=110)$ & 147 & $00: 52.0$ \\
$1830-0000(C=90)$ & & $00: 26.0$ \\
\hline
\end{tabular}

Table 6.3 shows the comparison travel time for the before-and-after periods with the data presented in the same time-of-day plan bins. During the bin of 0630-1500, travel time values for both east- and westbound directions decreased during the analysis period. For the overnight time periods, westbound travel time increased slightly while eastbound travel time decreased slightly during the evening bin. During the morning bin, westbound travel time decreased significantly while eastbound travel time increased significantly.

Table 6.3: Mesa Deployment, Travel Time Data

\begin{tabular}{l|rrrr}
\hline & WB Count of Cars & $\begin{array}{c}\text { WB Avg. Travel } \\
\text { Time (s) }\end{array}$ & EB Count of Cars & $\begin{array}{c}\text { EB Avg. Travel } \\
\text { Time (s) }\end{array}$ \\
\hline $\begin{array}{l}\text { Two weeks, before } \\
\text { (weekdays) }\end{array}$ & & & & \\
0000-0630 (C=90) & 145 & 52.87 & 162 & 31.7 \\
0630-1500 (C=100) & 1780 & 55.9 & 1098 & 58.95 \\
1500-1830 (C=110) & 809 & 60.12 & 959 & 62.63 \\
1830-0000 (C=90) & 917 & 57.5 & 766 & 64 \\
$\quad$ Two weeks, after & & & & \\
$\quad$ (weekdays) & 103 & 43.50 & 80 & 47.53 \\
0000-0630 (C=90) & 1534 & 50.95 & 895 & 56.96 \\
$0630-1500$ (C=100) & 768 & 54.83 & 827 & 59.94 \\
$1500-1830$ (C=110) & 650 & 58.51 & 678 & 62.70 \\
$1830-0000$ (C=90) & & & & \\
\hline
\end{tabular}

At the onset, it was expected that decreases in pedestrian delays would be accompanied by increases in travel time, and while that was found to be the case in several of the bins, it was not consistent. It is believed that the random impact on travel time due to the free operation at the $\mathrm{PHB}$ resulted in the somewhat random change in travel times.

Lastly, it is useful to note that the research team was not able to report the number of times the operational plan was changed due to a deficiency in the controller event-based data logger. 


\subsubsection{Flagstaff, AZ}

The research team and city of Flagstaff staff analyzed a historical 24-hour volume count at the intersection and decided upon a volume threshold that should roughly activate the algorithm between the hours of 10 a.m. and 3 p.m., after 7 p.m., and before 6 a.m., similar to Mesa. Since the volume count was three years old, current volumes were collected using the video detection onsite and compared to the historical data set to see if any adjustments needed to be made to the volume thresholds due to changes in traffic volumes or the accuracy of the detection unit. Once a volume threshold was decided upon, the team also decided that the operational plan that the controller would drop into when prioritizing pedestrian service was free, similar to Mesa, as this would provide the most pedestrian user benefit.

In October 2015, the team installed two portable probe data travel time collection devices at the ends of the coordinated system to provide before-and-after travel time data. Pedestrian delay information was collected in the same manner as other sites. With the before data set collected, the team manually enabled the logic processor statements to begin after data collection. A series of challenges occurred during the after data collection at this location as well, ranging from the intersection hanging in free due to an unchecked box in the controller to logic statements staying enabled after they were disabled, but the setting wasn't saved due to a power cycle (20 minutes must pass before these types of changes are locked into the ASC/3 memory). Before a successful after data set could be collected, the snow began to fly and data collection was put on hold until spring 2016.

In order to avoid the mishaps of fall 2015, in April 2016 a Raspberry Pi was installed at the intersection to collect data and control the logic of the algorithm. Updated vehicle counts were taken using data collected from the Raspberry Pi, as was done at Mesa, as well as with tubes installed by the city. With a threshold set, before data was collected from April 20-28, 2016, with after data collected from May 11-18, 2016. Table 6.4 summarizes the results of the deployment. Note, there is no travel time data for this deployment because during our data collection one of the units was vandalized. Critical parts of the unit were stolen, and there was insufficient time to repair / replace within the project timeline.

Table 6.4: Flagstaff Deployment, Pedestrian Data

\begin{tabular}{|l|r|r|}
\hline One week, before (Weekdays) & Count of Pedestrians Call & Average Pedestrian Delay \\
\hline $0000-0715(C=F r e e)$ & 72 & $0: 00: 35$ \\
\hline $0715-0815(C=90)$ & 140 & $0: 00: 23$ \\
\hline $0815-1630(C=95)$ & 394 & $0: 00: 41$ \\
\hline $1630-1730(C=75)$ & 73 & $0: 00: 19$ \\
\hline $1730-0000(C=F r e e)$ & 143 & $0: 00: 26$ \\
\hline & & \\
\hline One week, after (Weekdays) & Count of Pedestrians Call & Average Pedestrian Delay \\
\hline $0000-0715(C=F r e e)$ & 94 & $0: 00: 37$ \\
\hline $0715-0815(C=90)$ & 78 & $0: 00: 40$ \\
\hline $0815-1630(C=95)$ & 591 & $0: 00: 34$ \\
\hline $1630-1730(C=75)$ & 52 & $0: 00: 48$ \\
\hline $1730-0000(C=F r e e)$ & 206 & $0: 00: 36$ \\
\hline
\end{tabular}


The results from the Flagstaff deployment are not as clear cut as those from the Mesa deployment. Similar to Mesa, the mid-day time period (0815-1630) is the period where it was expected that operation of the algorithm would have the greatest results. At this site, as expected the average delay dropped during this time period, seven seconds in this case, a decrease of 17 percent. However, delay did increase in all other time periods, with the largest increase in delay occurring during the PM peak time period (29 seconds, or 153 percent). As was noted earlier, the team was not able to report the number of times the operational plan was changed due to a deficiency in the controller event-based data logger. This would have been extremely helpful in troubleshooting this pattern. Without this data, the team believes that an issue with the video detection is the likely cause for the increase in delay during the PM period (increases during the other time periods were not as severe). During multiple site visits, performance issues were noted with the video detection cameras (in fact, the threshold chosen for entering into PPOP was much greater than would otherwise make sense for the volumes at the site; the team worked with the inherent inaccuracies of the units at the site), including missed, false, and erroneously held calls.

\subsection{FIELD DEPLOYMENT SUMMARY}

The developed algorithm was deployed at three separate locations, two using a Raspberry Pi device and one using the onboard logic processor of the ASC/3 controller. Data from the Portland and Arizona sites showed reduced pedestrian delay values during daytime off-peak timing periods, as was expected at the onset of the work. Data from the Flagstaff site showed pedestrian delay increases during other time periods, something that the authors attribute to the accuracy of the video detection units driving the intersection.

While the problems deploying the algorithm in Arizona proved challenging, they ended up driving the team to develop a better solution. Because of the desire of one of the project partners to see the work succeed, the algorithm was deployed on a rather cheap and ubiquitous computing device, one that can be deployed on any controller using NTCIP. This allows the algorithm to be deployed on virtually any traffic controller with little modification, greatly expanding the impact of this work. 


\subsection{CONCLUSIONS AND RECOMMENDATIONS}

This report covers several areas of study, including:

- The development and testing of a microsimulation model that examined the effects from the implementation of the following pedestrian specific treatments at signalized intersections on all users (motor vehicles, heavy vehicles, bicyclists and pedestrians):

o Coordination (base case)

0 Leading pedestrian intervals

o Exclusive pedestrian phase (Barnes Dance)

o Cycle length manipulation

o Actuated-coordinated operation

o Free operation

- The development and testing of a novel pedestrian priority algorithm that was used to change the mode of operation of a signal controller based on field-derived inputs in order to better serve pedestrians, and,

- The field deployment of the algorithm at sites in Arizona and Oregon.

The key conclusions from each of these will be discussed below.

\subsection{SIMULATION RESULTS}

A VISSIM microsimulation model of a high-traffic corridor in Portland, OR, was created to test the effects of several signal timing changes designed to favor pedestrian movements. These include: operating in coordination with the adjacent intersections (which operated as the base case used to compare the other treatments against); operating in free mode; the implementation of an exclusive pedestrian phase (EPP); the implementation of a leading pedestrian interval (LPI); and manipulating the cycle length. All three intersections within the study corridor were examined in order to determine the corridor-wide effects on the treatments. Each of the treatments was examined for effects on user delay with several modes being modeled, including passenger cars, heavy vehicles, pedestrians, and bicyclists. The key takeaways based on simulation of each control strategy are presented below.

- Coordinated operation: At all three intersections, pedestrians faced the largest delays of all users and these delays were statistically significantly higher than those experienced by motor vehicles. The results demonstrate that coordination primarily benefits major-street vehicular movements, while increasing delays for the minor-street vehicular and pedestrian movements, findings which are consistent with common practice.

- Free operation: Results from free operation showed that for two out of the three intersections, overall delay decreased for all users. Additionally, pedestrian delay decreased at all intersections that were studied. These results suggest that operating in free mode is beneficial in terms of delay reduction for minor-street vehicular and pedestrian movements and may be less beneficial for major-street movements, especially if the volumes on the major street are substantially greater than the minor-street volumes. 
- Cycle Length Manipulation: Pedestrian results for the minor phases at all three intersections showed a clear trend of substantial delay reductions at lower cycle lengths, and increased delay at the higher cycle lengths, when compared to the base case. Vehicular delays increased with increased cycle length.

- Leading Pedestrian Interval: Implementation of an LPI on minor, major and both phases resulted in increased overall delays due to an increase in vehicular delays. Pedestrian delay was largely unaffected for all three scenarios that were tested in the simulation.

- Exclusive Pedestrian Phase: Significantly increased delays were observed across all modes due to the implementation of an EPP.

Based on the simulation results, a ranking of control strategies that were tested was undertaken based on impacts on minor-street pedestrian delay and major-street vehicle delay.

\subsubsection{Ranking of Existing Control Strategies}

Table 7.1 and Table 7.2 show the ranking of the control strategies based on major-street vehicular delays and minor-street pedestrian delays. Higher numbers indicate increased delays. For pedestrians, free operation resulted in the lowest delays and Barnes Dance produced the highest delay. For vehicles, coordination produced the lowest delay for the major-street phases and Barnes Dance resulted in the highest delay. Of course, while changes in the settings of the various strategies could adjust the order presented below, these rankings provide a general comparative list of the various strategies.

Table 7.1 Ranking of Control Strategies based on Major-Street Vehicle Delay

\begin{tabular}{lc}
\hline Control Strategy & Vehicle Delay Ranking \\
\hline Coordination & 1 \\
\hline Actuated-coordination & 2 \\
\hline Short cycle lengths & 3 \\
\hline Free operation & 4 \\
\hline Leading pedestrian intervals & 5 \\
\hline Barnes Dance & 6 \\
\hline
\end{tabular}

Table 7.2 Ranking of Control Strategies based on Minor-Street Pedestrian Delay

\begin{tabular}{lc}
\hline Control Strategy & Pedestrian Delay Ranking \\
\hline Free operation & 1 \\
\hline Short cycle lengths & 2 \\
\hline Leading pedestrian intervals & 3 \\
\hline Actuated-coordination & 4 \\
\hline Coordination & 5 \\
\hline Barnes Dance & 6 \\
\hline
\end{tabular}




\subsubsection{Pedestrian Priority Algorithm Development and Field Deployment}

Pedestrian priority algorithm is another strategy that is available to practitioners to place a priority on serving minor-phase pedestrians with lesser delay than typically experienced with status quo signal timing. This algorithm was designed to change the operational plan of a traffic signal to a plan which is favorable to pedestrians when vehicular volumes drop below a certain threshold. This algorithm, along with several operational scenarios, was analyzed with VISSIM SITL simulation to determine their impact on user delays. In addition, a sensitivity analysis was performed on vehicle extension timers to explore the impact that this coordinated movement parameter has on user delay. In the scenario analysis, employing free operation either with the designed algorithm or without was an effective method of reducing minor-street pedestrian delay while also decreasing average intersection vehicle delay. The vehicle extension sensitivity analysis showed that shortening the extension timer of an actuated-coordinated phase can reduce the minor-street pedestrian delay without increasing overall vehicle delay.

While the algorithm was developed and successfully tested in the lab using the onboard logic processor of an off-the-shelf traffic controller, deployment in the field proved to be problematic due to a variety of reasons, especially at the Arizona sites. Because of this, the algorithm was programmed into a Raspberry Pi device using Python code and successfully deployed at intersections in Mesa and Flagstaff, AZ, as well as Portland, OR. With free operation selected as the pedestrian priority operational plan, during the mid-day period pedestrian delay was reduced by 6 percent in Portland, 55 percent in Mesa and 17 percent in Flagstaff. In Mesa, vehicular travel times were only slightly impacted (this data was not available at the Portland and Flagstaff sites). The Flagstaff data showed some anomalies in other timing periods which were believed to be related to the performance of the video detection units at the site, highlighting the need for reliable detection equipment for deployment of an algorithm such as this.

\subsection{RECOMMENDATIONS}

The results from this research show that certain pedestrian control strategies can be successfully used at signalized intersections to reduce pedestrian delay without negatively impacting vehicle delays. Below are the key recommendations:

- Free operation was shown to reduce pedestrian delays significantly; however, it may not be applicable in situations where vehicular movement along major streets is the priority. It may be best suited for intersections where either the major- and minor-street volumes are similar, or it could be applied at intersections with greater major-street and lower minor-street volumes selectively based on time of day.

- Coordinating major corridors to prioritize vehicular movements during peak periods may be warranted to facilitate higher demands. However, if cities want to prioritize pedestrian movements, removing signal coordination during the off-peak periods when major-street traffic volumes are lower may be beneficial for balancing user priorities.

- If jurisdictions want to operate in coordinated mode, employing shorter cycle lengths can reduce pedestrian delays for the minor-street pedestrian phases. However, the tradeoff of increased major-street vehicle delay should be taken into consideration. 
- Another strategy to reduce pedestrian delay is to actuate a portion of the coordinated phase. However, employing actuated-coordination does require detection on the major street, which could lead to increased capital costs and maintenance costs.

- Leading pedestrian intervals may be used to increase the visibility of the pedestrians; however, vehicle delay increases due to lost time for vehicles. They may be most applicable at intersections with high crash rates for pedestrians and turning vehicles. They may also be useful at offset intersections, where visibility of pedestrians may be an issue.

- Barnes Dance increases safety for pedestrian crossings by removing all conflicts with vehicles; however, delays for all modes increase significantly. Previous research has shown increased noncompliance as a result of the increased delays (Abrams and Smith, 1977; Zegeer et al., 1985; Zaidel and Hocherman, 1987; Gårder, 1989; (Bechtel et al., 2004; Kattan et al., 2009). Hence this strategy should be used judiciously, only in those situations where pedestrian volumes are high and safety is a critical concern.

- The pedestrian priority algorithm developed in this study is another option to reduce pedestrian delays especially for the minor street pedestrian movements. The effectiveness depends on the choice of the operational plan and appropriate thresholds.

Generally, there is no one "right solution" for all situations. Implementation of a control strategy depends upon operational objectives and intersection characteristics. Ultimately, tradeoffs in delays between user groups may be warranted to prioritize different modes based on time of day.

\subsection{FUTURE WORK}

Going forward, there are several natural extensions for this work. First, field deployments could be conducted using different pedestrian priority strategies listed in this work. Second, to make the work truly based upon pedestrians, the algorithm could be redesigned to activate based on pedestrian volumes or delays as opposed to vehicular volumes. Regardless of the direction the work takes, this has been a successful example of improving pedestrian operations while attempting to preserve vehicle priority when needed. 


\subsection{REFERENCES}

Abbas, Montasir, Milos Mladenovic, Surender Granta, Yatish Kasaraneni, and Catherine McGhee. 2013. Development and Use of Critical Functional Requirements for Controller Upgrade Decisions. Washington, D.C.: Transportation Research Record: Journal of the Transportation Research Board (2355), 83-92.

Abrams, Charles M, and S A Smith. 1977. "Selection of pedestrian signal phasing." Transportation Research Board 629: 1-6.

Akçelik, Rahmi. 2007. "Microsimulation and Analytical Models for Traffic Engineering." Presentation at the ARRB-AUSTROADS Microsimulation Forum. Melbourne: ARRBAUSTROADS, September.

Anderson, Susan, Michael Armstrong, Pete Chism, Steve Cohen, Michele Crim, and Kyle Diesner. 2015. Climate Action Plan, 2015. Portland, OR: City of Portland Oregon.

Baker, Ronald J, John Collura, James J Dale, L Head, B Hemily, M Ivanovic, J T Jarzab, et al. 2002. An Overview of Transit Signal Priority. The National Academies of Sciences, Washington, D.C.: Transportation Research Board.

Balke, Kevin, Conrad Dudek, and Thomas Urbanik II. 2000. Development and Evaluation of Intelligent Bus Priority Concept. Washington, D.C.: Transportation Research Record: Journal of the Transportation Research Board.

Bechtel, Allyson, Kara MacLeod, and David Ragland. 2004. "Pedestrian scramble signal in Chinatown neighborhood of Oakland, California: an evaluation." Transportation Research Record: Journal of the Transportation Research Board 1878: 19-26.

Byrne, Neil, Peter Koonce, Robert Bertini, Chris Pangilinan, and Matt Lasky. 2005. "Using hardware-in-the-loop simulation to evaluate signal control strategies for transit signal priority." Transportation Research Record: Journal of the Transportation Research Board (1925): 227-234.

Day, Christopher, and Darcy Bullock. 2012. "Calibration of platoon dispersion model with highresolution signal event data." Transportation Research Record: Journal of the Transportation Research Board (2311): 16-28.

Day, Christopher, and Darcy Bullock. 2014. "Design Guidelines and Conditions That Warrant Deployment of Fully Actuated Coordination." Transportation Research Record: Journal of the Transportation Research Board (2439): 1-11.

Day, Christopher, Edward Smaglik, Darcy Bullock, and James Sturdevant. 2008. "Quantitative evaluation of fully actuated versus nonactuated coordinated phases." Transportation Research Record: Journal of the Transportation Research Board (2080): 8-21.

de Castro-Neto, Manoel Mendonca. 2005. "An Evaluation of Alternative Permissive Periods on Non-Coordinated Phase Performance in Coordinated Traffic Signal Systems." University of Tennessee. http://trace.tennessee.edu/utk_gradthes/1835.

Dunn, R C M, and R Pretty. 1984. "Mid-Block Pedestrian Crossings-An Examination of Delay." Australian Road Research (ARRB Group Limited) 12 (4): 118-127.

Fayish, Aaron, and Frank Gross. 2010. "Safety Effectiveness of Leading Pedestrian Intervals Evaluated by a Before-After Study with Comparison Groups." Transportation Research Record: Journal of the Transportation Research Board (2198): 15-22. 
Federal Highway Administration. 2013. Pedestrain Safety Countermeasure Deployment Project. Washington, D.C.: US Department of Transportation.

http://safety.fhwa.dot.gov/ped_bike/tools_solve/ped_scdproj/.

Furth, Peter, and Theo H Muller. 2000. "Conditional bus priority at signalized intersections: better service with less traffic disruption." Transportation Research Record: Journal of the Transportation Research Board (Transportation Research Board of the National Academies) 23-30.

Gårder, Per. 1989. "Pedestrian safety at traffic signals: a study carried out with the help of a traffic conflicts technique." Accident Analysis \& Prevention (Elsevier) 21 (5): 435-444.

Grace, M J, and R B Potts. 1964. "A Theory of the Diffusion of Traffic Platoons." Operations 12 (2): $255-275$

He, Qing, Larry K Head, and Jun Ding. 2014. "Multi-modal traffic signal control with priority, signal actuation and coordination." Transportation Research Part C: Emerging Technologies (Elsevier) 46: 65-82.

Head, K Larry. 1998. "Improved Traffic Signal Priority for Transit." TCRP Project A-16, Interm Report.

Heydecker, B G, and S A Robertson. 2009. Evaluation of pedestrian priority zones in the European area. Centre for Transport Studies University College London.

Houten, Ron Van, Ralph Ellis, Jose Sanda, and Jin-Lee Kim. 2006. "Pedestrian push-button confirmation increases call button usage and compliance." Transportation Research Record: Journal of the Transportation Research Board (1982): 99-103.

Houten, Ron Van, Richard Retting, Charles Farmer, and Joy Houten. 2000. "Field Evaluation of a Leading Pedestrian Interval Signal Phase at Three Urban Intersections." Transportation Research Record: Journal of the Transportation Research Board (1734): 86-92.

Hubbard, Sarah L, Ramzi J Awwad, and Darcy M Bullock. 2007. "Assessing the Impact of Turning Vehicles." Transportation Research Record 27-36.

Ishaque, Muhammad Moazzam. 2006. "Policies for pedestrian access: Multi-modal trade-off analysis using micro-simulation techniques." (University of London-Imperial College London).

Ishaque, Muhammad Moazzam, and Robert B Noland. 2007. "Trade-offs between vehicular and pedestrian traffic using." Transport Policy (Elsevier) 14 (2): 124-138.

Ishaque, Muhammad Moazzam, and Robert Noland. 2005. "Multimodal microsimulation of vehicle and pedestrian signal timings." Transportation Research Record: Journal of the Transportation Research Board (National Academy of Sciences) (1939): 107-114.

Kattan, Lina, Shanti Acharjee, and Richard Tay. 2009. "Pedestrian Scramble Operations: Pilot Study in Calgary, Alberta, Canada." Transportation Research Record: Journal of the Transportation Research Board (National Academy of Sciences) (2140): 79-84.

Khoshmagham, Shayan, Yiheng Feng, Mehdi Zamanipour, and Larry K Head. 2015. "Travel Time Observation in Privacy Ensured Connected Vehicle Environment Using Partial Vehicle Trajectories and Extended Tardity." Transportation Research Board 94th Annual Meeting. Vols. no. 15-5011. Washington, D.C.

King, Michael R. 1999. "Calming New York City Intersections." Transportation Research Circular E-C019: Urban Street Symposium ( Transportation Research Board).

Koonce, Peter, Lee Rodegerts, Kevin Lee, Shaun Quayle, Scott Beaird, Cade Braud, Jim Bonneson, Phil Tarnoff, and Tom Urbanik. 2008. Traffic Signal Timing Manual. U. S. 
Department of Transportation, Federal Highway Administration.

http://ops.fhwa.dot.gov/publications/fhwahop08024/fhwa_hop_08_024.pdf.

Kothuri, Sirisha, Peter Koonce, Christopher Monsere, and Titus Reynolds. 2015. "Exploring Thresholds for Timing Strategies on a Pedestrian Active Corridor." Transportation Research Board 94th Annual Meeting. no. 15-3025.

Kothuri, Sirisha, Titus Reynolds, Christopher Monsere, and Peter Koonce. 2013. "Testing strategies to reduce pedestrian delay at signalized intersections: A pilot study in Portland, Oregon." Transportation Research Board 92nd Annual Meeting. no. 13-3854.

Liu, Hong-chao, Alexander Skabardonis, and Wei-bin Zhang. 2003. "A dynamic model for adaptive bus signal priority." Transportation Research Board 82nd Annual Meeting.

Ma, Wanjing, Xiaoguang Yang, and Yue Liu. 2010. "Development and evaluation of a coordinated and conditional bus priority approach." Transportation Research Record: Journal of the Transportation Research Board (2145): 49-58.

NACTO, National Association of City Transportation Officials. 2013. Urban Street Design Guide. New York.

Noland, Robert. 1996. "Pedestrian travel times and motor vehicle traffic signals." Transportation Research Record: Journal of the Transportation Research Board (Transportation Research Record: Journal of the Transportation Research Board) (1553): 28-33.

Oregon Department of Transportation. 2011. Protocol for Vissim Simulation. Oregon Department of Transportation.

Petterman, J L. 1947. "Timing progressive signal systems - Part II." Traffic Engineering 29: 242249.

Petterman, J L. 1947. "Timing progressive signal systems." Traffic Engineering 29: 194-199.

Portland Bureau of Transportation. 2014. High Crash Corridors. August 5. Accessed September 16, 2015. http://www.portlandoregon.gov/transportation/article/439832.

Pucher, J., Buehler, R., Merom, D., and A. Bauman. Walking and Cycling in the United States, 2001-2009: Evidence from the NHTS, American Journal of Public Health, Vol. 101, July 2011

Robertson, Dennis I. 1969. "'TRANSYT" method for area traffic control." Traffic Engineering \& Control 11 (6).

Robertson, Dennis I. 1969. Transyt: A Traffic Network Study Tool. Report No. LR 253, Crowthorne, Berkshire, United Kingdom: Road Research Laboratory.

Saneinejad, Sheyda, and Janet Lo. 2015. "Leading Pedestrian Interval Assessment and Implementation Guidelines." Transportation Research Board 94th Annual Meeting.

Sharma, Anuj, Darcy Bullock, and Srinivas Peeta. 2007. "Recasting dilemma zone design as a marginal cost-benefit problem." Transportation Research Record: Journal of the Transportation Research Board (2035): 88-96.

Sheddon, P A. 1971. "Another look at platoon dispersion: 1. The kinematic wave theory." Traffic Engineering and Control 13 (8): 332-336.

Shoufeng, Lu, and Liu Ximin. 2007. "Platoon dispersion prediction under the condition of adjacent cycle traffic flow overlapping based on support vector regression." International Conference on Computational Intelligence and Security Workshops. IEEE. 918-921.

Skabardonis, Alexander. 2000. "Control strategies for transit priority." Transportation Research Record: Journal of the Transportation Research Board (1727): 20-26.

Skabardonis, Alexander, and Nikolas Geroliminis. 2008. "Real-time monitoring and control on signalized arterials." Journal of Intelligent Transportation Systems 12 (2): 64-74. 
Smaglik, Edward James, Darcy M Bullock, and Thomas Urbanik II. 2008. "Bench Implementation of Restricted-Flow Bottleneck Identification and Flow-Based Phase Termination." Transportation Research Board 87th Annual Meeting.

Smaglik, Edward James, Peter Tarmo Savolainen, Robert Christopher Steele, and John E DiBiasi. 2011. "Delay Analysis of a Traffic Signal Phase Termination Algorithm Using Computer Simulation." Transportation Research Board 90th Annual Meeting.

Smaglik, Edward, Darcy Bullock, James Sturdevant, and Thomas Urbanik II. 2007. "Implementation of Lane-by-Lane Detection at Actuated Controlled Intersections." Transportation Research Record: Journal of the Transportation Research Board (2035): 81-87.

Smith, Harriet R, Brendon Hemily, and Miomir Ivanovic. 2005. "Transit signal priority (TSP): A planning and implementation handbook."

Taylor, Dean, and Hani Mahmassani. 2000. "Coordinating Traffic Signals for Bicycle Progression." Transportation Research Record 1705 (1): 85-92.

Transportation Research Board. 2010. Highway Capacity Manual. Washington, D.C.: National Academy of Sciences.

Turner, Patricia A. 2000. Making Crosswalks Safer for Pedestrians. Center for Urban Transportation Research, University of South Florida.

Urbanik, Tom, Alison Tanaka, Bailey Lozner, Kevin Lee, Shaun Quayle, Scott Beaird, Shing Tsoi, and Paul Ryus. 2015. Signal Timing Manual, 2nd Edition. NCHRP, Washington, D.C.: Tranportation Research Board.

Vallyon, Chris, Shane Turner, and Steve Hodgson. 2011. Reducing pedestrian delay at traffic signals. NZ Transport Agency.

Wang, Wuhong, Hongwei Guo, Ziyou Gao, and Heiner Bubb. 2011. "Individual differences of pedestrian behaviour in midblock crosswalk and intersection." International Journal of Crashworthiness 16 (1): 1-9.

Yu, L, and M Van Aerde. 1995. "Implementing TRANSYT's macroscopic platoon dispersion in microscopic traffic simulation models." Transportation Research Board Annual Meeting, 74th. Washington, DC, USA.

Yu, Lei. 2000. "Calibration of platoon dispersion parameters on the basis of link travel time statistics." Transportation Research Record: Journal of the Transportation Research Board (1727): 89-94.

Zaidel, David M, and Irit Hocherman. 1987. "Safety of pedestrian crossings at signalized intersections." Transportation Research Record 1141: 1-6.

Zegeer, Charles V, Cara Seiderman, Peter Lagerwey, Mike Cynecki, Michael Ronkin, and Robert Schneider. 2002. Pedestrian Facilities Users Guide - Providing safety and mobility. Federal Highway Administration.

Zegeer, Charles V, Kenneth S Opiela, and Michael J Cynecki. 1985. Pedestrian Signalization Alternatives. McLean, VA: Federal Highway Administration.

Zlatkovic, Milan, and Aleksandar Stevanovic. 2014. "Assessment of Impacts of Increased Train Frequency and Predictive Transit Priority on a LRT Corridor in Salt Lake City." Transportation Research Board 93rd Annual Meeting. 


\subsection{APPENDIX}

\subsection{PRACTITIONER SURVEY}

Table 9.1: Practitioner Survey, Abbreviated Results

\begin{tabular}{|c|c|c|c|c|c|}
\hline & & $\begin{array}{l}\text { Toronto, } \\
\text { Canada }\end{array}$ & $\begin{array}{l}\text { Flagstaff, } \\
\text { AZ }\end{array}$ & Mesa, AZ & Milwaukee, WI \\
\hline \multicolumn{2}{|c|}{$\begin{array}{l}\text { Control strategies } \\
\text { employed for pedestrians? }\end{array}$} & NA & None & $\begin{array}{c}\text { LPI, Barnes Dance for } \\
\text { special events, pedestrians } \\
\text { in recall, } \\
\text { accessible pedestrian signals }\end{array}$ & $\begin{array}{l}\text { 99.9\% intersections } \\
\text { have signalized } \\
\text { crosswalk. Pre- } \\
\text { timed ped recall or } \\
\text { semi-actuated with } \\
\text { rest-in-walk for the } \\
\text { minor crossing. Cycle } \\
\text { lengths are } 90 \mathrm{~s} \\
\text { maximum. }\end{array}$ \\
\hline \multirow{6}{*}{$\begin{array}{l}\text { Strategies } \\
\text { employed: }\end{array}$} & LPI & Yes & No & Yes & Yes \\
\hline & Barnes Dance & Yes & No & Yes & No \\
\hline & $\begin{array}{l}\text { Permissive } \\
\text { Window }\end{array}$ & NA & No & No & No \\
\hline & $\begin{array}{l}\text { Cycle Length } \\
\text { Manipulation }\end{array}$ & NA & No & No & Yes \\
\hline & $\begin{array}{c}\text { Controller } \\
\text { Mode of } \\
\text { Operation }\end{array}$ & NA & No & Yes & No \\
\hline & $\begin{array}{c}\text { Leave } \\
\text { Coordination. }\end{array}$ & NA & No & No & No \\
\hline \multicolumn{2}{|c|}{$\begin{array}{l}\text { Trade-offs considered } \\
\text { before implementation? }\end{array}$} & NA & None & $\begin{array}{l}\text { Pedestrian safety is } \\
\text { paramount. Pedestrian delay } \\
\text { is critical factor at } \\
\text { intersections with high non- } \\
\text { compliance. }\end{array}$ & Pedestrian safety \\
\hline \multicolumn{2}{|c|}{$\begin{array}{c}\text { Challenges implementing? } \\
\text { Steps taken to resolve? }\end{array}$} & NA & None & None & None \\
\hline \multicolumn{2}{|c|}{ Written documentation? } & Yes & None & None & None \\
\hline
\end{tabular}


Transportation Research and Education Center

Portland State University

1900 S.W. Fourth Ave., Suite 175

Portland, OR 97201 